\title{
Social Networks, Technology Adoption and Technical Efficiency in Smallholder Agriculture: The Case of Cereal Growers in Central Tanzania
}

\author{
Dissertation \\ to obtain the $\mathrm{Ph}$. D. degree \\ in the International Ph. D. Program for Agricultural Sciences in Goettingen (IPAG) \\ at the Faculty of Agricultural Sciences, \\ Georg-August-University Göttingen, Germany
}

presented by

Elijah Nzula Muange

born in Mwingi, Kitui County, Kenya

Göttingen, December 2014 
D7

1. Name of supervisor: Prof. Dr. Matin Qaim

2. Name of co-supervisor: Prof. Dr. Bernhard Brümmer

Date of dissertation: $12^{\text {th }}$ February 2015 


\section{Summary}

Global demand for food and agricultural products is on the rise. There is hence the need to increase production to meet this growing demand and smallholders will play a significant role. One strategy for smallholders to sustainably increase agricultural production is the use of modern productivity-enhancing technologies such as improved crop varieties. Investments in global agricultural research have resulted in the development and release of thousands of new varieties since the first Green Revolution. However, especially in Sub-Saharan Africa, traditional varieties still dominate smallholder farming, limiting the envisaged output and productivity gains. Lack of agricultural information is often cited as a major constraint to adoption of improved varieties, and the role of social networks in diffusion of information relevant for adoption of these varieties is increasingly being studied.

This research contributes to the growing literature by looking at a number of elements that to the best of our knowledge have not been studied before. First, most studies on social network effects in agricultural technology diffusion tend to focus on networks within villages (intra-village networks). In this study, we look at effects of social networks across villages (intra-village networks) as well. Furthermore we explore other types of networks, in particular to community leaders (village administrators), who are part of formal information dissemination channels. Second, while the role of social networks in cereal farming has been investigated in the context of well-developed private seed markets, we do not find any studies assessing the role of social networks in situations where seed markets are underdeveloped. This study investigates effects of social networks in two contexts: one with developed seed markets and the other with frequently failing seed markets. Third, studies linking social networks to new agricultural technologies tend to focus on technology diffusion. However, information conveyed through social networks might also affect other farming practices and hence we investigate also the effects of social networks on technical efficiency.

The main objective of this dissertation is to assess social networks and their explicit role in technology adoption and technical efficiency in smallholder agriculture. Using data collected from 345 cereal growers in Central Tanzania between September and November 2012, we focus on improved varieties of sorghum and maize, the staple cereals in the study area. Improved varieties of sorghum in Tanzania are characterized by underdeveloped private seed markets, while those of maize have mostly functioning private seed markets. This enabled us to make interesting comparisons that have not been made before. Our specific objectives are (1) to assess the factors that determine the existence of network links for the 
exchange of agricultural information between farmers, (2) to examine the role of social networks in exposing farmers to improved sorghum and maize varieties and hybrids (as a precondition for adoption of the technologies), (3) to assess the effects of social networks on adoption of improved varieties, and (4) to investigate the role of social networks for technical efficiency. In addition to descriptive analyses, a number of econometric tools were developed and used to achieve the objectives. These include dyadic regressions to identify determinants of network links, Poisson regressions to assess exposure to improved varieties, and the average treatment effect (ATE) framework to analyze adoption while controlling for nonexposure bias. To analyze technical efficiency, a stochastic frontier framework was applied. Propensity score matching techniques were used to control for endogeneity in the stochastic frontier analysis.

We find that even at the lowest administrative unit, the sub-village, not all farmers know each other. Interestingly, even in the cases where farmers know one another, only about one third of randomly drawn pairs of such farmers exchange agricultural information. The exchange of relevant information is more likely between farmers who have similar levels of education, different farm sizes, are members of the same community association, live in the same village, have known each other for a longer time, have kinship ties, and if one of them is a community leader or has a direct link to a public extension officer. These patterns are almost the same for sorghum and maize, meaning that if farmers exchange farming information, they are unlikely to limit this exchange to certain crops.

Farmer-to-farmer networks are important sources of first information on improved sorghum and maize varieties, with neighbors and friends playing a bigger role than relatives. Moreover, controlling for other farmer characteristics, we find that increasing the size of a farmer's network increases the farmer's intensity of exposure (number of varieties known) to improved varieties of sorghum, but not to those of maize. Further disaggregation of maize varieties shows that while larger social networks increase farmers' exposure to open pollinated varieties (OPVs), the result remains insignificant for hybrids. Seed markets for hybrids are more developed than those of OPVs. Hence, the flow of information through informal networks is more important for seed technologies for which formal markets fail. Strikingly, inter-village networks play a larger role in creating awareness about new varieties than intra-village networks. Other results show that by networking with public extension officers and village administrators, farmers increase their exposure to improved varieties considerably. We conclude that informal information channels complement, but do not substitute awareness creation through formal channels. 
Consistent with expectations, we find evidence that for both crops, lack of exposure is indeed a constraint to the adoption of improved varieties, signaling a need to create more awareness. Interestingly, even after accounting for the role of social networks in exposure, and controlling for the intensity of exposure, we find that social networks for sorghum have a positive effect on variety adoption. We do not find significant social network effects on adoption of improved maize varieties, implying that the influence of social networks on adoption is greater for improved varieties whose markets often fail. Contrary to the influence of social networks on exposure, it is the intra-village and not inter-village networks that produce this effect in the case of sorghum. It means that while inter-village networks are more important for learning about new varieties as shown above, intra-village networks play a more important role in adoption. Network links with village administrators or extension officers do not influence adoption significantly, meaning that in the adoption process, formal channels are more relevant for the first step, which is, raising awareness.

Finally, while the total and intra-village network sizes do not significantly influence technical efficiency, the inter-village sorghum network size has a positive effect on technical efficiency of improved but not of traditional varieties of sorghum. When comparing between improved varieties of the two crops, we conclude that social network effects are more relevant for varieties that do not have functioning private seed markets, consistent with the findings for exposure and adoption. Networking with village administrators did not have any significant effect on technical efficiency, but having links to the public extension officers and attending technology and information dissemination events organized through the officers had a positive effect on technical efficiency for improved varieties of maize. This shows that efficiency-enhancing production information for the largely commercialized seed technologies may be much more technical, hence requiring more specialized dissemination.

The findings raise a number of implications for policy and future research. First, social networks matter for the spread and efficient utilization of new agricultural technologies. Hence, technology dissemination programs should try to make use of such networks. Second, inter-village networks matter for farmers' exposure to and technical efficiency of improved varieties; hence facilitation of information exchange across village boundaries may improve awareness creation and the spread and productivity of new technologies. Third, the power of farmer networks with community leaders and village administrators can be exploited for increased awareness of improved technologies. Fourth, extension officers facilitate discussions about crop farming, and help in increasing awareness and technical efficiency of improved technologies. Therefore, new extension models could be 
developed that explicitly build on the synergies between formal and informal information channels. 


\section{Acknowledgements}

This study was funded by Federal Ministry for Economic Cooperation and Development (BMZ), Germany, as well as the Bill and Melinda Gates Foundation through the HOPE project, to both of whom I am grateful. The study would have been impossible without the assistance of several people and institutions. I thank Prof. Matin Qaim for the opportunity to conduct this research at the chair of International Food Economics and Rural Development, and his overall guidance and supervision. I am grateful to Dr. Stefan Schwarze who served as my project coordinator, advisor and mentor, for his input and support, and steering the project to successful completion. I also thank Dr. Theda Gödecke, for reviewing my early work and her technical advice especially in the field of social networks. I am grateful to Prof. Bernhard Brümmer for serving as my second supervisor and for his generous input, particularly in modeling technical efficiency, as well as Prof. Meike Wollni, for serving as a member of my examination committee.

I acknowledge the International Crops Research Institute for the Semi-Arid Tropics (ICRISAT), the project partners, for this study opportunity and supporting my research. I thank Dr. Alastair Orr and colleagues at the Nairobi office for their technical and logistical support. Special thanks go to Dr. Christin Schipmann-Schwarze, for her role in initiating this project, her technical input, and kind logistical support in Goettingen. The field data collection in Tanzania was greatly supported by the Agricultural Research Institute (ARI) in Makutupora of the Department of Research and Development (DRD), Tanzania. My gratitude goes to: Leon Mrosso, the Institute's Director and Director of DRD Central Zone; Saada Hussein, the survey coordinator; and enumerators Ashura Ally, Devotha Mchau, Faraji Matata, Frank Mbilinyi, Mary Stephen, Nuru Mgale and Soma Said. I also thank officials from the Tanzanian Ministry of Agriculture, Food and Cooperatives in Kondoa and Singida Rural districts for their help in the design and implementation of the survey. Special thanks to the Ward and Village administrators in the project areas for their logistical support.

I would like to acknowledge my colleagues at the chair of International Food Economics and Rural Development and the chair of International Agricultural Economics of the Department for Agricultural Economics and Rural Development, for their input through discussions, motivation and logistical support while doing this research. In particular, I am thankful to Jonas Kathage, Kibrom Sibhatu, Marcel Gatto, Wilhelm Klümper, Michael Euler, Priscilla Wainaina, Stefan Koppmair, Ken Sibiko, Miriam Vorlaufer, Lukas Semmler, Christine Kiria-Chege, Ilona Hoepfner and Jessica Torluccio. I also thank a couple of other 
friends and colleagues in the University of Goettingen fraternity for making my stay in Goettingen comfortable. Special thanks go to members of the Goettingen International Church for their moral support during my studies.

Finally, I am grateful to my mother and my late dad, who introduced me into the academic world, and my brothers and sisters, for their inspiration. I dedicate this dissertation to my dear wife Judy, and adoring children, Esther and David, for their love, encouragement and unwavering support, and enduring long periods of my absence during my $\mathrm{PhD}$ studies. 


\section{Table of Contents}

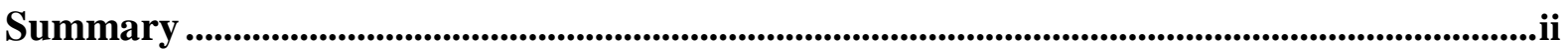

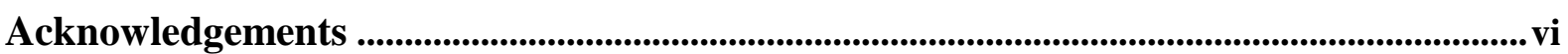

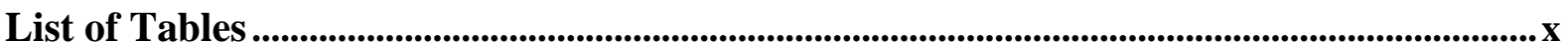

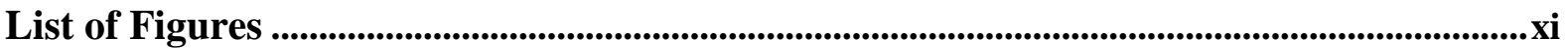

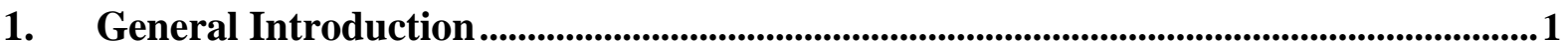

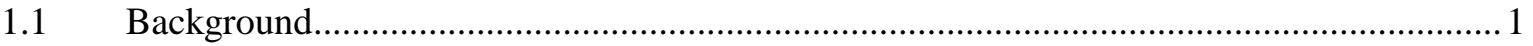

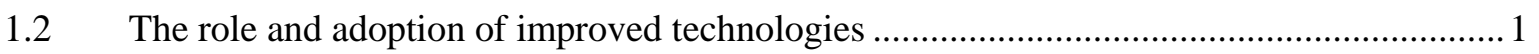

1.3 Social networks and their potential role in agriculture ......................................................

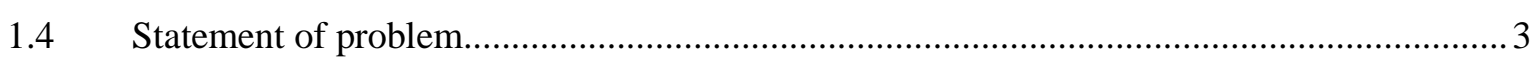

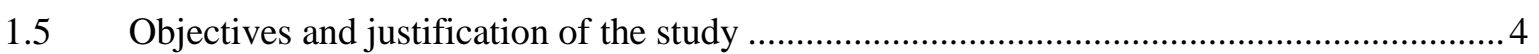

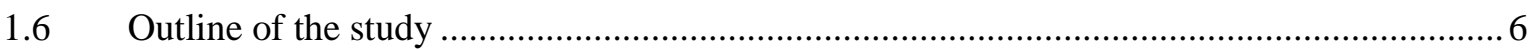

2. Social networks and farmer exposure to improved crop varieties in Tanzania ........ 7

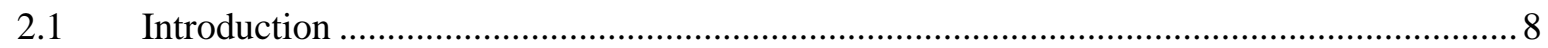

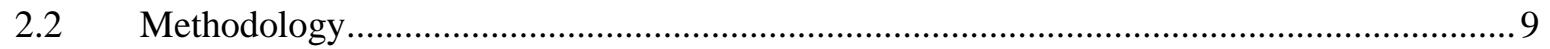

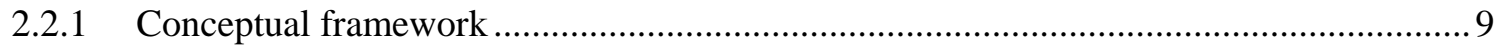

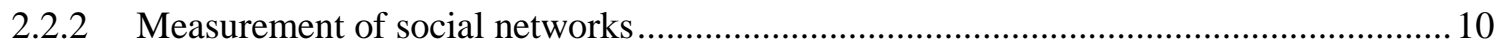

2.2.3 Estimating determinants of information exchange networks ........................................... 12

2.2.4 Estimating determinants of exposure to improved varieties ........................................... 13

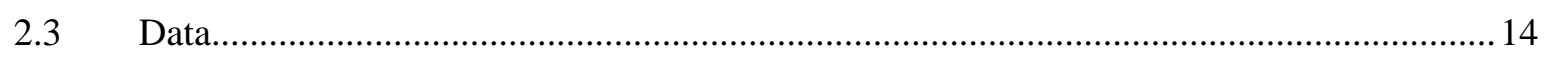

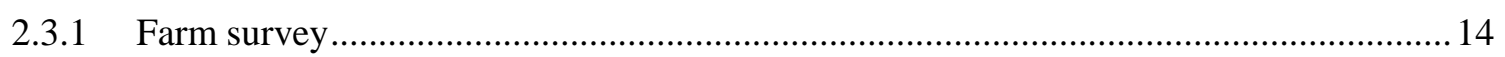

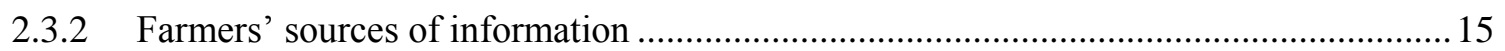

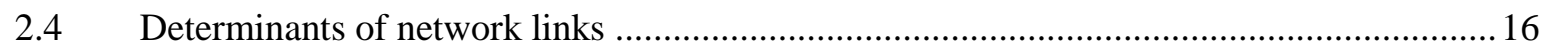

2.5 Determinants of exposure to improved varieties ............................................................. 19

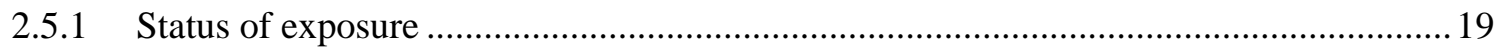

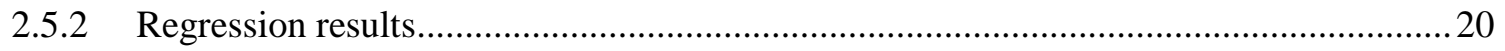

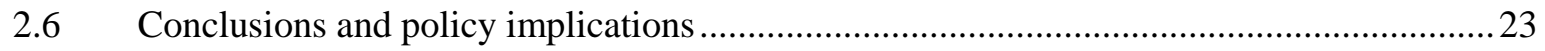

3. Social networks and the adoption of agricultural innovations: The case of improved cereal varieties in Central Tanzania ..............................................................26

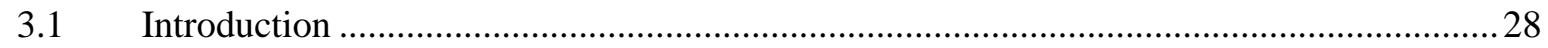

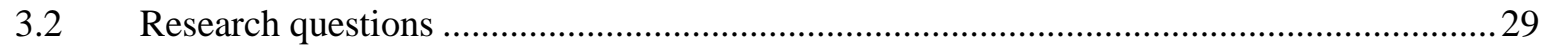

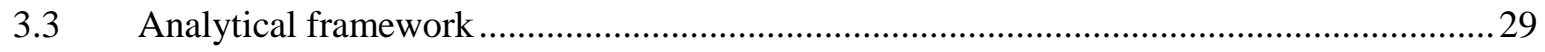

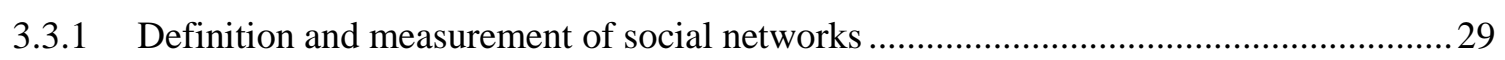

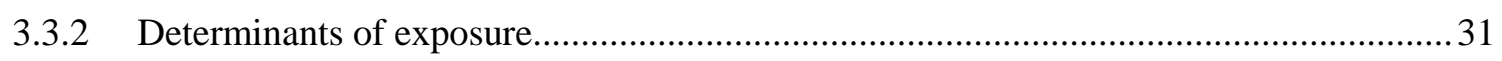

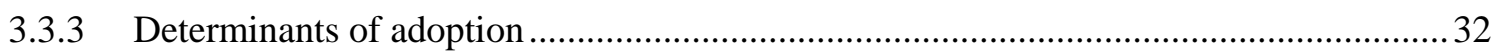




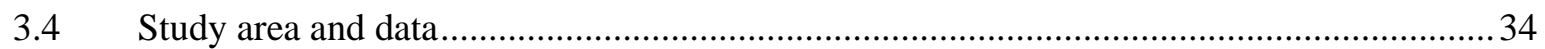

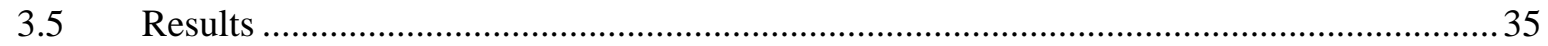

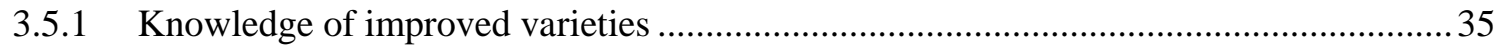

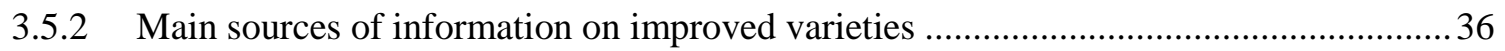

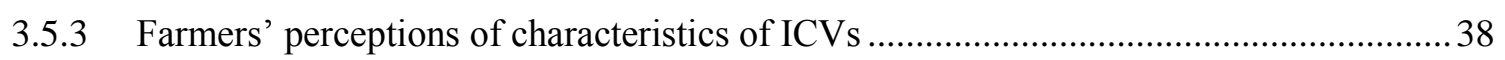

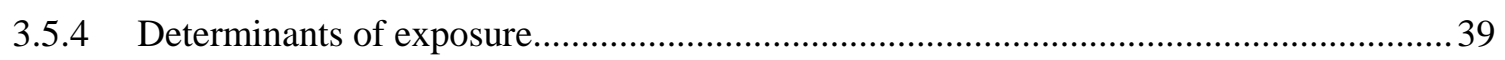

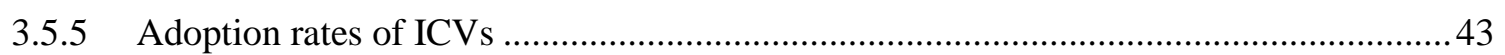

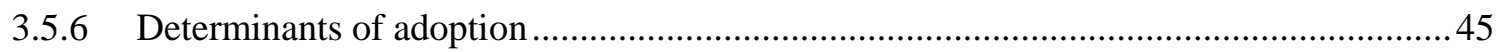

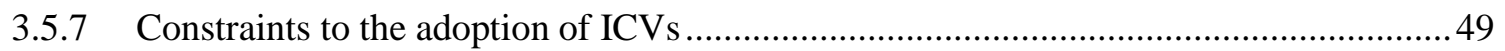

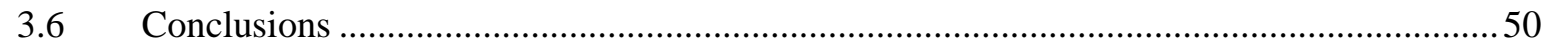

4. Effects of social networks on technical efficiency in smallholder agriculture: The case of cereal producers Tanzania...................................................................................53

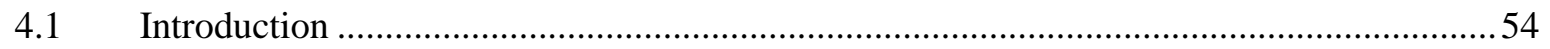

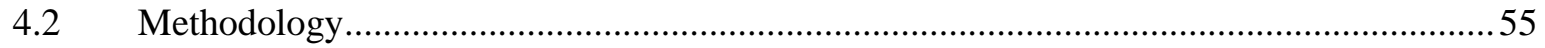

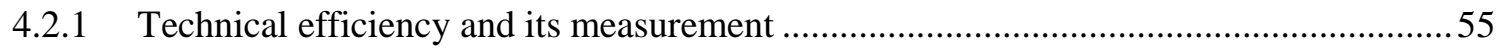

4.2.2 Information, social networks and technical efficiency …...............................................56

4.2.3 Potential endogeneity in adoption of improved varieties ...............................................57

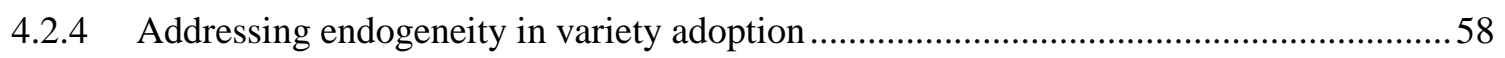

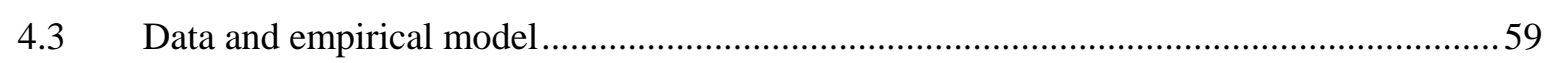

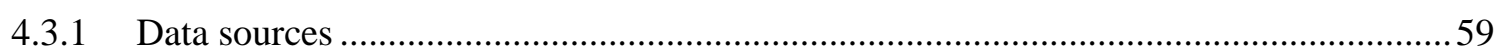

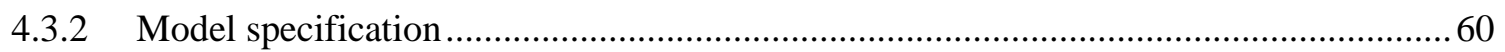

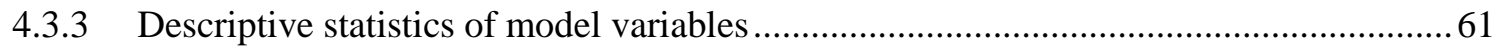

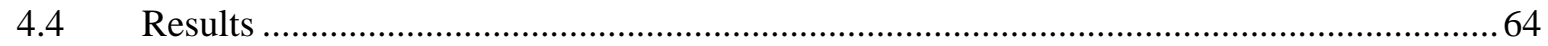

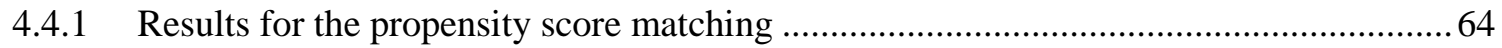

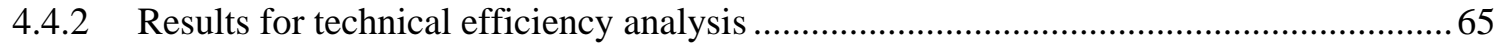

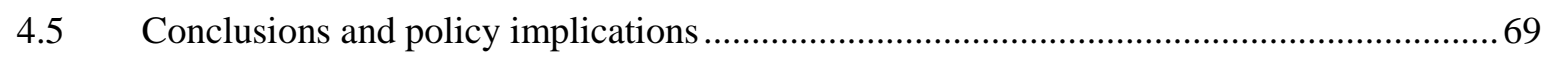

5. Conclusions and policy implications ........................................................................

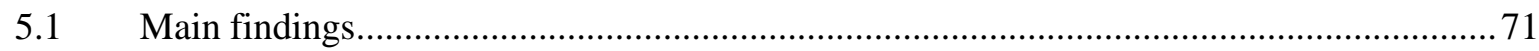

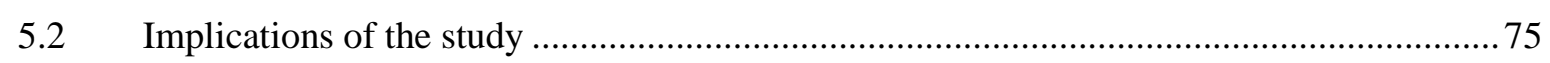

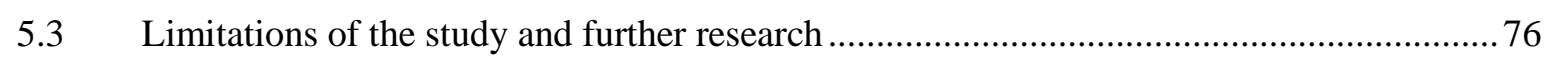

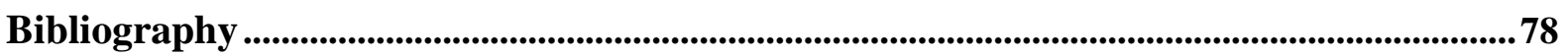

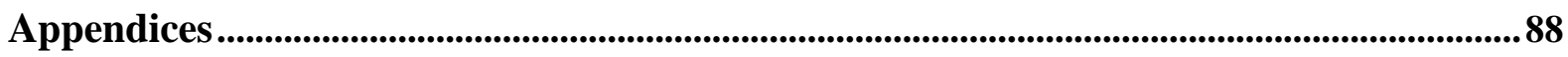

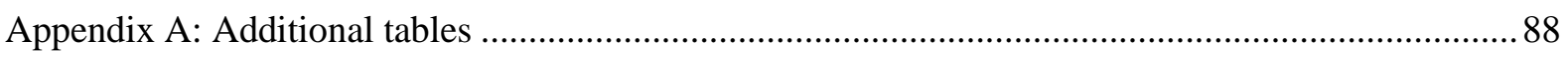

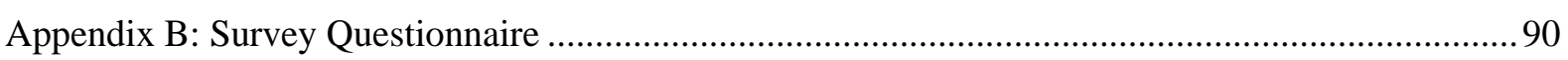




\section{List of Tables}

Table 1.1: Surveyed areas .5

Table 2.1: Farmers' sources of first information about improved varieties .16

Table 2.2: Definitions and descriptive statistics for variables used in the dyadic regressions 17

Table 2.3: Determinants of information network links..................................................... 18

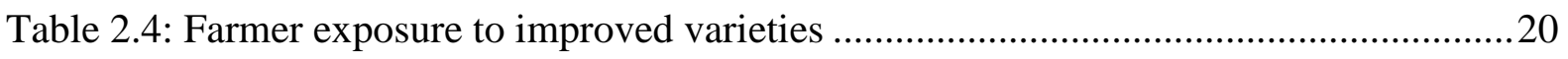

Table 2.5: Definitions and descriptive statistics for variables used in the exposure models...21

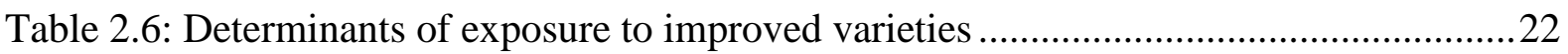

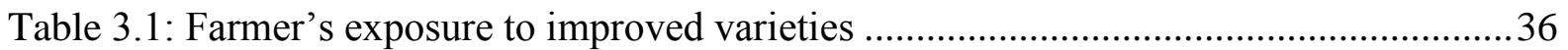

Table 3.2: Sources of first information on improved sorghum and maize varieties.................37

Table 3.3: Farmers' perception about improved varieties compared to traditional ones.........39

Table 3.4: Definitions and descriptive statistics for the variables used in the exposure model

Table 3.5: Estimates of the determinants of exposure to improved varieties .........................42

Table 3.6: Observed exposure and adoption rates of improved varieties .............................. 43

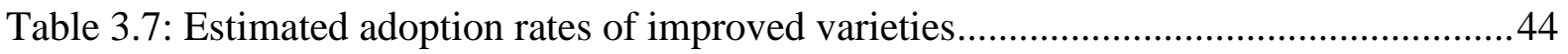

Table 3.8: Description and mean values of variables used in adoption models ..................... 46

Table 3.9: Determinants of adoption of improved varieties ................................................ 48

Table 3.10: Stated reasons for non-adoption of known varieties (\% responses) .....................50

Table 4.1: Descriptive statistics for variables used in the production frontier models ............62

Table 4.2: Descriptive statistics for variables used in the technical inefficiency models........63

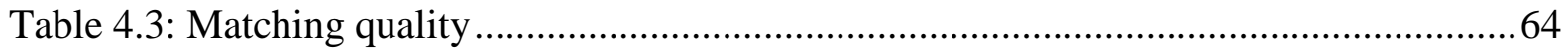

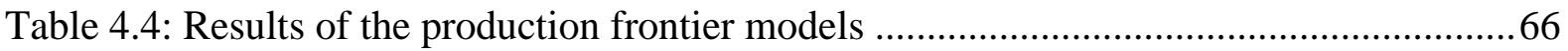

Table 4.5: Determinants of technical inefficiency and estimated technical efficiency scores 68

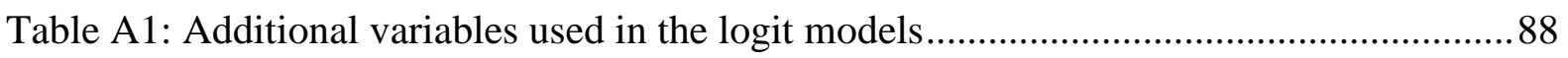

Table A2: Logit results for the estimation of propensity scores .......................................... 88

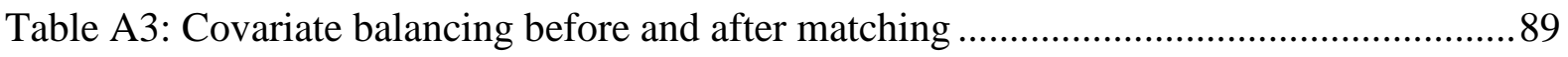




\section{List of Figures}

Figure 2.1: A framework for understanding drivers of learning about improved varieties ..... 10

Figure 4.1: Information sources and pathways, and the role of social networks for technical efficiency.

Figure 4.2: Distribution of propensity scores for sorghum (left) and maize (right), showing common support. .65

Figure 5.1: Effects of social networks on agricultural outcomes. .73 


\section{General Introduction}

\subsection{Background}

Global demand for food and agricultural products is on the rise as human population and incomes increase (FAO, 2014). Moreover, food insecurity remains a major development challenge for many agrarian economies, especially in Sub-Saharan Africa (World Bank, 2007). Projections show that aggregate agricultural production should increase by about $60 \%$ between 2005/2007 and 2050 to meet the world's consumption demand (Alexandratos and Bruinsma, 2012). Such increase calls for growth in productivity, implying that available production resources would have to be used much more efficiently. Smallholders, who form the majority of farmers around the world, will play a significant role in this regard (FAO, 2014). By increasing their production, smallholders will improve not only the availability of food and agricultural products, but also their incomes and those of others employed directly or indirectly by the agriculture sector. This will contribute further to poverty reduction in rural areas of developing countries, where farming is the main source of livelihood.

\subsection{The role and adoption of improved technologies}

One strategy for increasing agricultural productivity is the development and use of modern technologies such as improved crop varieties (ICVs) (World Bank, 2007). Studies show that ICVs account for 50-90 percent of global crop yield increase (Bruins, 2009), can increase farmer's incomes and also reduce rural poverty (Krishna and Qaim, 2008; Alene et al., 2009; Nguezet et al., 2011). Since the Green revolution, investments in global agricultural research have seen the development and release of thousands of ICVs for cultivation by farmers (CGIAR, 2011). However, especially in the predominantly smallholder farming communities in Sub-Sahara Africa, the adoption of improved varieties remains relatively low (Gollin et al., 2005; Smale et al., 2011). Recent estimates show that improved varieties of 20 key crops grown by farmers in Africa occupy just about 35\% of the area cultivated with the crops (Walker et al., 2014). The low use of improved variety limits envisaged productivity gains for farmers, especially in this region, where crop productivity and productivity growth have been low relative to global trends and the continent's population growth (Rakotoarisoa, Iafrate and Paschali, 2012).

Lack of farmer exposure to new varieties has been identified as one major constraint for wider adoption (Doss et al., 2003; Diagne, 2006; Simtowe et al., 2011; Kabunga et al., 
2012). The argument in these studies is that farmers cannot adopt technologies that they are unaware of, in the first place. Such lack of exposure may surprise, given that variety development and testing often involve farmer participation (Bellon and Reeves, 2002; Heinrich and Mgonja, 2002). The philosophy behind participatory breeding approaches is that the farmers involved would adopt superior varieties themselves and further disseminate information and seeds through their social networks, leading to wider diffusion and adoption.

\subsection{Social networks and their potential role in agriculture}

A social network is a set of actors that have relationships with one another (Marin and Wellman, 2011). Social networks are seen as an important mechanism for the spread of information and technology (Baerenklau, 2005). The theory of social networks has been applied to study general behavior, as well as outcomes that have social and economic implications, such as employment, prices and firm productivity and profitability (Granovetter 2005, Borgatti et al., 2009 and Kimura, 2011). In the recent past, there has been growing interest in the use this theory to assess participation in and impacts of development initiatives, such as health programs, and adoption and diffusion of technological innovations (Dufhues et al. 2006).

Social networks can influence diffusion and productivity of agricultural technologies by providing an opportunity for farmers to gather more information about the technologies from each other - through social learning, or merely copying their colleagues (Young, 2009). The networks help to reduce risks associated with adoption of new technologies by providing information on how to use the technologies and the expected benefits (Kimura, 2011). This can be especially useful in contexts where agricultural extension services or technology and information markets are weak or missing. In many developing countries, the lack of seeds has often been cited as a key constraint to adoption of improved varieties (Asfaw et al., 2011). Moreover, for some crops, improved varieties lack reliable seed markets. In these contexts, social networks could facilitate awareness and adoption of improved varieties when farmers share information and seeds with their fellows (Tripp, 2006).

The exchange of information on farming practices and trust between small-holders can also influence behavior of farmers with respect to the choice of other farming practices, resulting in changes in the use of available resources and consequently technical efficiency and productivity. For instance, information and trust could influence farmers to adjust the type and timing of crop husbandry methods used, such as seedbed preparation, sowing, and management of soil fertility, pests and diseases, factors that as Bindraban et al. (2009) show, 
have great influence on agricultural productivity in Sub-Saharan Africa. Christoplos (2010) demonstrates that extension services to smallholders will play a critical role if the farmers are to increase their productivity and meet the demand for food and agricultural products in 2050 . Moreover, Anandajayasekeram et al. (2008) argue that future agricultural extension services will be more successful if the approaches employed would involve farmers as well. In this study, we hypothesize that informal information exchange through social networks can complement formal agricultural extension services. Hence, a better understanding of how social networks function, and their role in agriculture, can contribute to the design of participatory farmer advisory polices and services that improve performance of the sector.

\subsection{Statement of problem}

The development and use of improved crop varieties is seen as a key to increasing agricultural output and productivity. However, especially in the predominantly smallholder farming communities in Sub-Sahara Africa, adoption of improved varieties remains relatively low, limiting the envisaged productivity gains. Lack of farmer exposure to new varieties has been identified as one major constraint for wider adoption. Social networks are seen as an important mechanism for the spread of information and technology, and developers of improved varieties usually tap into these informal institutions by employing participatory breeding approaches. The philosophy underlying such approaches is that the farmers involved would adopt superior varieties and further disseminate information and seeds through their social networks. However, the concrete role of these networks is still a subject of research.

A few recent studies looked at the role of social networks in agricultural technology diffusion. In general, these studies find that social networks and social learning promote technology awareness and adoption among smallholders, but the strengths of the effect seem to vary by technology and context. Most of these studies focus on cash crops such as sunflower (Bandiera and Rasul, 2006) and pineapples (Conley and Udry, 2010), while the few that analyzed technologies in food crops focused on hybrids, for which private seed markets exist (Matuschke and Qaim, 2009). Hence, to our knowledge, the role of social networks in food crop production in contexts where seed markets are weak or missing has not been investigated. Moreover, a comparison of the role of social networks in contexts where both market conditions prevail has not been done. This analysis is of critical importance especially in Sub-Saharan Africa, where seed markets are not equally well-developed for all key crops. We hypothesize that the roles played by social networks may differ between varieties with developed markets and those without. 
Strikingly, most empirical studies assessing the role of informal information in agricultural technology diffusion investigate their effects only on technology adoption, yet it has long been shown that the role of information may extend to influencing the productivity of, or efficiency with which farmers use these technologies (Müller, 1974). Technical efficiency is an important determinant of productivity differences among producers (Fried et $a l ., 2008)$, and understanding its drivers can help policymakers in designing programs that increase efficiency and ultimately productivity, among smallholder farmers. However, empirical literature on the concrete role of social networks in technical efficiency of crop producers is hard to find.

Furthermore, although past social network studies often report that these networks cross geographical boundaries (De Weerdt, 2004; Fafchamps and Gubert, 2007), most analyses of network effects in agricultural technology diffusion tend to focus on intra-village links, ignoring inter-village networks that may play an important role. In addition to farmerto-farmer networks, farmer links with other actors may also matter for agricultural outcomes. For instance, agricultural research and development actors in Africa usually involve community leaders and public extension staff in disseminating information about their activities and technologies (Rusike et al., 2006; Saka et al., 2008). While farmers with closer network ties to such leaders may be expected to have access to more information about these activities and technologies, effects of such ties have not been concretely analyzed from a social network perspective.

\subsection{Objectives and justification of the study}

The main objective of the study is therefore to assess social networks and their explicit role in technology adoption and technical efficiency in smallholder agriculture. We do so by using data collected from 345 cereal growers in Central Tanzania between September and November 2012, as an example (see Table 1.1 for surveyed areas). We focus on improved crop varieties, and Tanzania as one of the Sub-Saharan African countries where partnerships between national and international agricultural research institutions and private seed sector have led to development and release of many improved varieties, but where variety adoption rates and crop productivity are still low. Specifically, we look at sorghum and maize, the two main staple cereals grown in Central Tanzania. Official records from the variety list updated in 2008 show that 6 improved varieties of sorghum and 72 of maize are released in the country (Ngwediagi et al. 2010). In Singida and Dodoma, the two administrative regions of central Tanzania where this study was carried out, improved varieties occupy only $11 \%$ and 
$14 \%$ of cultivated area respectively. Moreover, average productivity of sorghum in the regions is $0.7-1.1$ tons/ha while that of and maize is 1.0-1.3 tons/ha (United republic of Tanzania, 2012). This is quite low compared to potential yields of 1.6-3.5 tons/ha for improved sorghum and 3-8 tons/ha for most dryland maize varieties contained in the official variety list. Hence, studies on diffusion and productivity of improved varieties are still relevant in Tanzania.

Improved varieties of sorghum available in Tanzania are open pollinated varieties (OPVs) whose seeds farmers usually recycle and exchange among themselves, while those of maize are OPVs and hybrids. Seeds of improved maize varieties are available in the private market, but the market for hybrids is much more developed (Shiferaw, Kebede and You, 2008). Thus, with this heterogeneity in seed market conditions, interesting comparisons can be made. Moreover, farming communities in Tanzania are open, with social interactions occurring even across geographically defined boundaries (Van den Broeck and Dercon, 2011). This allows us to assess effects of social networks both within and across villages.

Our specific objectives are to:

i. assess the factors that determine the existence of network links for the exchange of agricultural information between farmers,

ii. examine the role of social networks in exposing farmers to improved sorghum and maize varieties and hybrids,

iii. assess the effects of social networks on adoption of improved varieties,

iv. investigate the role of social networks in technical efficiency.

Table 1.1: Surveyed areas

\begin{tabular}{lll}
\hline Village clusters & Ward & Villages surveyed \\
\hline Kondoa District & & \\
Cluster 1 & Kingale & Kingale, Iyoli, Chemchem, Tampori \\
Cluster 2 & Kwa Mtoro & $\begin{array}{l}\text { Ndoroboni, Kurio, Porobanguma, Msera, Kwamtoro } \\
\text { Gumbu, Gungi, Sanzawa, Motto }\end{array}$ \\
Singida 3 & Sanzawa & \\
Cluster 1 & & Mungaa, Makiungu, Unyaghumpi \\
Cluster 2 & Mungaa & Minyinga, Kimbwi, Kinku \\
Cluster 3 & Mungaa & Ntuntu, Ntewa \\
\hline
\end{tabular}




\subsection{Outline of the study}

The rest of the study is organized into three main chapters that address the study objectives, and a concluding chapter. The study is based on the same dataset and hence the sampling methods and most key variables are described in a similar manner. In Chapter 2 entitled "Social networks and farmer exposure to improved crop varieties in Tanzania", we first define social networks and discuss measurement challenges and how they are addressed in the study. We then assess the factors that determine the existence of network links for the exchange of agricultural information between farmers, and proceed to examine the role that social networks play in exposing farmers to improved sorghum and maize varieties. Chapter 3 is entitled "Social networks and the adoption of agricultural innovations: The case of improved cereal cultivars in Central Tanzania". Here, we critically assess what farmers know about improved varieties with respect to some key agronomic and utilization characteristics, and examine the current adoption rates and constraints. We then investigate the effects of social networks on the adoption of improved varieties, after controlling for biases arising from non-random exposure. Some of the information and results in this chapter overlap with those of Chapter 2. The analytical framework we use to assess adoption in Chapter 3 corrects for non-exposure bias, hence it was necessary to discuss exposure also in this chapter, and in a manner similar to Chapter 2, for consistency. In Chapter 4, which is entitled "Effects of social networks on technical efficiency in smallholder agriculture: The case of cereal producers Tanzania", we investigate the role of social networks in technical efficiency, after correcting for potential selectivity problems in variety adoption. The results are compared between sorghum and maize, and between traditional and improved varieties, for each crop. Chapter 5 concludes by discussing implications of the study for policy and further research. 


\title{
2. Social networks and farmer exposure to improved crop varieties in Tanzania ${ }^{1}$
}

\begin{abstract}
In Sub-Sahara Africa, adoption rates of improved crop varieties remain relatively low, which is partly due to farmers' limited access to information. In smallholder settings, information often spreads through informal networks. Better understanding of such networks could potentially help to spur innovation and farmers' exposure to new technologies. This study uses survey data from Tanzania to analyze social networks and their role for the spread of information about improved varieties of maize and sorghum. Regression models show that network links for the exchange of agricultural information are more likely between farmers who have similar educational but different wealth levels. Moreover, network links are more likely when farmers have direct contacts to extension officers, suggesting that information flows through informal channels can support but not replace formal channels. Social networks play a significant role for the spread of information about open-pollinated varieties. This is not the case for maize hybrids, which are sold by private seed companies.
\end{abstract}

Key words: social networks, exposure, improved varieties, sorghum, maize, gender

\footnotetext{
${ }^{1}$ This chapter is published online as "Muange, E.N., Schwarze, S., Qaim, M., 2014. Social networks and farmer exposure to improved crop varieties in Tanzania. GlobalFood Discussion Papers No.45, RTG 1666 GlobalFood, Georg-August-University of Göttingen". Parts of the chapter were also presented as a paper entitled "Social Networks and Farmer Exposure to Improved Cereal Varieties in Central Tanzania" at the EAAE 2014 Congress, August 26 to 29, 2014, Ljubljana, Slovenia. The authors acknowledge the contribution of Dr. Theda Gödecke (Assistant Professor, Department of Agricultural Economics and Rural Development, Georg-AugustUniversity Göttingen).
} 


\subsection{Introduction}

The development and use of improved crop varieties is an important strategy to increase food production and food security. However, especially in Sub-Sahara Africa, the adoption of improved varieties remains relatively low (Gollin et al., 2005; Smale et al., 2011). Lack of farmer exposure to new varieties has been identified as one major constraint for wider adoption (Doss et al., 2003; Diagne, 2006; Simtowe et al., 2011; Kabunga et al., 2012). Such lack of exposure may surprise, given that variety development and testing often involve farmer participation ( Bellon and Reeves, 2002; Heinrich and Mgonja, 2002). The philosophy behind participatory breeding approaches is that the farmers involved would adopt superior varieties themselves and further disseminate information and seeds through their social networks. Hence, social networks are seen as an important mechanism for the spread of information and technology, but the concrete role of these networks has rarely been investigated.

A few recent studies looked at the role of social networks for agricultural technology diffusion (Bandiera and Rasul, 2006; Matuschke and Qaim, 2009; Conley and Udry, 2010; Hogset and Barrett, 2010; Maertens and Barrett, 2013). In general, these studies find that social networks and social learning promote technology awareness and adoption among smallholders, but the strengths of the effect seems to vary by technology and context. Most existing studies focused on cash crops such as pineapples (Conley and Udry, 2010), sunflower (Bandiera and Rasul, 2006), and cotton (Maertens and Barrett, 2013). The few studies that analyzed technologies in food crops focused on hybrids, for which formal seed markets exist (Matuschke and Qaim, 2009). As hybrid seeds are often promoted by private companies, one may expect that informal social networks are less important than for openpollinated varieties (OPVs), for which formal seed markets frequently fail. To our knowledge, a comparison of the role of social networks between hybrids and OPVs has never been made. Moreover, previous technology-related studies primarily examined farmers' networks within villages, although social networks are known to cross geographical boundaries (Fafchamps and Gubert, 2007).

We add to the literature by looking at both intra-village and inter-village networks for the exchange of information on improved crop varieties, building on a survey of smallholders in Central Tanzania. In the study region, many farmers grow sorghum and maize, which differ in terms of technology and seed market conditions. While sorghum is only grown as OPVs, for maize, improved OPVs and hybrids are available in the market. Hence, interesting 
comparisons can be made. Specifically, we address two questions. First, what factors determine network links for the exchange of agricultural information between farmers? Second, what effects do social networks have on farmer exposure to improved sorghum and maize varieties and hybrids?

\subsection{Methodology}

\subsubsection{Conceptual framework}

We define a social network as a set of actors or nodes (individuals, agents, or groups) that have relationships with one another (Hanneman and Riddle, 2005; Marin and Wellman, 2011). Social networks evolve due to ties between actors, which may arise because of kinship, affection, or familiarity between them (Easley and Kleinberg, 2010). The simplest social network is a dyad (pair of linked actors), in which one actor (whose network is being studied), is referred to as the ego, and the other as the alter (Smith and Christakis, 2008). This raises two fundamental questions for our study. First, what factors contribute to placing farmers in each other's information exchange network? Second, does the size and structure of the individual network influence farmers' exposure to improved crop varieties?

We illustrate the idea behind the first question using two farmers $A$ (not exposed to an improved variety) and $B$ (exposed). By invoking elements of social contagion theories, which focus on dyadic relationships in the social system (Burt, 1987), we hypothesize that there are characteristics of both $A$ and $B$ that position them close enough to each other (social proximity) for $A$ to socially learn from $B$, thereby also getting exposed to the improved variety. We summarize these characteristics in two categories, as shown in Figure 2.1. First are similarities, such as living in same geographical location, having common membership in associations, and personal attributes such as gender, education, and wealth. In the second category, we consider social relationships, including kinship ties, friendship, and cognitive relations such as shared knowledge. These characteristics determine the nature and intensity of interactions between the ego and alter (such as doing things together, discussing issues, and advising each other) and the flow of information, beliefs, and resources necessary for exposure to improved varieties. 


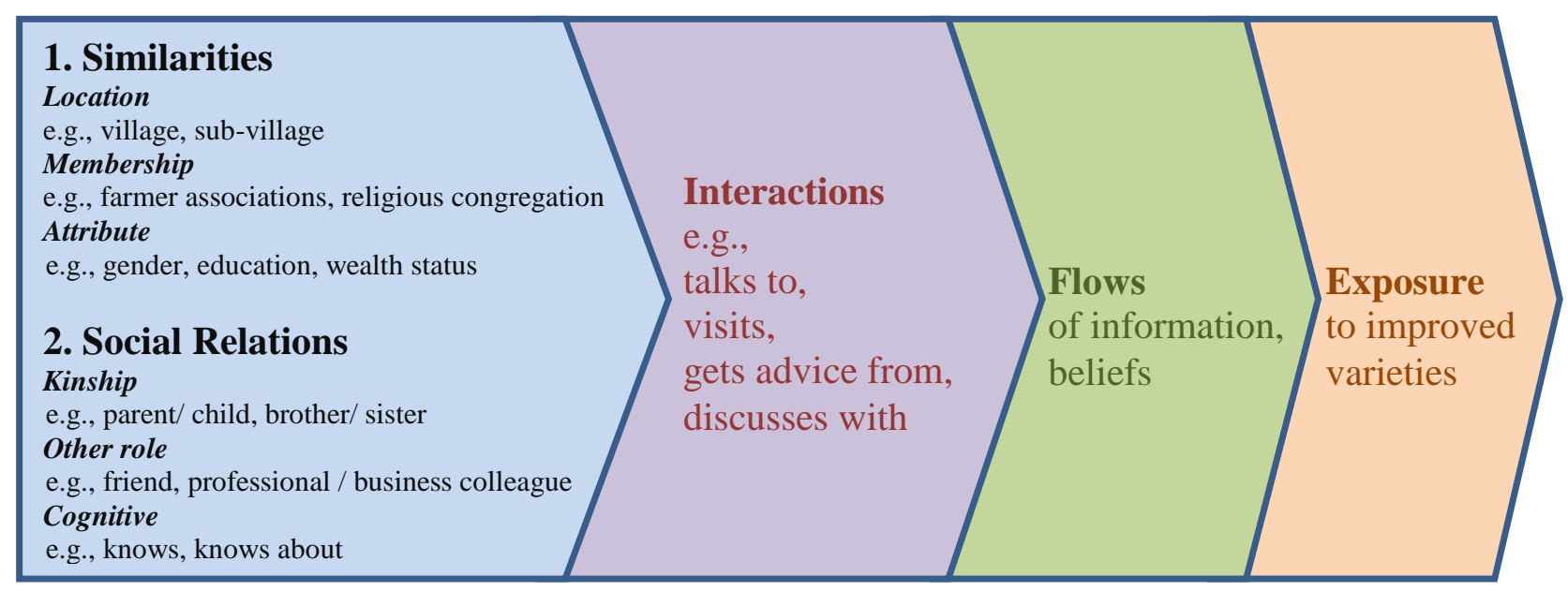

Figure 2.1: A framework for understanding drivers of learning about improved varieties Source: Adapted from Borgatti et al. (2009).

To address the second question, we apply the concept of node-level properties of social networks, particularly centrality measures (Borgatti, 2005). These measures determine positions and power of network actors, contributing to opportunities and constraints that determine outcomes (House et al., 2007; Borgatti et al., 2009). Key among the centrality measures is degree, which refers to the number of alters to which an ego is directly connected (Newman, 2010). We hypothesize that respondents with a higher network degree occupy positions that predispose them to more learning opportunities about improved varieties; hence they are more likely to have a higher intensity of exposure than those with a lower degree.

\subsubsection{Measurement of social networks}

Empirical measurement of social networks is an evolving topic. When designing a network study, two particular challenges need to be addressed. The first involves selection of actors to be studied. Some researchers use a complete network approach, which involves a census of the population being studied (Barroga-Jamias and Brien, 1996; Goswami and Basu, 2010; van den Broeck and Dercon, 2011). While theoretically appealing, this approach is of limited practical use in studying large populations. Besides, even with a complete census, it is impossible to capture all of an individual's social links, because some may remain unreported, while others may span out of the geographical boundary (Fafchamps and Gubert, 2007; Handcock and Gile, 2010). Researchers therefore often use samples to study social networks in large populations. However, Santos and Barrett (2010) and Chandrasekhar and Lewis (2011) argue that little can be learned about the real networks if individuals in the 
network are sampled, and recommend the sampling of paired actors (dyads). We follow this recommendation and use the sampling of dyads approach.

The second challenge is how to establish which actors constitute an individual's network. Three main approaches have been used in past studies. In one approach, each individual is asked to name a certain number of people with whom they interact (BarrogaJamias and Brien, 1996; Bandiera and Rasul, 2006; Tatlonghari et al., 2012). The weakness of this approach is that individuals are likely to name only persons to whom they are strongly linked, leading to estimates of network properties that are biased towards strong links. The second method, called matches within sample, asks each individual about their ties and interactions with every other individual in the sample, while the third approach, called random matching within sample, pairs each individual in the sample with only a specified number of individuals randomly selected from the sample (Santos and Barrett, 2008). The matches within sample approach suffers the same limitations as the census method if the sample is large (Fafchamps and Gubert, 2007). Santos and Barrett (2008) demonstrate that the random matching within sample approach produces parameters that represent the real network more efficiently. We use this latter approach in our study.

When using the random matching approach, there is no clear rule regarding the number of matches per respondent. More than seven random matches have rarely been used in previous studies. We paired each farmer with six others in the sample: three from the respondent's village and three from neighboring villages. Most previous studies considered only intra-village networks. We decided to also consider possible inter-village links, because social networks do not necessarily stop at village boundaries.

In the survey, respondents were asked whether they know their random matches and for how long they have known them, whether and how often they talk about agricultural issues in general and specific crop aspects in particular, and whether they have kinship ties or common membership in a group or association. In addition, respondents were asked about the frequency of interactions with village administrators (chair or other executives at village or subvillage level) and public extension officers. This was done to compare the influence of formal and informal information channels on farmers' exposure to improved varieties. Further details about the survey are presented below. 


\subsubsection{Estimating determinants of information exchange networks}

To analyze the factors that determine information exchange networks, we use an econometric framework similar to Conley and Udry (2010) and Maertens and Barrett (2013). Following the random matching approach discussed above, each farmer $i$ is paired with six other farmers $j$. We define farmer $j$ (the alter) to be in the sorghum or maize information network of farmer $i$ (the ego) if the two exchange information about these crops, as reported by the ego. Two different approaches can be used to elicit these kind of data (Santos and Barrett, 2008). The first, referred to as potential network approach, involves asking the ego whether he/she could approach the alter for information regarding the specific crop. Alternatively, in the real network approach, the ego is asked whether he/she has ever sought such information from the alter. Since our aim is to assess exposure to improved varieties, which is a function of actual information flows in the past, the latter approach is more useful in our context. Hence, we define $j$ to be in $i$ 's sorghum/maize information network if $i$ reports that he/she discusses farming issues related to these crops with $j$.

For each crop, $c$, we estimate the following probit model to assess the determinants of an information network link in a random pair of farmers $i$ and $j$ (or random dyad, $d$ ):

$$
P\left(Y_{d c}=1 \mid x_{d}\right)=\Phi\left(\beta_{0}+\sum_{k=1}^{K} \beta_{k} x_{k d}\right) \quad d=1,2, \ldots, D
$$

where, the outcome $P\left(Y_{d c}=1 \mid x_{d}\right)$ is the probability of detecting an information network link, conditional on a set of observable characteristics, $\boldsymbol{x}$, defined for each dyad, $d{ }^{2}$ Key among these characteristics are similarities in personal attributes of ego and alter (such as age, sex, education level, wealth status, and religion), membership in the same association, kinship ties, and geographical proximity. $\Phi$ is a standard normal cumulative distribution function that forces predicted probabilities to be between zero and one, $\beta_{0}$ and $\boldsymbol{\beta}_{\boldsymbol{k}}$ are parameters to be estimated, $K$ is the total number of explanatory variables, while $D$ is the total number of dyads used in the regression.

A potential problem associated with estimating equation (2.1) is that the stochastic errors for each dyad are not independent (Fafchamps and Gubert, 2007; Cameron et al., 2011). Given that each respondent is paired with several others, the error terms for all dyads involving the same respondent are correlated in two dimensions. The first dimension refers to

\footnotetext{
${ }^{2}$ Since matching is random, not all of a farmer's matches are necessarily known to the respondent. We do not expect a network link between matches who do not know each other; hence we restrict this regression analysis to the subsample of pairs where the respondent knows the match (Fafchamps and Gubert, 2007; Santos and Barrett, 2010).
} 
dyads where the respondent is the ego, and the second to dyads where the respondent is the alter. We account for such correlation by clustering the probit standard errors in these dimensions, following Petersen (2009).

\subsubsection{Estimating determinants of exposure to improved varieties}

In a next step, we are interested to understand whether information flows through social networks influence farmers' exposure to improved sorghum and maize varieties. Previous studies defined farmers to be exposed if they are aware of at least one variety (Diagne and Demont, 2007). This makes sense when looking at broader technologies or traits that are incorporated in different varieties. In our case, different improved varieties are more distinct, so that it makes more sense to consider each variety as a separate technology. Hence, instead of using a binary exposure variable, we consider the intensity of exposure in terms of the number of improved varieties a farmer is aware of. In our dataset, this intensity of exposure is closely correlated with the adoption of improved varieties.

To determine the effect of social networks on exposure, we regress exposure intensity, $V$, on a set of explanatory variables, including a social network measure, assuming a Poisson distribution:

$$
\operatorname{Pr}\left(V=v_{i} \mid z_{i}, \boldsymbol{w}_{i}\right)=\frac{e^{-\mu_{i} \mu_{i}} v_{i}^{i}}{v_{i}^{l}} \quad v_{i}=0,1,2 \ldots
$$

where $\mu$ is a loglinear function that can be expressed as:

$$
\ln \mu_{i}=z_{i}^{\prime} \boldsymbol{\beta}+\boldsymbol{w}_{i}^{\prime} \boldsymbol{\delta}
$$

Based on this specification, intensity of exposure is given by

$$
E\left[v_{i} \mid \boldsymbol{z}_{i,} \boldsymbol{w}_{i}\right]=\operatorname{Var}\left[v_{i} \mid \mathbf{z}_{i_{i}} \boldsymbol{w}_{i}\right]=\mu_{i}=e^{z_{i}^{t} \boldsymbol{\beta}+\mathbf{w}_{i}^{t} \delta} \quad v_{i}=0,1,2 \ldots
$$

For each farmer $i, v$ is the intensity of exposure to improved varieties, $z$ is a set of personal and household characteristics such as age, education, sex, and wealth, and $\boldsymbol{w}$ is a set of variables that capture the quantity of information about improved varieties available to the farmer through social networks, village administrators, and government agricultural extension officers. $\boldsymbol{\beta}$ and $\boldsymbol{\partial}$ are vectors of parameters to be estimated, denoting the partial effects of personal and household characteristics, and social networks, respectively. We hypothesize that controlling for $z$, social networks influence a farmer's exposure directly through discussions about improved varieties between the farmer and network members, or indirectly when the farmer is invited or persuaded in some other way by network members to 
attend forums where improved varieties are discussed, such as extension meetings and field days.

One critical assumption of the Poisson distribution in equation (2.4) is that the expected value of the dependent variable is equal to its expected variance (equidispersion), a condition that is violated if the latter exceeds the former (overdispersion) (Cameron and Trivedi, 1998). We tested for this using the likelihood ratio test for on-boundary values described by Gutierrez, Carter and Drukker (2001), and failed to reject the null hypothesis that the over-dispersion parameter was zero. Furthermore, results of a negative binomial regression model, which accounts for overdispersion, produced almost identical estimates. The assumption of a Poisson distribution is therefore appropriate in our study.

\subsection{Data}

\subsubsection{Farm survey}

This study uses farm survey data collected in Singida Rural and Kondoa Districts in Central Tanzania between September and November 2012. Central Tanzania is mainly semi-arid. Farmers in this region are smallholders who cultivate sorghum and maize, often in addition to millets, pulses, oil crops, and roots and tubers. Many also keep livestock. While maize is more popular among farmers and consumers, sorghum has recently been promoted by the government due to its larger tolerance to drought situations. Of the survey respondents, $88 \%$ grew maize, while $71 \%$ grew sorghum. Eighty-nine percent of the maize growers also cultivated sorghum, while $72 \%$ of the sorghum growers also cultivated maize. Until the late1960s, sorghum and maize varieties in the study area were mainly landraces. Since then, public and private agricultural research organizations have developed improved varieties, which were transferred to farmers through approaches such as on-farm trials, participatory variety selection, field days, direct seed distribution by government and non-governmental organizations, and farmer field schools (Heinrich and Mgonja, 2002; Mgonja and Monyo, 2002; Erenstein et al., 2011).

The data were collected through a survey involving 345 farmers from 21 villages. In both districts, three village clusters (each consisting of 2-5 villages) were purposively selected. Within the villages, respondents were randomly selected. Face-to-face interviews with the household heads were conducted using a structured questionnaire. A broad set of agricultural and socioeconomic variables were captured. To elicit data on social network links, survey respondents were asked questions about their six random matches in this sequence: "Do you know $j$ (the match)?" If the answer was "no", no further network 
questions about the particular match were asked. If the answer was "yes", the respondent was asked: "Do you discuss sorghum (maize) farming issues with $j$ ?" Based on these answers, we interpret a "yes" response as presence of a network link between ego and alter for sorghum (maize), and a "no" response as absence of such a link. Similar information about the respondent was not sought from his/her alters, implying that we assess undirected networks. We also collected data on dyadic attributes by asking the respondent: "Since when have you known $j$ ?" "How is $j$ related to you?", "Are you member of an association that $j$ is also member of?" Other dyadic attributes used in the models were constructed from personal and household characteristics of ego and alter, since both are in our sample.

\subsubsection{Farmers' sources of information}

We are particularly interested in the flow of information about improved sorghum and maize varieties. Table 2.1 shows the sources of first information about improved varieties, as stated by farmers. Since many respondents were exposed to more than one improved variety, and sources of first information are not necessarily the same for all varieties, we report the percentage of 'responses' rather than 'respondents'. For sorghum varieties, government extension officers are the main source of first information, followed by other farmers. For maize varieties, this order is reversed. Besides, more than $20 \%$ of the farmers receive their first information about improved maize varieties from the mass media (radio, newspaper) and grain or seed traders, while these sources hardly play a role for sorghum varieties. The last two columns in Table 2.1 differentiate between maize OPVs and hybrids. Mass media as a source of information are especially important for hybrids. Unlike OPVs, hybrids are sold by private seed companies that advertise their products through commercial media channels.

To better understand the flow of information between farmers, respondents who named other farmers as the source of first information were also asked about the type of relationship they have with the informant and the occasion at which they got exposed to the variety. This information is shown in the lower part of Table 2.1. For all varieties, neighbors and friends were the main source of first information, followed by parents and other relatives. Most respondents stated that they first saw the improved variety in the other farmer's field and then approached that other farmer for more information. These results suggest that the experience individual farmers make with new varieties is a very important source of information for other farmers to learn about the new varieties. 
Table 2.1: Farmers' sources of first information about improved varieties

\begin{tabular}{lllll}
\hline & $\begin{array}{l}\text { Sorghum } \\
\text { varieties }\end{array}$ & $\begin{array}{l}\text { Maize } \\
\text { varieties }\end{array}$ & $\begin{array}{l}\text { Maize } \\
\text { OPVs }\end{array}$ & $\begin{array}{l}\text { Maize } \\
\text { hybrids }\end{array}$ \\
\hline $\begin{array}{l}\text { Source of information (\% of responses) } \\
\text { Other farmer }\end{array}$ & 27.7 & $49.7 * * *$ & 52.8 & 48.6 \\
Government extension officer & 67.3 & $23.9^{* * *}$ & 25.9 & 22.2 \\
Trader & 0.9 & $8.7 * *$ & 9.3 & 8.2 \\
Mass media & 0.5 & $12.2^{* * *}$ & 5.6 & $16.5^{* * *}$ \\
Other & 3.6 & $5.6^{* *}$ & 6.5 & 4.4 \\
$\begin{array}{l}\text { Relationship if source is other farmer (\% of } \\
\text { responses) }\end{array}$ & $(N=159)$ & $(N=326)$ & $(N=114)$ & $(N=196)$ \\
Neighbor/friend & 68.9 & 67.1 & 63.2 & 68.5 \\
Parent & 16.2 & 16.8 & 18.4 & 16.2 \\
Other relative & 14.9 & 16.2 & 18.4 & 15.2 \\
$\begin{array}{l}\text { How learned about variety if source is other farmer } \\
\text { (\% of responses) }\end{array}$ & & & & \\
Saw it in farmer's field and enquired & 69.8 & 71.2 & 66.7 & $74.0 *$ \\
Information came from the other farmer first & 11.3 & 9.8 & 9.6 & 9.7 \\
Not specified & 18.9 & 19.0 & 23.7 & $16.3 *$ \\
\hline
\end{tabular}

$*, * *, * * *$ differences between sorghum and maize varieties (first two columns), and between maize OPVs and hybrids (last two columns), significant at 10\%, 5\%, and $1 \%$ level, respectively.

\subsection{Determinants of network links}

As explained, each farmer was matched to six randomly selected other farmers in the sample. For the 345 farmers interviewed, this would make a total of 2,070 dyads. However, because matching was random, 109 dyads were discovered to be duplicates (the alter was also asked about the ego). For 82 other dyads, some information about the alters was missing. These dyads were excluded from the analysis. In about $50 \%$ of the remaining cases, respondents did not know their random match. These cases were also excluded. We use 948 dyads in the regression analysis.

The probit model specified in equation (2.1) is employed to assess the influence of dyadic characteristics on the probability of detecting an information network link for sorghum and maize. We include village cluster dummies to control for unobserved cluster fixed effects, but these are not reported. Two-way cluster robust standard errors discussed earlier are estimated to correct for heteroscedasticity. Subject to knowing each other, about one third of the random dyads discuss sorghum or maize farming issues, with about $17 \%$ of these discussions occurring across village boundaries. The explanatory variables used in the regressions are defined in Table 2.2 together with descriptive statistics. 
Table 2.2: Definitions and descriptive statistics for variables used in the dyadic regressions

\begin{tabular}{|c|c|c|}
\hline Variable & Definition & Mean \\
\hline Sorghum network & $\begin{array}{l}\text { Presence of sorghum network link between ego and alter } \\
(1=\text { yes; } 0=\text { otherwise })\end{array}$ & $\begin{array}{r}0.34 \\
(0.47)\end{array}$ \\
\hline Maize network & $\begin{array}{l}\text { Presence of maize network link between ego and alter } \\
(1=\text { yes; } 0=\text { otherwise })\end{array}$ & $\begin{array}{r}0.32 \\
(0.47)\end{array}$ \\
\hline Age difference & Ego and alter absolute age difference (years) & $\begin{array}{r}11.9 \\
(8.98)\end{array}$ \\
\hline Education difference & $\begin{array}{l}\text { Ego and alter belong to different education levels ( } 1=y e s ; \\
0=\text { otherwise) }\end{array}$ & $\begin{array}{r}0.26 \\
(0.44)\end{array}$ \\
\hline Gender difference & $\begin{array}{l}\text { Ego and alter belong to different gender }(1=y e s ; \\
0=\text { otherwise })\end{array}$ & $\begin{array}{r}0.25 \\
(0.43)\end{array}$ \\
\hline Religion difference & $\begin{array}{l}\text { Ego and alter belong to different religions ( } 1=y e s ; \\
0=\text { otherwise) }\end{array}$ & $\begin{array}{r}0.32 \\
(0.47)\end{array}$ \\
\hline Land difference & Absolute difference in ego's and alter's size of own land (ha) & $\begin{array}{r}3.82 \\
(6.19)\end{array}$ \\
\hline Livestock difference & $\begin{array}{l}\text { Absolute difference in ego's and alter's livestock value } \\
\text { [millions of shillings ( } 1,560 \text { Shillings }=1 \text { USD during survey)] }\end{array}$ & $\begin{array}{r}2.73 \\
(3.86)\end{array}$ \\
\hline Same association & $\begin{array}{l}\text { Ego and alter belong to a common association or group } \\
\text { (1=yes; } 0=\text { otherwise })\end{array}$ & $\begin{array}{r}0.09 \\
(0.28)\end{array}$ \\
\hline Same village & Ego and alter live in same village ( $1=$ yes; $0=$ otherwise) & $\begin{array}{r}0.73 \\
(0.44)\end{array}$ \\
\hline Same subvillage & Ego and alter live in same subvillage ( $1=y e s ; 0=$ otherwise) & $\begin{array}{r}0.24 \\
(0.43)\end{array}$ \\
\hline Kinship & Ego and alter have kinship tie ( $1=$ yes; $0=$ otherwise $)$ & $\begin{array}{r}0.14 \\
(0.35)\end{array}$ \\
\hline Duration & Duration since ego and alter knew each other (years) & $\begin{array}{r}26.2 \\
(12.8)\end{array}$ \\
\hline Leader & $\begin{array}{l}\text { Ego or alter has a leadership role in the community }(1=y e s ; \\
0=\text { otherwise) }\end{array}$ & $\begin{array}{r}0.67 \\
(0.47)\end{array}$ \\
\hline Extension1 & $\begin{array}{l}\text { Only ego or alter has links with public extension officer } \\
\text { (1=yes; } 0=\text { otherwise })\end{array}$ & $\begin{array}{r}0.36 \\
(0.48)\end{array}$ \\
\hline Extension2 & $\begin{array}{l}\text { Both ego and alter have links with public extension officer } \\
(1=\text { yes; } 0=\text { otherwise })\end{array}$ & $\begin{array}{r}0.55 \\
(0.50)\end{array}$ \\
\hline
\end{tabular}

Notes: Figures in parentheses are standard deviations. D (total dyads used) $=948$.

The probit estimation results are shown in Table 2.3. The effects of all variables are very similar for the sorghum and maize models. This is expected, because farmers who grow the same crops and communicate with each other are unlikely to discuss only one crop and not the other. Differences in education levels between ego and alter reduce the probability of an information network link. Larger differences in the size of land owned by the households (which is commonly used as a wealth indicator) increase the likelihood of a network link. For this variable, an a priori expectation is difficult to form. In their analysis for cotton technology, Maertens and Barrett (2013) found the opposite effect, namely that farmers with 
similar farm sizes are more likely to exchange information. We interpret our result such that farmers with similar landholdings may also have similar technological experiences, so that an information exchange could be less fruitful (Borgatti et al., 2009; Dufhues et al., 2010).

Table 2.3: Determinants of information network links

\begin{tabular}{|c|c|c|c|c|}
\hline \multirow[t]{2}{*}{ Variable } & \multicolumn{2}{|l|}{ Sorghum } & \multicolumn{2}{|l|}{ Maize } \\
\hline & Coefficient & ME & Coefficient & ME \\
\hline Constant & $\begin{array}{l}-2.029 * * * \\
(0.299)\end{array}$ & & $\begin{array}{l}-1.967 * * * \\
(0.306)\end{array}$ & \\
\hline Age difference & $\begin{array}{l}0.002 \\
(0.001)\end{array}$ & 0.001 & $\begin{array}{l}-0.001 \\
(0.006)\end{array}$ & -0.000 \\
\hline Education difference & $\begin{array}{l}-0.202 * \\
(0.117)\end{array}$ & -0.063 & $\begin{array}{l}-0.232^{* * *} \\
(0.112)\end{array}$ & -0.073 \\
\hline Gender difference & $\begin{array}{l}-0.229 \\
(0.144)\end{array}$ & -0.072 & $\begin{array}{l}-0.215 \\
(0.147)\end{array}$ & -0.067 \\
\hline Religion difference & $\begin{array}{l}-0.039 \\
(0.096)\end{array}$ & -0.012 & $\begin{array}{l}-0.107 \\
(0.104)\end{array}$ & -0.034 \\
\hline Land difference & $\begin{array}{l}0.022 * \\
(0.012)\end{array}$ & 0.007 & $\begin{array}{l}0.030 * * * \\
(0.011)\end{array}$ & 0.009 \\
\hline Livestock difference & $\begin{array}{l}0.018 \\
(0.015)\end{array}$ & 0.006 & $\begin{array}{l}0.004 \\
(0.013)\end{array}$ & 0.001 \\
\hline Same association & $\begin{array}{l}0.808 * * * \\
(0.218)\end{array}$ & 0.254 & $\begin{array}{l}0.6783^{* * * *} \\
(0.195)\end{array}$ & 0.213 \\
\hline Same village & $\begin{array}{l}0.395^{* * * *} \\
(129)\end{array}$ & 0.124 & $\begin{array}{l}0.84 * * \\
(0.119)\end{array}$ & 0.089 \\
\hline Same subvillage & $\begin{array}{l}0.378 * * * \\
(0.124)\end{array}$ & 0.119 & $\begin{array}{l}0.309 * * * \\
(0.120)\end{array}$ & 0.097 \\
\hline Kinship & $\begin{array}{l}0.413 * * * \\
(0.142)\end{array}$ & 0.130 & $\begin{array}{l}0.356 * * \\
(0.151)\end{array}$ & 0.112 \\
\hline Duration & $\begin{array}{l}0.012 * * \\
(0.005)\end{array}$ & 0.004 & $\begin{array}{l}0.015 * * * \\
(0.005)\end{array}$ & 0.005 \\
\hline Leader & $\begin{array}{l}0.250 * * \\
(0.114)\end{array}$ & 0.079 & $\begin{array}{l}0.206^{*} \\
(0.121)\end{array}$ & 0.065 \\
\hline Extension1 & $\begin{array}{l}0.379 * \\
(0.199)\end{array}$ & 0.119 & $\begin{array}{l}0.450 * * \\
(0.208)\end{array}$ & 0.141 \\
\hline Extension2 & $\begin{array}{l}0.403 * \\
(0.208)\end{array}$ & 0.127 & $\begin{array}{l}0.489 * * \\
(0.255)\end{array}$ & 0.153 \\
\hline
\end{tabular}

Notes: Dependent variables are sorghum network and maize network. In parentheses are cluster robust standard errors; ME, marginal effects. D (dyads used) $=948 . *, * *, * * *$ significant at $10 \%, 5 \%$, and $1 \%$ level, respectively.

Being member in the same group or association increases the probability of an information network link by more than 20 percentage points, for both crops. This is plausible, because farmers who belong to the same association meet more frequently and hence have a higher propensity to exchange information. Similarly, geographical proximity between ego and alter has a positive influence: living in the same village increases the probability of a 
network link by 12 and 9 percentage points for sorghum and maize, respectively. Living in the same subvillage further increases the likelihood of information exchange. Moreover, family ties between farmers and the duration of knowing each other have positive effects on the exchange of farming information. This is expected and is likely related to trust. Similar results for the role of kinship for information networks were reported by Conley and Udry (2010).

If either ego or alter have a community leadership role, the likelihood of an active information link is higher. Community leaders do not only know more people, but they are also likely to have more and better information, so they are attractive contact points for other farmers to seek advice. Similarly, the likelihood of information exchange is higher if either one or both of the farmers have a direct link with a public extension officer. Extension officers are an important source of information about agricultural technologies - information which is then further discussed among farmers themselves. However, the relatively high marginal effect of the extension variables suggest that farmers rely on first and second-hand information and that the farmer-to-farmer exchange may be less effective across multiple network nodes. Hence, informal social networks can support the flow of information among farmers, but they do not reduce the need for widespread outreach of agricultural extension services.

\subsection{Determinants of exposure to improved varieties}

\subsubsection{Status of exposure}

Farmers' exposure to improved varieties is summarized in Table 2.4. For sorghum, a total of six improved varieties are available in the study area. About $79 \%$ of the respondents know at least one of these varieties. For maize, 11 improved varieties are available, of which six are hybrids and five OPVs. About $74 \%$ of the respondents know at least one of these improved maize varieties. If we would define exposure to improved varieties as a binary variable, as often done in the literature, exposure would be somewhat lower for maize than for sorghum. However, as explained above, we define exposure in terms of the number of improved varieties known, where the picture is reversed. On average, farmers know more improved maize than sorghum varieties. Nevertheless, for both crops the number of improved varieties known by farmers is quite small. This indicates that farmers are constrained in their access to information, so that better understanding the factors that influence exposure is important. 
Table 2.4: Farmer exposure to improved varieties

\begin{tabular}{lrrrr}
\hline Exposure & Sorghum & Maize & $\begin{array}{r}\text { Maize } \\
\text { OPVs }\end{array}$ & $\begin{array}{r}\text { Maize } \\
\text { hybrids }\end{array}$ \\
\hline Total number of varieties known in the study area & 6 & 11 & 5 & 6 \\
Exposed to at least one (\% of sample) & 78.8 & 73.6 & 42.3 & 66.1 \\
Intensity of exposure (\% of sample) & & & & \\
0 & 21.2 & 26.4 & 58.0 & 33.9 \\
1 & 30.4 & 25.2 & 24.9 & 32.2 \\
2 & 21.5 & 18.0 & 13.9 & 20.6 \\
3 & 16.8 & 12.5 & 3.19 & 9.86 \\
4 & 7.83 & 11.0 & 0.0 & 3.19 \\
5 and above & 2.32 & 6.96 & 0.0 & 0.29 \\
Mean intensity of exposure & 1.67 & 1.79 & 0.62 & 1.17 \\
& $(1.32)$ & $(1.62)$ & $(0.84)$ & $(1.12)$ \\
\hline
\end{tabular}

Notes: Figures in parenthesis are standard deviations. $\mathrm{N}=345$.

\subsubsection{Regression results}

To analyze the determinants of exposure to improved varieties, we estimate Poisson regression models, as described in equations (2.3) and (2.4). The explanatory variables used in these models are defined in Table 2.5. In addition to these variables, we include village cluster dummies; these dummies are not shown for brevity. Regression results are presented in Table 2.6. In models (1) to (4), we use network variables that capture the network degree relative to all six random matches for each farmer. In models (5) to (8), we differentiate between intra-village and inter-village network degrees by referring to the three random matches within and outside the ego's village, respectively.

The results of model (1) show that the network degree positively influences the intensity of exposure to improved sorghum varieties. Each additional network link increases the number of sorghum varieties known by almost 0.09 . For maize, this effect is not statistically significant (model 2). However, once we disaggregate between maize OPVs and hybrids (models 3 and 4), the effect for OPVs turns significant. Remember that the sorghum varieties available in the study area are also all OPVs. This is an interesting result, as it suggests that social networks are more important for the spread of information about technologies for which formal markets fail. Unlike maize hybrids, improved sorghum and maize OPVs are not promoted by the private seed sector, so informal sources of information play a larger role. 
Table 2.5: Definitions and descriptive statistics for variables used in the exposure models

\begin{tabular}{llc}
\hline Variable & Definition & Mean \\
\hline Sorghum & Number of sorghum information links out of six random matches & 1.11 \\
network degree & & $(1.40)$ \\
Sorghum & Intra-village sorghum network degree (number of links out of three & 0.93 \\
network degree1 & random matches within the village) & $(1.08)$ \\
Sorghum & Inter-village sorghum network degree (number of links out of three & 0.19 \\
network degree2 & random links outside the village) & $(0.57)$ \\
Maize network & Number of maize information links out of six random matches & 1.03 \\
degree & & $(1.38)$ \\
Maize network & Intra-village maize network degree (number of links out of three & 0.83 \\
degree1 & random matches within the village) & $(1.06)$ \\
Maize network & Inter-village maize network degree (number of links out of three & 0.20 \\
degree2 & random links outside the village) & $(0.55)$ \\
Admin link & Strength of links with village administration (number of contacts & 13.8 \\
& per month with village administrators) & $(9.57)$ \\
Extension link & Talks with public extension officer at least once per month (1=yes, & 0.64 \\
& 0=otherwise) & $(0.48)$ \\
Age & Age of respondent (years) & 46.0 \\
& & $(11.4)$ \\
Female & Respondent is a female (1=yes; 0=otherwise) & 0.27 \\
& & $(0.44)$ \\
Education & Respondent has more than four years of formal education (1=yes; & 0.83 \\
& 0=otherwise) & $(0.37)$ \\
Muslim & Respondent is Muslim (1=yes; 0=otherwise - mostly Christian) & 0.57 \\
& & $(0.50)$ \\
Land owned & Land owned by the respondent's household (ha) & 4.41 \\
Mobile phone & Household owns a mobile phone (1=yes; 0=otherwise) & $(5.71)$ \\
Radio & Household owns a radio (1=yes; 0=otherwise) & 0.70 \\
& & $0.46)$ \\
\hline Non & & 0.75 \\
& & $0.43)$ \\
\hline
\end{tabular}

Notes: Figures in parentheses are standard deviations. $\mathrm{N}=345$.

The results of models (5) and (7) in Table 2.6 indicate that inter-village networks matter more than intra-village networks for gaining awareness of improved sorghum and maize OPVs. This does not imply that networks outside the own village are stronger, but they seem to be more relevant for the influx of new information than networks within the farmer's own village. This is consistent with Schaefer (2010) who argues that strong ties within an established network (for instance, those in intra-village networks) can make such networks conservative and less exposed to new ideas. In a similar vein, Rauch (2010) posits that bridging network clusters produces synergies that lead to higher outcomes. As mentioned, previous studies that investigated the role of social networks for technology diffusion 
primarily focused on intra-village networks, thus missing the potentially important role of inter-village networks.

Table 2.6: Determinants of exposure to improved varieties

\begin{tabular}{|c|c|c|c|c|c|c|c|c|}
\hline Variable & $\begin{array}{c}\text { (1) } \\
\text { Sorghum }\end{array}$ & $\begin{array}{c}(2) \\
\text { Maize }\end{array}$ & $\begin{array}{c}(3) \\
\text { Maize } \\
\text { OPVs } \\
\end{array}$ & $\begin{array}{c}(4) \\
\text { Maize } \\
\text { hybrids }\end{array}$ & $\begin{array}{c}(5) \\
\text { Sorghum }\end{array}$ & $\begin{array}{c}(6) \\
\text { Maize }\end{array}$ & $\begin{array}{c}(7) \\
\text { Maize } \\
\text { OPVs } \\
\end{array}$ & $\begin{array}{c}(8) \\
\text { Maize } \\
\text { hybrids } \\
\end{array}$ \\
\hline $\begin{array}{l}\text { Sorghum network } \\
\text { degree }\end{array}$ & $\begin{array}{l}0.087 * * \\
(0.042)\end{array}$ & & & & & & & \\
\hline $\begin{array}{l}\text { Sorghum network } \\
\text { degree } 1 \\
\text { Sorghum network } \\
\text { degree2 }\end{array}$ & & & & & $\begin{array}{l}0.022 \\
(0.065) \\
0.223 * * \\
(0.106)\end{array}$ & & & \\
\hline $\begin{array}{l}\text { Maize network } \\
\text { degree }\end{array}$ & & $\begin{array}{l}0.047 \\
(0.056)\end{array}$ & $\begin{array}{l}0.048^{*} \\
(0.028)\end{array}$ & $\begin{array}{l}-0.006 \\
(0.040)\end{array}$ & & & & \\
\hline $\begin{array}{l}\text { Maize network } \\
\text { degree } 1 \\
\text { Maize network } \\
\text { degree2 }\end{array}$ & & & & & & $\begin{array}{l}-0.018 \\
(0.082) \\
0.194 \\
(0.140)\end{array}$ & $\begin{array}{l}-0.003 \\
(0.044) \\
0.148 * * \\
(0.072)\end{array}$ & $\begin{array}{l}-0.020 \\
(0.058) \\
0.029 \\
(0.101)\end{array}$ \\
\hline Admin link & $\begin{array}{l}0.014 * * \\
(0.007)\end{array}$ & $\begin{array}{l}0.013 \\
(0.008)\end{array}$ & $\begin{array}{l}0.005 \\
(0.005)\end{array}$ & $\begin{array}{l}0.008 \\
(0.006)\end{array}$ & $\begin{array}{l}0.014 * * \\
(0.007)\end{array}$ & $\begin{array}{l}0.014 \\
(0.008)\end{array}$ & $\begin{array}{l}0.0051 \\
(0.005)\end{array}$ & $\begin{array}{l}0.008 \\
(0.006)\end{array}$ \\
\hline Extension link & $\begin{array}{l}0.365^{* *} \\
(0.147)\end{array}$ & $\begin{array}{l}0.410 * * \\
(0.179)\end{array}$ & $\begin{array}{l}0.156 \\
(0.096)\end{array}$ & $\begin{array}{l}0.254 * * \\
(0.129)\end{array}$ & $\begin{array}{l}0.379 * * * \\
(0.146)\end{array}$ & $\begin{array}{l}0.423 * * \\
(0.182)\end{array}$ & $\begin{array}{l}0.168^{*} \\
(0.098)\end{array}$ & $\begin{array}{l}0.256^{* *} \\
(0.130)\end{array}$ \\
\hline Age & $\begin{array}{l}0.018 * * \\
(0.007)\end{array}$ & $\begin{array}{l}0.017^{*} \\
(0.007)\end{array}$ & $\begin{array}{l}0.013^{* * *} \\
(0.005)\end{array}$ & $\begin{array}{l}0.004 \\
(0.007)\end{array}$ & $\begin{array}{l}0.019 * * * \\
(0.007)\end{array}$ & $\begin{array}{l}0.018^{*} \\
(0.010)\end{array}$ & $\begin{array}{l}0.014 * * * \\
(0.005)\end{array}$ & $\begin{array}{l}0.004 \\
(0.007)\end{array}$ \\
\hline Female & $\begin{array}{l}-0.298 \\
(0.201)\end{array}$ & $\begin{array}{l}-0.576^{* *} \\
(0.248)\end{array}$ & $\begin{array}{l}-0.147 \\
(0.128)\end{array}$ & $\begin{array}{l}-0.437 * * \\
(0.172)\end{array}$ & $\begin{array}{l}-0.320 \\
(0.201)\end{array}$ & $\begin{array}{l}-0.584^{* *} \\
(0.246)\end{array}$ & $\begin{array}{l}-0.149 \\
(0.128)\end{array}$ & $\begin{array}{l}-0.439 * * \\
(0.172)\end{array}$ \\
\hline Education & $\begin{array}{l}0.348 \\
(0.213)\end{array}$ & $\begin{array}{l}0.495^{*} \\
(0.268)\end{array}$ & $\begin{array}{l}0.286 * * \\
(0.141)\end{array}$ & $\begin{array}{l}0.208 \\
(0.192)\end{array}$ & $\begin{array}{l}0.359^{*} \\
(0.213)\end{array}$ & $\begin{array}{l}0.496^{*} \\
(0.268)\end{array}$ & $\begin{array}{l}0.291 * * \\
(0.140)\end{array}$ & $\begin{array}{l}0.207 \\
(0.192)\end{array}$ \\
\hline Land owned & $\begin{array}{l}-0.005 \\
(0.011)\end{array}$ & $\begin{array}{l}-0.009 \\
(0.017)\end{array}$ & $\begin{array}{l}-0.003 \\
(0.010)\end{array}$ & $\begin{array}{l}-0.008 \\
(0.010)\end{array}$ & $\begin{array}{l}-0.008 \\
(0.012)\end{array}$ & $\begin{array}{l}-0.011 \\
(0.017)\end{array}$ & $\begin{array}{l}-0.005 \\
(0.010)\end{array}$ & $\begin{array}{l}-0.008 \\
(0.010)\end{array}$ \\
\hline Mobile phone & $\begin{array}{l}0.221 \\
(0.154)\end{array}$ & $\begin{array}{l}0.306 \\
(0.206)\end{array}$ & $\begin{array}{l}0.280 * * \\
(0.120)\end{array}$ & $\begin{array}{l}0.032 \\
(0.145)\end{array}$ & $\begin{array}{l}0.219 \\
(0.153)\end{array}$ & $\begin{array}{l}0.298 \\
(0.205)\end{array}$ & $\begin{array}{l}0.272 * * \\
(0.118)\end{array}$ & $\begin{array}{l}0.030 \\
(0.145)\end{array}$ \\
\hline Radio & $\begin{array}{l}0.123 \\
(0.185)\end{array}$ & $\begin{array}{l}0.421^{*} \\
(0.241)\end{array}$ & $\begin{array}{l}0.156 \\
(0.135)\end{array}$ & $\begin{array}{l}0.267^{*} \\
(0.160)\end{array}$ & $\begin{array}{l}0.128 \\
(0.185)\end{array}$ & $\begin{array}{l}0.432 * \\
(0.241)\end{array}$ & $\begin{array}{l}0.170 \\
(0.134)\end{array}$ & $\begin{array}{l}0.269^{*} \\
(0.161)\end{array}$ \\
\hline
\end{tabular}

Notes: Dependent variables are the number of improved varieties known by the respondent. Marginal effects of Poisson regressions are shown with robust standard errors in parentheses. $\mathrm{N}=345 . *, * * * *$ significant at $10 \%$, $5 \%$, and $1 \%$ level, respectively.

Having frequent interactions with village administrators significantly increases exposure to improved sorghum varieties. The same effect is not observed for maize, neither for hybrids nor for OPVs. This difference is probably due to the fact that the government has recently promoted sorghum cultivation in the study area. Village administrators are involved in this campaign as local government representatives. Furthermore, frequent interactions with public extension officers have positive and significant effects in almost all models in Table 2.6. It is worth noting that for both crops the marginal effects of these extension variables are several times larger than those of the network links with other farmers. This reinforces our 
earlier statement that informal social networks can support but not replace the flow of information through the extension service and other formal channels.

In terms of farmers' personal characteristics, age increases exposure to improved varieties, which we attribute to the longer experience of older farmers. The only exception are the models for hybrid maize, where the effect of age is very small and not statistically significant. It is likely that older farmers are less receptive for technologies that require more profound changes in traditional cultivation practices, such as purchasing fresh seeds every year, which is required with hybrids in order to prevent productivity decline. Education increases exposure to improved varieties in most models, which is expected. Farmers with more education tend to have better access to new information. Furthermore, owning a mobile phone and/or a radio has positive impacts on exposure to improved maize varieties. Radio seems to play a significant role especially for maize hybrids. As hybrids are promoted by private seed companies, commercial media advertisements are commonplace.

Land ownership does not have significant effects on exposure, indicating that there is no scale bias in the flow of information about improved varieties. Yet, being a female farmer has a negative effect on exposure. There seems to be a gender bias in the flow of information about improved seed technologies, which holds for both OPVs and hybrids. This is consistent with Kabunga et al. (2012) who showed that women tend to be less aware of new banana technologies in Kenya.

\subsection{Conclusions and policy implications}

In this study, we have analyzed the role of social networks for farmers' exposure to improved crop varieties in Tanzania. Unlike previous social network studies, which mostly focused on crops for which formal seed markets exist, we have looked at sorghum and maize varieties for which seed market imperfections are commonplace. While maize hybrids are sold by private seed companies in Tanzania, improved OPVs of sorghum and maize are primarily promoted by public sector institutions. And, while previous studies concentrated primarily on intra-village social networks, we have extended the approach and have also considered intervillage networks.

In explaining the existence of informal networks, we found that farmers are more likely to exchange relevant agricultural information if they have similar levels of education, different farm sizes, are members of the same association, live in the same village, and have kinship ties. At the same time, the probability of exchanging farming information increases if 
a community leader is involved and if at least one of the farmers has a direct link to a public extension officer. These patterns are the same for both crops, sorghum and maize.

However, in terms of the role of social networks for farmers' exposure to improved varieties, we found more pronounced differences between the two crops. The degree of social network interactions increases farmers' awareness of improved sorghum varieties, but not of improved maize varieties. Further disaggregation showed that for maize the effect differs between improved OPVs and hybrids: while social networks play a positive and significant role for farmers' exposure to maize OPVs, the result remains insignificant for hybrids. Obviously, the flow of information through informal networks is more important for seed technologies for which formal markets fail. Strikingly, inter-village networks play a larger role for generating awareness about new varieties than intra-village networks.

In addition to social networks, personal characteristics of farmers matter for their awareness of improved varieties. Unsurprisingly, farmer education has a positive effect on exposure to improved varieties of both crops. Age has a positive effect for sorghum and maize OPVs, but not for maize hybrids. On the other hand, ownership of a radio increases farmers' awareness of improved maize hybrids, as these tend to be promoted by private companies through commercial media advertisements. The gender of the farmers also matters. Being a female farmer is associated with reduced exposure to improved sorghum and maize varieties, which points at a significant gender bias in information flows. Finally, the results show that regular contacts of farmers to public extension officers and village administrators increase exposure considerably. The marginal effects of extension are much larger than those of the social network variables, suggesting that informal information channels are not a substitute for awareness creation through formal channels.

These results have a number of policy and research implications. First, social networks matter for the spread of new agricultural technologies. Hence, technology dissemination programs should try to make use of such networks. Second, the role that social networks play for the spread of information differs by type of crop and technology. They seem to be more important for technologies that are not promoted by the private sector and for which formal markets fail. Third, social networks can support but not replace formal extension programs. Fourth, new extension models should be developed that explicitly build on the synergies between formal and informal information channels. Much more research is needed to establish what type of extension model is cost-effective in a particular situation. An intensive training of lead farmers, who then pass on their knowledge to other farmers, may be more effective than assuming that snowball effects across multiple network nodes would occur 
automatically. Farmer associations and well managed demonstration plots may play important roles in this respect. Fifth, gender biases in access to information about agricultural technologies should be addressed. This will require gender mainstreaming of extension programs, among other things. Sixth, the finding that inter-village networks matter for farmers' exposure to improved varieties points to the potential that facilitation of exchange across village boundaries may have for the spread of information and technology. Follow-up studies should explicitly analyze the formation and functioning of inter-village social networks. 


\title{
3 Social networks and the adoption of agricultural innovations: The case of improved cereal varieties in Central Tanzania ${ }^{5}$
}

\begin{abstract}
Literature on the adoption of agricultural innovations highlights the importance exposure to these technologies for the adoption decision of small scale farmers. This study assesses the relevance of exposure and other constraints in the adoption of improved sorghum and maize varieties in Central Tanzania. Specifically, we analyze the determinants of exposure to improved varieties; and of adoption itself, focusing more on the role of social networks. We use survey data collected from 345 farmers between September and November 2012. We apply Poisson models to assess exposure, and average treatment effect procedures to analyze adoption. Our results show that about $79 \%$ and $74 \%$ of the respondents are exposed to at least one improved variety of sorghum and maize respectively. The average intensity of exposure (number of improved varieties a farmer is exposed to) was 1.7 for sorghum and 1.8 for maize. Farmer networks are found to be a key source of variety information, and exchange of this information among farmers is triggered when a farmer sights a variety grown in a network member's field. Most farmers consider improved varieties of both crops generally better than traditional ones. However, while $83 \%$ of farmers think improved varieties of maize are better than traditional ones, only $54 \%$ of farmers think so for sorghum. The size of a farmer's network is found to positively influence their intensity of exposure to improved sorghum and open-pollinated maize varieties, but not to maize hybrids. This demonstrates that farmer networks facilitate higher exposure to seed technologies with mostly missing or malfunctioning markets. We find that farmers have substantial information networks outside their own villages, and it is these often understudied networks that determine the intensity of exposure. The strength of network connections with village administrators positively affects intensity of exposure to sorghum varieties, while network connections with agricultural

\footnotetext{
${ }^{5}$ This chapter is published online as "Muange, E.N., Schwarze, S., 2014. Social networks and the adoption of agricultural innovations: The case of improved cereal cultivars in Central Tanzania. Series Discussion Paper Number 18, Hyderabad, India, The International Crops Research Institute for the Semi-Arid Tropics (ICRISAT), Socioeconomics Discussion Paper Series".

As already pointed out in Chapter 1, the methodological framework we use to model adoption of improved varieties controls for biases in exposure to the varieties. Hence, some sections on exposure overlap with those discussed in the previous chapter, and this was intended to maintain consistency and make the paper more understandable as an independent article.
} 
extension officers influence intensity of exposure positively for sorghum varieties and maize hybrids. Other determinants of exposure are age and education of household head, and household ownership of information and communication assets. Female farmers have less exposure to maize hybrids than their male counterparts. On adoption, we find that adoption rates are pretty low - just about $42 \%$ in the case of sorghum and $60 \%$ for maize. After accounting for non-exposure and selection biases, the estimated population adoption rate is $52 \%$ for sorghum and $71 \%$ for maize, implying adoption gaps of 9.3 and 10.9 percentage points, respectively. Sorghum networks positively influence adoption even after accounting for their role in exposure. However, it is the intra-village and not inter-village networks that produce this effect. Intensity of exposure influences adoption positively for both crops. Households with more female adults are more likely to adopt improved sorghum, while those with more male adults are more likely to adopt improved maize. Poor soil fertility negatively affects adoption of improved sorghum, while non-farm income activities and size of maize farm positively influence adoption of maize varieties. Farmers mentioned seed availability followed by perceived susceptibility to pests as the most limiting factors to adoption. The importance of these reasons changes if we compare farmers without past adoption experience to those who have ever adopted. These results raise a number of implications for policy design and further research, which are discussed in the last chapter of this paper.

Keywords: social networks, exposure, adoption, improved varieties, maize, sorghum 


\subsection{Introduction}

Food insecurity remains a major development challenge for many agrarian economies (World Bank, 2007) and the use of improved crop varieties (ICVs) is seen as a key to increasing food production and hence food security (FAO, 2002). However, adoption of improved varieties remains incomplete. Estimates by the Consultative Group on International Agricultural Research (CGIAR, 2011) show that for the world's 10 key crops, improved varieties have been adopted in only $65 \%$ of the cultivated area, with Sub-Saharan Africa (SSA) recording the lowest adoption rates (Gollin et al., 2005; Smale et al., 2011).

Adoption of improved varieties has been widely studied (Doss, 2006), but the incomplete and heterogeneous diffusion of these technologies across regions calls for more research into the drivers of this process. A major strand in the adoption literature focused on the identification of constraints. Several recent studies (Ransom et al., 2003; Kijima et al., 2011; Uiaene, 2011; Mal et al., 2012) show that adoption is influenced by farm and farmer characteristics (such as age, experience, education) as well as institutional factors such as access to input markets, credit and extension services. Other have studies identified lack of exposure to improved varieties as a major constraint to adoption in many parts of SSA (Doss et al., 2003; Diagne 2006; Simtowe et al., 2011; Dibba et al., 2012; Kabunga et al., 2012). The argument in such studies is that farmers cannot adopt improved varieties whose existence or attributes they are unaware of. Building on the information constraint paradigm, a growing number of technology adoption studies (Bandiera and Rasul, 2006; Matuschke and Qaim, 2009; Conley and Udry, 2010) assessed the role of social ties and interactions, also known as social structures or social networks (Borgatti et al., 2009). This is based on the understanding that flows of information, ideas, beliefs and attitudes within social networks can influence the perception about the benefits of new varieties and hence farmers' decisions to adopt (Baerenklau, 2005).

In this study we analyze the determinants of exposure, which is a precondition for adoption, and of adoption itself. We focus on the role of social networks on exposure and adoption of improved cereal technologies. Our study deviates from Bandiera and Rasul (2006) and Conley and Udry (2010) by focusing on sorghum and maize, which are grown primarily for home consumption and are critical for food security in Central Tanzania. In a departure from Matuschke and Qaim (2009), who also investigate the role of social networks on technology adoption for key cereals, we explicitly address the role of different types of 
social networks (i.e. networks to other farmers as well as links to the village administration and the extension officer) on exposure and adoption.

\subsection{Research questions}

The above mentioned adoption literature highlights the importance of exposure constraints as well as farm and farmer characteristics for the adoption decision of small scale farmers in developing countries. This study aims to assess the relevance of these factors for the adoption of improved cereal varieties in Central Tanzania. The findings are important for designing policies to foster innovation adoption and productivity growth. Specifically, we address the following research questions:

1. With respect to knowledge about ICVs:

1.1. How many farmers know about ICVs of maize and sorghum?

1.2. What factors determine exposure? What role do social networks play?

1.3. What are the perceived characteristics of ICVs compared to local varieties?

2. With respect to adoption of ICVs:

2.1. What is the status of adoption of ICVs and how does this differ across crops?

2.2. What are determinants of adoption? What role do social networks play?

2.3. What are the stated key constraints to adoption of ICVs?

\subsection{Analytical framework}

\subsubsection{Definition and measurement of social networks}

We define a social network as a set of actors or nodes (individuals, agents, or groups) that have relationships with one another (Hanneman and Riddle, 2005; Marin and Wellman, 2011). Social networks evolve due to ties between actors, which may arise because of kinship, affection or familiarity between them (Easley and Kleinberg, 2010). The simplest social network is a dyad (pair of linked actors), in which one actor (whose network is being studied), is referred to as the ego, and the other as the alter (Smith and Christakis, 2008). This raises the question for our study, whether the number of connections an actor has determines their exposure to ICVs. To address this question, we apply the concept of node-level properties of social networks, particularly centrality measures (Borgatti, 2005). These measures determine positions and power of network actors, which predispose them to opportunities and constraints that determine outcomes (House et al., 2007; Borgatti et al., 2009). Key among centrality measures is degree, which refers to the number of other actors 
to which an actor is directly connected (Newman, 2010). We hypothesize that respondents with a higher network degree occupy positions that predispose them to more learning opportunities about improved varieties; hence they are more likely to have a higher intensity of exposure than those with a lower degree.

Empirical measurement of social networks is a highly debated and evolving topic. In this study, we address two major challenges commonly faced in measuring social networks, which informed our choice of data collection methods. The first involves selection of actors to be studied. Some researchers use a complete network approach, which involves a census of the population being studied (Barroga-Jamias and Brien, 1996; Goswami and Basu, 2010; van den Broeck and Dercon, 2011). This approach, while theoretically appealing, is of limited practical use in studying large populations. Besides, even with a complete census, it is impossible to capture all of an individual's social links, because some are often unreported, while others span out of geographical boundaries set by empirical studies (Udry and Conley, 2004; Fafchamps and Gubert, 2007; Handcock and Gile, 2010). Researchers therefore often use samples to study social networks in large populations. However, Santos and Barrett (2010) and Chandrasekhar and Lewis (2011) argue that little can be learned about the real networks if individuals in the network are sampled, and recommend the sampling of paired actors (dyads) and graphical reconstruction respectively. We use the sampling of dyads approach due to its simplicity, and because our interest is not in the characteristics of the actual networks per se.

The second challenge is how to establish which actors constitute an individual's network. Three main approaches have been used in past studies. In one approach, each individual being studied is asked to name a certain number of individuals with whom they interact (Barroga-Jamias and Brien, 1996; Bandiera and Rasul, 2006; Tatlonghari et al., 2012). The weakness of this approach is that individuals are likely to name only persons, to whom they are strongly linked, leading to estimates of network properties that are biased towards strong links. The second method, called matches within sample, asks each individual about their ties and interactions with every other individual in the sample while the third approach, called random matching within sample, pairs each individual in the sample with only a specified number of individuals randomly selected from the sample (Santos and Barrett, 2008). The matches-within-sample approach suffers the same limitations as the census method if the sample is large (Fafchamps and Gubert, 2007). Furthermore, Santos and 
Barrett (2008) demonstrate using Monte Carlo simulations that the latter approach produces network parameters that represent the real network more efficiently.

Based on these considerations, we formed hypothetical social networks by randomly pairing each farmer with six others in the sample: three from the respondent's village and three from neighboring villages which make up the respondent's village cluster (see Chapter 3.4 for a detailed description). Although single villages have been the geographical focus of most social network studies, we preferred a village clusters approach for two reasons. First, many technology awareness and dissemination activities carried out by research and extension agencies have been held at administrative units higher than the village (comprising several villages). Second, literature reviewed suggested that farmers' networks may extend outside their villages of residence, yet this information often disregarded in most social network studies. It was therefore interesting to assess the presence of inter-village social networks and their effect on information exchange across villages. The respondents were then asked whether they know their random matches and for how long they have known them, whether and how often they talk on general and crop specific (sorghum and maize) issues, and whether they have any kinship ties or common membership in community groups or associations. In addition to farmer-to-farmer networks, each respondent was asked about their ties with village administrators and public extension officers. This was aimed at assessing how strongly farmers are connected to official information channels and whether network connections to these channels influence exposure to improved varieties. We present a detailed description of data collection methods for social networks in Chapter 3.4.

\subsubsection{Determinants of exposure}

To identify the determinants of exposure, we define exposure in terms of intensity, i.e. the number of improved varieties to which a farmer is exposed. We model the farmer's intensity of exposure to improved varieties (number of varieties the farmer knows) as a discrete variable, V, with a Poisson distribution (Cameron and Trivedi, 1998; Greene, 2012) given by

$$
\operatorname{Pr}\left(V=v_{i} \mid z_{\bar{i}_{i}} w_{i}\right)=\frac{e^{-\mu_{i}} \mu_{i} v_{i}}{v_{i}^{i} \frac{1}{i}} \quad v_{i}=0,1,2 \ldots
$$

where $\mu$ is a loglinear function that can be expressed as:

$$
\ln \mu_{i}=z_{i}^{\prime} \beta+w_{i}^{\prime} \delta
$$

Based on this specification, intensity of exposure is given by

$$
E\left[v_{i} \mid z_{i,}, w_{i}\right]=\operatorname{Var}\left[v_{i} \mid z_{i,}, w_{i}\right]=\mu_{i}=e^{z_{i}^{I} \beta+w_{i}^{J} \delta}
$$$$
v_{i}=0,1,2 \ldots
$$ 
Where for each farmer $i, v$ is the intensity of exposure to improved varieties; $z$ is a set of personal and household attributes hypothesized to influence exposure, such as age, education level, sex, and wealth; $w$ is a set of variables that indirectly capture the quantity of information on improved varieties available to the farmer through social networks with other farmers, village administrators, and government agricultural extension officers; and $\beta$ and $\partial$ are vectors of parameters to be estimated by the model, denoting the partial effects of personal and household characteristics, and social networks, respectively. We hypothesize that controlling for $z$, social networks influence a farmer's exposure directly through discussions about improved varieties between the farmer and network members, or indirectly when the farmer is invited or persuaded in some other way by network members to attend forums where improved varieties are discussed, such as extension meetings and field days.

One critical assumption of the Poisson distribution in Equation 3.3 is that the expected value of the dependent variable is equal to its expected variance (equidispersion), a condition that is violated if the latter exceeds the former (overdispersion), leading to imprecise estimators (Cameron and Trivedi, 1998). A likelihood ratio test did not reject the null hypothesis of no overdispersion in our data. Furthermore, results of a negative binomial regression model (not presented here), which accounts for overdispersion, produced almost identical estimates. We therefore maintained the results of the Poisson regression models.

\subsubsection{Determinants of adoption}

To determine the drivers of adoption of improved varieties, we apply the methodology proposed by Diagne and Demont (2007). The basic logic of this framework is that farmer exposure to improved varieties, which is a precondition for adoption of the varieties, is not necessarily random in the population. For instance, farmers may self-select themselves into exposure, or be targeted by technology promoters for exposure into these varieties. Furthermore, adoption may be influenced by unobserved factors that influence exposure. Thus, if exposure to improved varieties among farmers is incomplete (as it is the case for ICVs of sorghum and maize in Central Tanzania), modeling adoption without taking into account the potential non-exposure bias yields inconsistent estimates. That also means that the interpretation of the coefficients of standard adoption models is difficult if there is a lack of exposure (Besley and Case, 1993; Saha et al., 1994; Dimara and Skuras, 2003).

Diagne and Demont's (2007) method is based on the modern treatment effect estimation literature, which goes back to the seminal work of Rubin (1973). They use a counterfactual outcome framework, which assumes that every farmer in the population has 
two potential adoption outcomes: with and without exposure. Following the notation of Diagne and Demont (2007) we denote the observed exposure status as the binary variable $w$ that takes on the value one if the farmer is exposed to the new technology and zero otherwise. The binary outcome variable $y_{1}$ indicates the potential adoption status of a farmer, who is exposed to the technology and $y_{0}$ if he is not exposed. The treatment effect for farmer $i$ is then measured by the difference $\left(y_{i 1}-y_{i 0}\right)$. The corresponding population level effect is given by $E\left(y_{1}-y_{0}\right)$, which is by definition the average treatment effect (ATE). We cannot measure this effect directly because it is not possible to observe both the outcome and its counterfactual for an individual farmer. However, since exposure to a new technology is a necessary condition, $y_{i 0}$ is always equal to zero and hence the effect for an exposed farmer $i$ is given by $y_{i 1}$. The corresponding population level reduces to $E\left(y_{1}\right)$, which is called the average treatment effect on the treated $\left(\mathrm{ATE}_{1}\right)$. The adoption impact $y_{i 1}$ for non-exposed farmers, which is called the average treatment effect on the untreated $\left(\mathrm{ATE}_{0}\right)$, is not observed and has to be estimated. The identification and estimation of $\mathrm{ATE}_{0}$ and ATE is based on the conditional independence (CI) assumption, which states that the treatment status $w$ is independent of the potential outcomes $y_{1}$ and $y_{0}$ conditional on an observed set of covariates $\mathrm{z:} P\left(y_{j}=1 \mid w, z\right)=P\left(y_{j}=1 \mid z\right) ; j=0,1$. Based on this assumption the ATE estimators can be obtained using parametric or non-parametric methods. Following Diagne et al. (2009), we apply a parametric estimation approach for the following model, which involves the observed covariates $x, y$ and $w$ :

$$
\mathrm{E}(y \mid x, w=1)=g(x, \beta),
$$

where $g$ is a function of the vector of covariates $x$ and the unknown parameter vector $\beta$. The parameter vector $\beta$ can be estimated by standard Least Squares (LS) or Maximum Likelihood Estimation (MLE) using the observations from the subsample of exposed farmers with $y$ as the dependent variable and $x$ as the independent variables. The estimated parameters of $\beta, \hat{\beta}$, are used to calculate the predicted values for all the observations in the sample including the observations in the non-exposed subsample. ATE, $\mathrm{ATE}_{1}$ and $\mathrm{ATE}_{0}$ are estimated by taking the average of the predicted values across the full sample in the case of ATE and respective subsamples in the case of $\mathrm{ATE}_{1}$ and $\mathrm{ATE}_{0}$ :

$$
\begin{aligned}
& \widehat{A T E}=\frac{1}{n} \sum_{i=1}^{n} g\left(x_{i}, \hat{\beta}\right) \\
& \widehat{A T E_{1}}=\frac{1}{n_{i}} \sum_{i=1}^{n} w_{i} g\left(x_{i}, \hat{\beta}\right)
\end{aligned}
$$




$$
\widehat{A T E_{0}}=\frac{1}{n-n_{e}} \sum_{i=1}^{n}\left(1-w_{i}\right) g\left(x_{i}, \hat{\beta}\right)
$$

As mentioned earlier, exposure to a technology is not random and hence we need to control for it. This is done before estimating the adoption model by estimating the determinants of exposure (Diagne and Demont, 2007).

\subsection{Study area and data}

This study uses primary data collected in Singida Rural and Kondoa Districts in Central Tanzania between September and November 2012. Central Tanzania is mainly semi-arid, and farmers in this region cultivate mainly cereals (sorghum and maize), but also grow some pulses, oil, root and tuber crops, and keep livestock. There has been a deliberate effort by the government to promote cultivation of sorghum over maize in the study region, but maize is still popular. Among the cereals cultivated in the season preceding the survey, maize was the most widely grown ( $88 \%$ of surveyed households), followed by sorghum (71\%). Pearl millet and finger millet are less important and grown by $37 \%$ and $33 \%$ of the sample, respectively. Most sorghum growers also grow maize $-89 \%$ of maize growers cultivated sorghum while $72 \%$ of sorghum growers also cultivated maize. Until late 1960s, sorghum and maize varieties grown in the study area were mainly landraces. However, over the last four decades, the agricultural research system in Tanzania (which includes national and international agricultural research organizations and private seed companies) has been developing improved sorghum and maize varieties, which are introduced to farmers through approaches such as on-farm trials, participatory variety selection (PVS), field days, direct seed distributions by government and non-governmental organizations' extension staff, and farmer field schools (Heinrich and Mgonja, 2002; Mgonja and Monyo, 2002; Erenstein et al., 2011; Lyimo et al., 2014).

The data were collected through a household survey involving 345 farmers from 21 villages. The farmers were part of the 360 respondents interviewed by the International Crops Research Institute for Semi-Arid Tropics (ICRISAT), Nairobi, during their HOPE project baseline survey in Tanzania, in 2010. Fifteen of the 360 households were not re-interviewed because either the entire household had migrated, or the household head was temporarily out of the study area doing off-farm jobs. In each district, 3 village clusters (2-5 villages each) were purposively selected from 2-3 administrative Wards, for the purposes of the HOPE Project implementation. The logic followed in this clustering was to group villages that are geographically close to each other and sharing the same local agricultural extension officer. 
Respondents were then randomly selected from each village. Face-to-face interviews with heads of selected households were conducted using a pre-tested structured questionnaire administered by enumerators, under the supervision of the first author and a representative of the Agriculture Ministry's Department of Research and Development (DRD), Central Zone. To elicit data on presence (absence) of social network links, the respondents were asked questions about their random matches in this sequence: "Do you know $\mathrm{j}$ (the match)?" if the answer was "no", then no further network questions about the match were asked. If the answer was yes, then the respondent was asked "Do you discuss sorghum (maize) farming issues with $\mathrm{j}$ ?" We interpret a "yes" response as presence of a network link for sorghum (maize), and a "no" answer as absence of a network link between ego and alter. Similar information about the respondent was not sought from his/her alters, implying that we assess undirected networks. We also collected data on household characteristics, knowledge and adoption of cereal varieties, farmers' perception of characteristics of ICVs, and input and output data for crop production.

\subsection{Results}

\subsubsection{Knowledge of improved varieties}

We begin our analysis by looking at the exposure of farmers to improved varieties (Table 3.1); i.e. how many farmers know about the existence of ICVs. For sorghum, six improved varieties are known in the study area, and about $79 \%$ of respondents are aware of at least one. On the other hand, maize has 11 improved varieties, of which six are hybrids and five are open pollinated varieties (OPVs). About $74 \%$ of respondents know at least one maize variety, meaning that when exposure is defined as a binary variable, the average level of exposure to maize varieties is slightly lower than that of sorghum varieties, although more varieties of maize than sorghum are known in the area. The proportion of farmers exposed to a certain number of improved varieties does not differ much too. About $30 \%$ of the farmers are aware of only one variety of sorghum and a slightly lower proportion is aware of only one maize variety. For sorghum, the proportion of farmers aware of two and three varieties respectively was $22 \%$ and $17 \%$. Similar values were also reported for maize varieties. Only about $10 \%$ and $18 \%$ of farmers are aware of more than three varieties of sorghum and maize, respectively. On average each farmer knows 1.7 varieties of sorghum and 1.8 of maize. For maize, exposure to hybrids is higher than to OPVs; and this is probably due to the role of seed markets (see Chapter 3.5.2). It is surprising that farmers are aware of just two improved 
varieties on average. This may be attributed to constraints in information flows about the varieties, or it may be the case that some varieties do not perform to the satisfaction of many farmers, such that the farmers are not persuaded to seek information about the varieties from social network members who try them out.

Table 3.1: Farmer's exposure to improved varieties

\begin{tabular}{lrrrr}
\hline Exposure & Sorghum & Maize & $\begin{array}{r}\text { Maize } \\
\text { OPVs Hybrids }\end{array}$ & $\begin{array}{r}\text { Maize } \\
\text { Total number of varieties known in the study area }\end{array}$ \\
Exposed to at least one (\% sample) & 6 & 11 & 5 & 6 \\
Intensity of exposure (\% sample) & 78.8 & 73.6 & 42.3 & 66.1 \\
0 & & & & \\
1 & 21.2 & 26.4 & 58.0 & 33.9 \\
2 & 30.4 & 25.2 & 24.9 & 32.2 \\
3 & 21.5 & 18.0 & 13.9 & 20.6 \\
4 & 16.8 & 12.5 & 3.19 & 9.86 \\
5 and above & 7.83 & 11.0 & 0.0 & 3.19 \\
Mean intensity of exposure & 2.32 & 6.96 & 0.0 & 0.29 \\
& 1.67 & 1.79 & 0.62 & 1.17 \\
& $(1.32)$ & $(1.62)$ & $(0.84)$ & $(1.12)$ \\
\hline
\end{tabular}

Note: $\mathrm{N}=345$; Figures in parenthesis are standard deviations.

\subsubsection{Main sources of information on improved varieties}

We continue our analysis by looking at the source of first information that exposes respondents to improved varieties. Since many respondents are exposed to more than one improved variety, and sources of first information are not necessarily the same for all the varieties, we report percentage of 'responses' rather than of 'respondents', to account for multiple responses (Table 3.2). Our results indicate that for sorghum, government extension officers are the main source of first information (67\% of responses). Other farmers also play a key, but far less important role, with $28 \%$ of responses from exposed farmers reporting other farmers as their source of first information. A similar pattern is also reported by Hossain et al. (2012) in their study on adoption of rice varieties in Bangladesh and India. For maize, however, other farmers are the main source of information, accounting for $50 \%$ of responses. Contrary to the case of sorghum, government extension officers play a much less important role, as they account for only $24 \%$ of responses. Another striking contrast is that, while media and grain/seed traders jointly account for $21 \%$ of responses in maize, their role in the case of sorghum is almost negligible (less than $2 \%$ of responses). Differentiating between maize OPVs and hybrids shows that media as a source of information is particularly important for maize hybrids. Contrary to the case of sorghum varieties and to a large extent, maize OPVs, 
the demand for maize hybrid seeds has attracted seed companies to invest in the maize seed market, leading to the development of a seed industry which disseminates information about the technologies through private and commercial channels such as radio and print media (AGRA, 2010).

Table 3.2: Sources of first information on improved sorghum and maize varieties

\begin{tabular}{lllll}
\hline & $\begin{array}{l}\text { Sorghum } \\
\text { varieties }\end{array}$ & $\begin{array}{l}\text { Maize } \\
\text { varieties }\end{array}$ & $\begin{array}{l}\text { Maize } \\
\text { OPVs }\end{array}$ & $\begin{array}{l}\text { Maize } \\
\text { hybrids }\end{array}$ \\
\hline $\begin{array}{l}\text { Source of information (\% of responses) } \\
(N=578)\end{array}$ & $\begin{array}{l}(N=658) \\
(N=216)\end{array}$ & $(N=405)$ \\
Other farmer & 27.7 & $49.7 * * *$ & 52.8 & 48.6 \\
Government extension officer & 67.3 & $23.9 * * *$ & 25.9 & 22.2 \\
Trader & 0.9 & $8.7 * *$ & 9.3 & 8.2 \\
Mass media & 0.5 & $12.2^{* * *}$ & 5.6 & $16.5^{* * *}$ \\
Other & 3.6 & $5.6^{* *}$ & 6.5 & 4.4 \\
Relationship if source is other farmer (\% of & & & & \\
responses) & $(N=159)$ & $(N=326)$ & $(N=114)$ & $(N=196)$ \\
Neighbor/friend & 68.9 & 67.1 & 63.2 & 68.5 \\
Parent & 16.2 & 16.8 & 18.4 & 16.2 \\
Other relative & 14.9 & 16.2 & 18.4 & 15.2 \\
How learned about variety if source is other & & & & \\
farmer (\% of responses) & & & & \\
Saw it in farmer's field and enquired & 69.8 & 71.2 & 66.7 & $74.0^{*}$ \\
Information came from the other farmer first & 11.3 & 9.8 & 9.6 & 9.7 \\
Not specified & 18.9 & 19.0 & 23.7 & $16.3^{*}$ \\
\hline
\end{tabular}

$*, * *, * * *$ differences between sorghum and maize varieties (first two columns) or maize OPVs and Hybrids (last two columns) significant at $10 \%, 5 \%$ and $1 \%$ respectively.

To better understand how information that leads to farmer exposure to improved varieties is transmitted from exposed farmers to non-exposed colleagues, we asked farmers who reported their fellows as the source of first information on improved varieties to state their relationship with the information source, and how they learnt about the improved variety of these farmers. Results in Table 3.2 show that neighbors and friends were the main source of first information (69\% and 67\% of the sorghum and maize responses respectively), followed by other relatives and parents in almost equal proportions of $15 \%$ to $17 \%$ of the responses for both crops. The main mechanism through which respondents become exposed to the source farmer's improved variety is by seeing it in the farmer's field and then enquiring more about it from the farmer $(70 \%$ and $71 \%$ of responses for sorghum and maize respectively). These results have two implications. One, farmer networks facilitate exposure to improved varieties by first 'displaying' them, which stimulates demand for more information, and thereafter provide information about them to network members. Two, 
farmers are more likely to exchange information on improved varieties if their residences or fields are more geographically close.

\subsubsection{Farmers' perceptions of characteristics of ICVs}

We asked the respondents during the survey to compare the best improved and the best traditional variety known to them with respect to some specific characteristics. The farmers who were aware of improved varieties but unable to name a particular variety compared the best local variety known to improved varieties in general. A number of key agronomic, utilization- and market-related traits identified from variety descriptors and focus group discussions with farmers prior to the household survey, were used in this comparisons module. For each trait, farmers were asked to state whether the ICVs, the local varieties, or none of them was superior. Susceptibility to bird damage is a problem related to sorghum cultivation, while maize is not commonly used for traditional brewing. These traits are therefore only analyzed for sorghum. Table 3.3 summarizes the results of these comparisons for improved varieties which were mentioned by at least 20 respondents (n). In addition, the last two rows for each crop show the responses for improved and traditional varieties in general.

As shown in the last column, improved varieties of both crops are generally considered better than traditional ones by most farmers. However, while $83 \%$ of farmers think improved varieties of maize are better than traditional ones, only 54\% of farmers think so for sorghum, a factor that may, ceteris paribus, result in improved varieties of maize being adopted more than those of sorghum. Results of specific traits show that improved varieties of sorghum are perceived to be better in terms of grain yield and size, drought tolerance and threshabililty, but were more susceptible to bird damage, compared to traditional ones. On the other hand, traditional varieties were rated better than improved varieties in tolerance to excess rain (especially if planted early), market demand and prices, storability, taste, and suitability for traditional brewing. However, the varieties were perceived to be more susceptible to lodging. For maize, improved varieties were perceived to have better grain yield and size, drought tolerance, threshabililty and market demand and prices. On the other hand, traditional varieties were perceived to be better only in storability, but were rated more susceptible to lodging. For other traits, neither traditional nor improved varieties were perceived to be better by more than half of the respondents. Specific variety results show that 
Macia and Pato varieties were overall ranked better than traditional sorghum varieties. For maize, all improved varieties shown were perceived to be better than traditional ones.

Table 3.3: Farmers' perception about improved varieties compared to traditional ones.

\begin{tabular}{|c|c|c|c|c|c|c|c|c|c|c|c|c|c|c|c|c|c|}
\hline Crop/Variety & 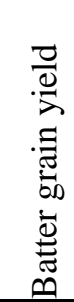 & 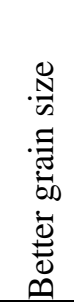 & 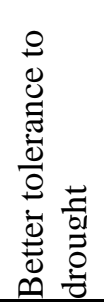 & 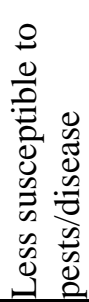 & 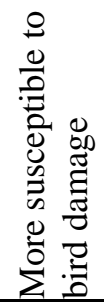 & 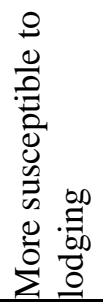 & 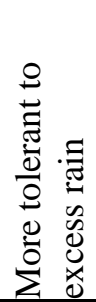 & 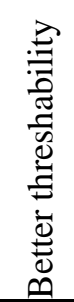 & 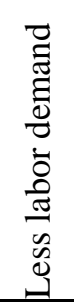 & 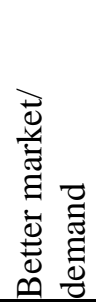 & 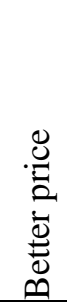 & 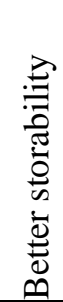 & 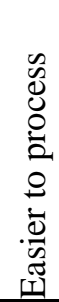 & 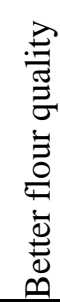 & 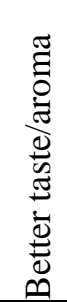 & 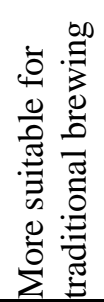 & 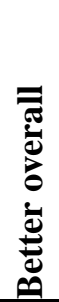 \\
\hline \multicolumn{18}{|l|}{ Sorghum $(\mathrm{N}=277)$} \\
\hline Macia $(\mathrm{n}=91)$ & 79 & 70 & 63 & 30 & 65 & 18 & 32 & 51 & 34 & 24 & 23 & 25 & 45 & 56 & 46 & 10 & 63 \\
\hline Pato $(n=66)$ & 79 & 76 & 61 & 45 & 68 & 21 & 21 & 59 & 41 & 21 & 23 & 12 & 45 & 41 & 26 & 12 & 61 \\
\hline Tegemeo $(n=51)$ & 65 & 65 & 43 & 29 & 55 & 20 & 22 & 49 & 41 & 25 & 24 & 24 & 27 & 33 & 37 & 14 & 43 \\
\hline Serena $(n=39)$ & 49 & 74 & 46 & 36 & 44 & 15 & 28 & 44 & 18 & 15 & 13 & 10 & 28 & 23 & 28 & 13 & 41 \\
\hline Impro & 71 & 71 & 29 & 33 & 33 & 24 & 14 & 48 & 33 & 29 & 19 & 10 & 38 & 19 & 14 & 5 & 52 \\
\hline Improved & 71 & 71 & 54 & 34 & 58 & 19 & 25 & 51 & 34 & 23 & 21 & 18 & 39 & 39 & 33 & 12 & 54 \\
\hline Traditional & 18 & 15 & 26 & 44 & 27 & 71 & 60 & 24 & 26 & 61 & 55 & 67 & 17 & 30 & 51 & 74 & 42 \\
\hline \multicolumn{18}{|l|}{ Maize $(\mathrm{N}=268)$} \\
\hline Pannar $(n=57)$ & 91 & 77 & 60 & 32 & & 37 & 26 & 45 & 40 & 79 & 68 & 16 & 37 & 47 & 46 & & 89 \\
\hline Seedco $(n=51)$ & 92 & 63 & 61 & 27 & & 45 & 33 & 75 & 33 & 53 & 47 & 20 & 35 & 39 & 39 & & 86 \\
\hline Kilim: & 90 & 68 & 77 & 45 & & 23 & 32 & 74 & 35 & 58 & 45 & 35 & 48 & 28 & 65 & & 80 \\
\hline Cargil $(n=53)$ & 77 & 58 & 49 & 33 & & 28 & 34 & 70 & 36 & 53 & 55 & 25 & 38 & 48 & 47 & & 75 \\
\hline Improved $(n=3$ & 88 & 76 & 61 & 30 & & 21 & 39 & 67 & 39 & 48 & 48 & 33 & 42 & 55 & 33 & & 82 \\
\hline Impro & 86 & 65 & 60 & 34 & & 32 & 32 & 72 & 39 & 59 & 55 & 24 & 39 & 47 & 45 & & 83 \\
\hline Traditional & 10 & 30 & 29 & 34 & & 52 & 45 & 11 & 26 & 15 & 13 & 54 & 15 & 18 & 29 & & 14 \\
\hline
\end{tabular}

\subsubsection{Determinants of exposure}

To assess the individual determinants of exposure to improved varieties, we estimate Poisson regression models following Equations (3.2) and (3.3). The definition of the explanatory variables used and some descriptive statistics are presented in Table 3.4. Also included in the regressions are village cluster dummies that control for heterogeneity across the clusters in some physical and economic characteristics not captured in the models, such as soil types and distances to market centers. Regression results are presented in Table 3.5, but village cluster dummies are not shown. In models 1-4, the total degree of the specific crop information network (number of dyads in which there is a link for exchange of crop information) is used, while in models $5-8$, the crop network is broken into a network within and a network outside the village. The reported estimates in Table 3.5 are marginal values, which for each explanatory variable show the partial change in expected intensity of exposure due to a unit change in the variable, holding other variables at their means.

The results show that the size of farmers' social networks matter for intensity of exposure to improved cereal varieties. Models (1) and (2) show that the network degree 
positively influences intensity of exposure to sorghum varieties. In case of maize, however, an extra link in the network has no significant effect on intensity of exposure. This implies that ceteris paribus, sorghum information networks may be more effective in exposing farmers to improved varieties than maize networks. However, by disaggregating maize varieties into OPVs and hybrids (Models 3 and 4); we find that the degree of maize networks is positively and significantly associated with the intensity of exposure to OPVs but not hybrids. This finding is consistent with that for sorghum, whose improved varieties are purely OPVs, and implies that farmer networks facilitate more exposure to seed technologies with mostly missing or malfunctioning markets, than to those with better markets.

Table 3.4: Definitions and descriptive statistics for the variables used in the exposure model

\begin{tabular}{llr}
\hline Variable & Definition & Mean \\
\hline Social network attributes of respondent & \\
Crop network size & & \\
Sorghum network & Number of sorghum information links out of six random matches & 1.11 \\
degree & & $(1.40)$ \\
Sorghum network & Intra-village sorghum network degree (number of links out of three & 0.93 \\
degree & random matches within the village) & $(1.08)$ \\
Sorghum network & Inter-village sorghum network degree (number of links out of three & 0.19 \\
degree & random links outside the village) & $(0.57)$ \\
Maize network & Number of maize information links out of six random matches & 1.03 \\
degree & & $(1.38)$ \\
Maize network & Intra-village maize network degree (number of links out of three random & 0.83 \\
degree1 & matches within the village) & $(1.06)$ \\
Maize network & Inter-village maize network degree (number of links out of three random & 0.20 \\
degree2 & links outside the village) & $(0.55)$ \\
Links with institutional information channels & \\
Admin link & Strength of links with village administration (number of contacts per & 13.8 \\
& month with village administrators) & $(9.57)$ \\
Extension link & Talks with public extension officer at least once per month (1=yes, & 0.64 \\
& 0=otherwise) & $(0.48)$ \\
Personal and household attributes of respondent & \\
Age & Age of respondent (years) & 46.0 \\
& & $(11.4)$ \\
Female & Respondent is a female (1=yes; 0=otherwise) & 0.27 \\
& & $(0.44)$ \\
Education & Respondent has more than four years of formal education (1=yes; & 0.83 \\
& 0=otherwise) & $(0.37)$ \\
Muslim & Respondent is Muslim (1=yes; 0=otherwise - mostly Christian) & 0.57 \\
Land owned & Land owned by the respondent's household (ha) & $(0.50)$ \\
& & 4.41 \\
Mobile phone & Household owns a mobile phone (1=yes; 0=otherwise) & $(5.71)$ \\
Radio & & 0.70 \\
& Household owns a radio (1=yes; 0=otherwise) & $(0.46)$ \\
& & 0.75 \\
& & $(0.43)$ \\
\hline
\end{tabular}


The results in models (5) and (7) indicate that the degree of the farmer network outside the village positively and significantly affects intensity of exposure to sorghum varieties and OPVs of maize, while the network degree within the village has no significant effect. We hypothesize that information about sorghum varieties and maize OPVs is not uniformly distributed across villages, such that varieties known in one village are not necessarily the same as those known in the neighboring villages. Farmers within a village are likely to be exposed to the same varieties, rendering variety information from additional network links within the village redundant. Schaefer (2010) argues that strong ties within a network (for instance, those in intra-village networks), can make such networks less exposed to new ideas or just conservative, while Rauch (2010) posits that bridging network clusters produces synergies that lead to higher outcomes. We thus hypothesize that networking across the village increases a farmer's chances of gaining higher intensity of exposure. Most studies that investigate the role of social networks in technology diffusion focus on intra-village networks, which are considered stronger and perhaps more relevant, but this result demonstrates that for some technologies, the apparently weak inter-village networks (when present) may matter even more, consistent with Granovetter's (1973) "strength of weak ties" notion.

Having network connections with institutions that facilitate information dissemination influences intensity of exposure to some technologies. Results show that an extra contact per month with a member of the village administration increases the intensity of exposure to improved sorghum varieties, but the result is insignificant for the maize models. Our explanation for this effect is that the government has been promoting sorghum farming in the study area, and these administrators, being part of the government, are involved in that campaign. Further results indicate that farmers with network links to extension officers have a higher intensity of exposure to improved varieties in all models. It is worth noting that for both crops, the marginal effect of network connections with an extension officer on intensity of exposure is several times larger than that of network links with another farmer. Being the information brokers between researchers and farmers, extension officers are naturally more informed about improved varieties and hence, more effective in exposing farmers to new seed technologies, than other actors in the farmers' information network. 
Table 3.5: Estimates of the determinants of exposure to improved varieties

\begin{tabular}{|c|c|c|c|c|c|c|c|c|}
\hline $\begin{array}{l}\text { Explanatory } \\
\text { Variable }\end{array}$ & $\begin{array}{l}\text { (1) } \\
\text { Sorghum }\end{array}$ & $\begin{array}{l}\text { (2) } \\
\text { Maize }\end{array}$ & $\begin{array}{l}\text { (3) } \\
\text { Maize } \\
\text { OPVs }\end{array}$ & $\begin{array}{l}\text { (4) } \\
\text { Maize } \\
\text { Hybrids }\end{array}$ & $\begin{array}{l}\text { (5) } \\
\text { Sorghum }\end{array}$ & $\begin{array}{l}\text { (6) } \\
\text { Maize }\end{array}$ & $\begin{array}{l}\text { (7) } \\
\text { Maize } \\
\text { OPVs }\end{array}$ & $\begin{array}{l}\mathbf{8}) \\
\text { Maize } \\
\text { Hybrids }\end{array}$ \\
\hline $\begin{array}{l}\text { Sorghum network } \\
\text { degree }\end{array}$ & $\begin{array}{l}0.087 * * \\
(0.042)\end{array}$ & & & & & & & \\
\hline $\begin{array}{l}\text { Sorghum network } \\
\text { degree } 1 \\
\text { Sorghum network } \\
\text { degree2 }\end{array}$ & & & & & $\begin{array}{l}0.022 \\
(0.065) \\
0.223 * * \\
(0.106)\end{array}$ & & & \\
\hline $\begin{array}{l}\text { Maize network } \\
\text { degree }\end{array}$ & & $\begin{array}{l}0.047 \\
(0.056)\end{array}$ & $\begin{array}{l}0.048^{*} \\
(0.028)\end{array}$ & $\begin{array}{l}-0.006 \\
(0.040)\end{array}$ & & & & \\
\hline $\begin{array}{l}\text { Maize network } \\
\text { degree } 1\end{array}$ & & & & & & $\begin{array}{l}-0.018 \\
(0.082)\end{array}$ & $\begin{array}{l}-0.003 \\
(0.044)\end{array}$ & $\begin{array}{l}-0.020 \\
(0.058)\end{array}$ \\
\hline $\begin{array}{l}\text { Maize network } \\
\text { degree2 }\end{array}$ & & & & & & $\begin{array}{l}0.194 \\
(0.140)\end{array}$ & $\begin{array}{l}0.148 * * \\
(0.072)\end{array}$ & $\begin{array}{l}0.029 \\
(0.101)\end{array}$ \\
\hline Admin link & $\begin{array}{l}0.014 * * \\
(0.007)\end{array}$ & $\begin{array}{l}0.013 \\
(0.008)\end{array}$ & $\begin{array}{l}0.005 \\
(0.005)\end{array}$ & $\begin{array}{l}0.008 \\
(0.006)\end{array}$ & $\begin{array}{l}0.014 * * \\
(0.007)\end{array}$ & $\begin{array}{l}0.014 \\
(0.008)\end{array}$ & $\begin{array}{l}0.0051 \\
(0.005)\end{array}$ & $\begin{array}{l}0.008 \\
(0.006)\end{array}$ \\
\hline Extension link & $\begin{array}{l}0.365 * * \\
(0.147)\end{array}$ & $\begin{array}{l}0.410 * * \\
(0.179)\end{array}$ & $\begin{array}{l}0.156 \\
(0.096)\end{array}$ & $\begin{array}{l}0.254 * * \\
(0.129)\end{array}$ & $\begin{array}{l}0.379 * * * \\
(0.146)\end{array}$ & $\begin{array}{l}0.423 * * \\
(0.182)\end{array}$ & $\begin{array}{l}0.168 * \\
(0.098)\end{array}$ & $\begin{array}{l}0.256^{* *} \\
(0.130)\end{array}$ \\
\hline Age & $\begin{array}{l}0.018 * * \\
(0.007)\end{array}$ & $\begin{array}{l}0.017 * \\
(0.007)\end{array}$ & $\begin{array}{l}0.013 * * * \\
(0.005)\end{array}$ & $\begin{array}{l}0.004 \\
(0.007)\end{array}$ & $\begin{array}{l}0.019 * * * \\
(0.007)\end{array}$ & $\begin{array}{l}0.018 * \\
(0.010)\end{array}$ & $\begin{array}{l}0.014 * * * \\
(0.005)\end{array}$ & $\begin{array}{l}0.004 \\
(0.007)\end{array}$ \\
\hline Female & $\begin{array}{l}-0.298 \\
(0.201)\end{array}$ & $\begin{array}{l}-0.576 * * \\
(0.248)\end{array}$ & $\begin{array}{l}-0.147 \\
(0.128)\end{array}$ & $\begin{array}{l}-0.437 * * \\
(0.172)\end{array}$ & $\begin{array}{l}-0.320 \\
(0.201)\end{array}$ & $\begin{array}{l}-0.584 * * \\
(0.246)\end{array}$ & $\begin{array}{l}-0.149 \\
(0.128)\end{array}$ & $\begin{array}{l}-0.439 * * \\
(0.172)\end{array}$ \\
\hline Education & $\begin{array}{l}0.348 \\
(0.213)\end{array}$ & $\begin{array}{l}0.495^{*} \\
(0.268)\end{array}$ & $\begin{array}{l}0.286^{* *} \\
(0.141)\end{array}$ & $\begin{array}{l}0.208 \\
(0.192)\end{array}$ & $\begin{array}{l}0.359 * \\
(0.213)\end{array}$ & $\begin{array}{l}0.496^{*} \\
(0.268)\end{array}$ & $\begin{array}{l}0.291 * * \\
(0.140)\end{array}$ & $\begin{array}{l}0.207 \\
(0.192)\end{array}$ \\
\hline Land owned & $\begin{array}{l}-0.005 \\
(0.011)\end{array}$ & $\begin{array}{l}-0.009 \\
(0.017)\end{array}$ & $\begin{array}{l}-0.003 \\
(0.010)\end{array}$ & $\begin{array}{l}-0.008 \\
(0.010)\end{array}$ & $\begin{array}{l}-0.008 \\
(0.012)\end{array}$ & $\begin{array}{l}-0.011 \\
(0.017)\end{array}$ & $\begin{array}{l}-0.005 \\
(0.010)\end{array}$ & $\begin{array}{l}-0.008 \\
(0.010)\end{array}$ \\
\hline Mobile phone & $\begin{array}{l}0.221 \\
(0.154)\end{array}$ & $\begin{array}{l}0.306 \\
(0.206)\end{array}$ & $\begin{array}{l}0.280^{* *} \\
(0.120)\end{array}$ & $\begin{array}{l}0.032 \\
(0.145)\end{array}$ & $\begin{array}{l}0.219 \\
(0.153)\end{array}$ & $\begin{array}{l}0.298 \\
(0.205)\end{array}$ & $\begin{array}{l}0.272^{* *} \\
(0.118)\end{array}$ & $\begin{array}{l}0.030 \\
(0.145)\end{array}$ \\
\hline Radio & $\begin{array}{l}0.123 \\
(0.185)\end{array}$ & $\begin{array}{l}0.421 * \\
(0.241)\end{array}$ & $\begin{array}{l}0.156 \\
(0.135)\end{array}$ & $\begin{array}{l}0.267 * \\
(0.160)\end{array}$ & $\begin{array}{l}0.128 \\
(0.185)\end{array}$ & $\begin{array}{l}0.432 * \\
(0.241)\end{array}$ & $\begin{array}{l}0.170 \\
(0.134)\end{array}$ & $\begin{array}{l}0.269 * \\
(0.161)\end{array}$ \\
\hline
\end{tabular}

Notes: $\mathrm{N}=345$. Column numbers represent different models for each technology under different specifications of farmer social networks. Figures inside the table are marginal values, with robust standard errors in parentheses. $* * * \mathrm{p}<0.01, * * \mathrm{p}<0.05, * \mathrm{p}<0.1$

Results for personal characteristics show that farmer's age is a positive and significant determinant of intensity of exposure to improved varieties, with exception of maize hybrids. This result is generally unsurprising since we expect older farmers to know more varieties, by virtue of their experience. Gender of farmers affects exposure intensity for maize varieties in general and hybrids in particular. Being a female farmer is the most limiting constraint to exposure to maize varieties. Women farmers are exposed to about 0.6 maize varieties less than their men counterparts. Another result shows that education generally influences intensity of exposure positively, but this effect is significant only for maize varieties, particularly OPVs. We hypothesize that with less information on maize OPVs reaching farmers through extension officers and seed market channels, higher cognitive ability gives farmers a higher propensity to seek information on OPVs, thereby getting more exposed to 
them. Interesting results emerge with respect to the effect of information and communication technologies on exposure. Ownership of cell-phones positively influences intensity of exposure to OPVs of maize, while radio ownership is associated with higher intensity of exposure to maize hybrids. The positive effect of radio could be explained by the fact that hybrids have a much more developed seed market than OPVs; hence more information about hybrids than OPVs may be passed to farmers through radio advertisements. A reason for positive effect of mobile phone ownership on exposure to OPVs might be that cell-phones enable farmers to search for information from other farmers and actors, since flow of information about OPVs through commercial channels is limited, and contrary to the case of sorghum, public sector interest in maize in the study area is much less.

\subsubsection{Adoption rates of ICVs}

We continue our analysis by investigating the relationship between exposure and adoption. The incidence of exposure is about $79 \%$ in the case of sorghum and $74 \%$ for maize (Table 3.6), a difference that is only weakly significant. The adoption rates in the full sample are pretty low and just about $42 \%$ for sorghum and $60 \%$ for maize. These findings, however, have to be interpreted with caution, because the estimated figures suffer from non-exposure bias (Diagne and Demont, 2007). This bias occurs when not all farmers, as it is the case in our study, are exposed to a new technology. Farmers who have not been exposed cannot adopt it even if they might have done so if they had known about it. In such a case, the observed sample adoption rate always underestimates the true population adoption rate.

Table 3.6: Observed exposure and adoption rates of improved varieties

\begin{tabular}{lcc}
\hline Exposure/Adoption rates & Sorghum & Maize \\
\hline Exposure (\% sample) & 0.788 & $0.736^{*}$ \\
& $(0.022)$ & $(0.024)$ \\
Ever adopted (\% sample) & 0.652 & 0.646 \\
& $(0.026)$ & $(0.026)$ \\
Ever adopted (\% of exposed) & 0.827 & $0.878^{*}$ \\
& $(0.023)$ & $(0.021)$ \\
Adopted in 2011/12 season (\% sample growers) & 0.424 & $0.600^{* * *}$ \\
& $(0.0316)$ & $(0.028)$ \\
Adopted in 2011/12 season (\% of exposed growers) & 0.531 & $0.769^{* * *}$ \\
& $(0.036)$ & $(0.027)$ \\
\hline
\end{tabular}

Note: Differences between sorghum and maize varieties significant at $* * * p<0.01,{ }^{*} \mathrm{p}<0.1$.

Conditional on exposure, the adoption rate increases in our case to about $53 \%$ for sorghum and $77 \%$ for maize (table 3.6). Strikingly, not all exposed farmers adopt ICVs, suggesting that further constraints exist or that the expected net benefits are low or uncertain, 
as demonstrated in Table 3.3. Moreover, the proportion of respondents that has ever adopted ICVs is statistically higher for maize than for sorghum (at $10 \%$ level). In case of maize almost $88 \%$ of the exposed have ever adopted an ICV, while it is $83 \%$ for sorghum. Comparing these figures to adoption rate in the last season suggests that a substantial share of farmers decided to cease using ICVs. The share of dis-adopters is higher in the case of sorghum. These descriptive results suggest that the lack of adoption cannot be explained by exposure alone, and that the adoption of sorghum ICVs is more constrained than that of maize ICVs. The findings, however, have to be interpreted cautiously, because even the estimated adoption rates conditional on exposure might still suffer from selection bias (Diagne and Demont, 2007). They are likely to overestimate the true population adoption rate, because farmers, who are most likely to adopt, get exposed first. Sources of such a positive selection bias are, for example, the targeting of progressive farmers by researchers and extension workers (Diagne, 2006). We use the framework developed by Diagne and Demont (2007) to calculate unbiased estimates of the population adoption rates.

After accounting for exposure, the predicted population adoption rate is $51.4 \%$ for sorghum and $71.0 \%$ for maize (Table 3.7). Comparing these findings to the adoption rate in the full sample shows that accounting for non-exposure bias increases population adoption rates by 9.3 and 10.9 percentage points for sorghum and maize, respectively. This is the socalled adoption gap. Furthermore, there is also a significant positive population selection bias of 6.1 percentage points for maize, meaning that farmers currently exposed to improved maize varieties are those with higher propensity to adopt than a randomly selected farmer in the population.

Table 3.7: Estimated adoption rates of improved varieties

\begin{tabular}{lcc}
\hline Predicted exposure/adoption rates (treatment effects) & $\begin{array}{c}\text { Sorghum } \\
(\mathbf{N = 2 4 5 )}\end{array}$ & $\begin{array}{c}\text { Maize } \\
(\mathbf{N = 3 0 5})\end{array}$ \\
\hline Population adoption rate (ATE) & $0.514^{* * *}$ & $0.710^{* * *}$ \\
& $(0.034)$ & $(0.031)$ \\
Adoption rate among exposed subsample (ATE1) & $0.526^{* * *}$ & $0.771^{* * *}$ \\
& $(0.031)$ & $(0.025)$ \\
Adoption rate among non-exposed subsample (ATE0) & $0.465^{* * *}$ & $0.495^{* * *}$ \\
& $(0.073)$ & $(0.075)$ \\
Classic adoption rate - joint exposure and adoption (JEA) & $0.421^{* * *}$ & $0.601^{* * *}$ \\
Non-exposure bias (Adoption gap) & $(0.025)$ & $(0.019)$ \\
& $-0.093^{* * *}$ & $-0.109^{* * *}$ \\
Population selection bias (PSB) & $(0.015)$ & $(0.016)$ \\
& 0.012 & $0.061^{* * *}$ \\
\hline
\end{tabular}

Notes: Figures in brackets are standard errors. $* * * \mathrm{p}<0.01$. 


\subsubsection{Determinants of adoption}

To estimate the drivers of adoption of improved varieties, we apply the average treatment effects (ATE) framework proposed by Diagne and Demont (2007). The basic logic of this framework is that farmer exposure to improved varieties, which is a precondition for adoption of the varieties, is not necessarily random in the population. For instance, farmers may selfselect themselves into exposure, or be targeted by technology promoters for exposure into these varieties. Furthermore, adoption may be influenced by unobserved factors that influence exposure. Thus, if exposure to improved varieties among farmers is incomplete, modeling adoption without taking into account the potential non-exposure bias yields inconsistent estimates. We employ Probit models to estimate determinants of exposure and of adoption after correcting for non-exposure bias. Table 3.8 presents the definitions and descriptive statistics of the variables used in the exposure-adoption model.

Estimates for determinants of adoption are shown in Table 3.9. The results of the exposure model are not discussed in detail here, because we have already discussed the determinants of exposure in Chapter 3.5.4. However, since the results discussed are from count models (Poisson regressions), we provide the results of the binary exposure models (Probit regressions) that were estimated together with the adoption models, for comparison and robustness check. The results show that inter-village social network size positively influences the probability of exposure improved varieties of sorghum. For maize, social network size has no effect on probability of exposure. These findings are qualitatively similar to those of the Poisson regressions, implying that the conclusions for the effects of social network size on exposure are robust to model specification. However, a number of variables that are significant in most of the Poisson regressions, including farmer links to village administrators and extension officers, and education and gender of the respondent, become insignificant in the Probit regression models, implying that the effects of these variables on exposure depend on how the exposure variable is specified. Moreover, modeling exposure as a discrete rather than binary variable gives results with richer policy implications.

Results for determinants of adoption are presented in two columns, for each crop. The parametric models shows results of the Probit regressions estimated for the sub-sample of exposed growers only, while the classic models show results for the full sample of growers, including those who are not exposed to ICVs. We discuss the results of the parametric models only, because the non-exposure bias for both crops was significant. However, we also show results for the classic models that do not control for non-exposure bias, for comparison. 
Table 3.8: Description and mean values of variables used in adoption models

\begin{tabular}{|c|c|c|c|}
\hline Variable & Definition and measurement & $\begin{array}{l}\text { Sorghum } \\
(N=245)\end{array}$ & $\begin{array}{l}\text { Maize } \\
(N=305)\end{array}$ \\
\hline Knwsorg & $\begin{array}{l}\text { Dependent variable1 }(1=\text { Yes if sorghum grower is aware of at } \\
\text { least one improved variety, } 0=\text { Otherwise) }\end{array}$ & $\begin{array}{c}0.80 \\
(0.40)\end{array}$ & \\
\hline Knwmaiz & $\begin{array}{l}\text { Dependent variable } 1(1=\text { Yes if maize grower is aware of at least } \\
\text { one improved variety, } 0=\text { Otherwise) }\end{array}$ & & $\begin{array}{c}0.78 \\
(0.41)\end{array}$ \\
\hline Adopso & $\begin{array}{l}\text { Dependent variable } 2(1=\text { Yes if sorghum grower cultivated at } \\
\text { least one improved variety in } 2011 / 12 \text { season, } 0=\text { Otherwise })\end{array}$ & $\begin{array}{c}0.42 \\
(0.50)\end{array}$ & \\
\hline Adopma & $\begin{array}{l}\text { Dependent variable } 2(1=\text { Yes if maize grower cultivated at least } \\
\text { one improved variety in } 2011 / 12 \text { season, } 0=\text { Otherwise) }\end{array}$ & & $\begin{array}{l}0.60 \\
(0.49)\end{array}$ \\
\hline $\begin{array}{l}\text { Sorghum network } \\
\text { degree1 }\end{array}$ & $\begin{array}{l}\text { Intra-village sorghum network degree (number of links out of } \\
\text { three random matches within the village) }\end{array}$ & $\begin{array}{c}1.09 \\
(1.10)\end{array}$ & \\
\hline $\begin{array}{l}\text { Sorghum network } \\
\text { degree2 }\end{array}$ & $\begin{array}{l}\text { Inter-village sorghum network degree (number of links out of } \\
\text { three random links outside the village) }\end{array}$ & $\begin{array}{c}0.23 \\
(0.63)\end{array}$ & \\
\hline $\begin{array}{l}\text { Maize network } \\
\text { degree } 1\end{array}$ & $\begin{array}{l}\text { Intra-village maize network degree (number of links out of three } \\
\text { random matches within the village) }\end{array}$ & & $\begin{array}{l}0.89 \\
(1.09)\end{array}$ \\
\hline $\begin{array}{l}\text { Maize network } \\
\text { degree } 2\end{array}$ & $\begin{array}{l}\text { Inter-village maize network degree (number of links out of three } \\
\text { random links outside the village) }\end{array}$ & & $\begin{array}{l}0.20 \\
(0.57)\end{array}$ \\
\hline Admin link & $\begin{array}{l}\text { Strength of links with village administration (number of } \\
\text { contacts per month with village administrators) }\end{array}$ & $\begin{array}{l}13.6 \\
(9.62)\end{array}$ & $\begin{array}{l}13.8 \\
(9.68)\end{array}$ \\
\hline Extension link & $\begin{array}{l}\text { Talks with public extension officer at least once per month } \\
(1=\text { yes, } 0=\text { otherwise })\end{array}$ & $\begin{array}{c}0.67 \\
(0.47)\end{array}$ & $\begin{array}{l}0.64 \\
(0.48)\end{array}$ \\
\hline Intesorg & $\begin{array}{l}\text { Intensity of exposure to sorghum varieties (number of improved } \\
\text { varieties known) }\end{array}$ & $\begin{array}{l}1.76 \\
(1.32)\end{array}$ & \\
\hline Intemaiz & $\begin{array}{l}\text { Intensity of exposure to maize varieties (number of improved } \\
\text { varieties known) }\end{array}$ & & $\begin{array}{l}1.97 \\
(1.57)\end{array}$ \\
\hline Mobile phone & Household owns a mobile phone $(1=y e s ; 0=$ otherwise $)$ & $\begin{array}{c}0.69 \\
(0.46)\end{array}$ & $\begin{array}{c}0.69 \\
(0.46)\end{array}$ \\
\hline Radio & Household owns a radio ( $1=$ yes; $0=$ otherwise $)$ & $\begin{array}{c}0.74 \\
(0.44)\end{array}$ & $\begin{array}{l}0.76 \\
(0.43)\end{array}$ \\
\hline Leader & Respondent is a community leader (Yes, $0=$ Otherwise) & $\begin{array}{c}0.41 \\
(0.49)\end{array}$ & $\begin{array}{l}0.37 \\
(0.48)\end{array}$ \\
\hline Female & Gender of respondent is female ( $1=$ Yes; $0=$ Otherwise $)$ & $\begin{array}{c}0.24 \\
(0.43)\end{array}$ & $\begin{array}{l}0.26 \\
(0.44)\end{array}$ \\
\hline Age & Age of respondent (years) & $\begin{array}{c}45.9 \\
(10.7)\end{array}$ & $\begin{array}{l}46.6 \\
(11.7)\end{array}$ \\
\hline Education & $\begin{array}{l}\text { Respondent has more than four years of formal education } \\
\text { (1=yes; } 0=\text { otherwise })\end{array}$ & $\begin{array}{c}0.86 \\
(0.35)\end{array}$ & $\begin{array}{c}0.82 \\
(0.39)\end{array}$ \\
\hline Hhsize & Household size (no. of members) & $\begin{array}{c}6.67 \\
(2.45)\end{array}$ & $\begin{array}{l}6.35 \\
(2.42)\end{array}$ \\
\hline Fem1564 & No. of female household members aged 15-64 years & $\begin{array}{c}1.54 \\
(0.93)\end{array}$ & $\begin{array}{l}1.43 \\
(0.87)\end{array}$ \\
\hline Mal1564 & No. of male household members aged $15-64$ years & $\begin{array}{c}1.80 \\
(1.11)\end{array}$ & $\begin{array}{l}1.66 \\
(1.07)\end{array}$ \\
\hline Nonfarm & Respondent has nonfarm income ( $1=$ Yes, $0=$ Otherwise $)$ & $\begin{array}{c}0.42 \\
(0.49)\end{array}$ & $\begin{array}{l}0.39 \\
(0.49)\end{array}$ \\
\hline Land owned & Land owned by the respondent's household (ha) & $\begin{array}{c}4.64 \\
(6.30)\end{array}$ & $\begin{array}{l}4.67 \\
(5.98)\end{array}$ \\
\hline Poorsoil & $\begin{array}{l}\text { Proportion }(\%) \text { of cultivated land area classified as having } \\
\text { 'poor' soil fertility by farmer }\end{array}$ & $\begin{array}{c}22.3 \\
(36.3)\end{array}$ & $\begin{array}{l}19.4 \\
(34.7)\end{array}$ \\
\hline Sorgarea & Size of land allocated to sorghum in 2011/12 (Ha) & $\begin{array}{c}1.02 \\
(1.03)\end{array}$ & \\
\hline Maizarea & Size of land allocated maize in 2011/12 (Ha) & & $\begin{array}{l}1.01 \\
(0.94)\end{array}$ \\
\hline
\end{tabular}

Notes: Figures in sorghum and maize columns are mean values, with standard deviations in brackets. 
Interestingly, we find that after accounting for the role of social networks in exposure, and controlling for the intensity of exposure, social networks have a further positive influence on variety adoption, especially for sorghum varieties. However, it is particularly the intravillage and not inter-village networks that produce this effect. This result implies that other than the learning effects of social networks, social influence could play a role in adoption of improved sorghum (Hogset and Barrett, 2010). Hedström et al., (2000) and Easley and Kleinberg (2010) hypothesize that such influence can result from imitation or mimicry, which means that farmers could adjust their adoption behavior just to conform to observed behavior of their peers and not because of any factual information that they learn about the varieties from the social network. This could happen because they admire the adopting peers or they just want to 'flow' with the rest. Another argument proposed by An (2010) may be that farmers are encouraged or persuaded by their social network members to adopt improved varieties. Given that (the stronger) intra-village networks are the more important drivers of adoption than inter-village networks, these arguments seem plausible.

The intensity of exposure to improved varieties positively influences adoption decision for both crops. This is plausible because different varieties present farmers with a much wider range of crop attributes from which they can choose, thereby increasing a farmer's chance of finding a variety with interesting attributes that compels him/her to adopt it. This is consistent with results in Table 3.3, where farmer perceptions of trait superiority between improved and traditional varieties differ for each improved variety. Households with higher number of female members in working age (15-64 years) are more likely to adopt improved sorghum varieties, while for maize, adoption of improved varieties is influenced by the number of male household members in working age. This implies that female labor is a key input in the cultivation of improved sorghum varieties, while for maize male, labor is more important. These results may be indicative of different gender responsibilities for different crops in Africa (Crehan, 1997). Interestingly, even after netting out the effect of non-farm income activities on exposure, we find that having these activities also increases the probability of adopting improved maize varieties. This is plausible since seeds of improved maize varieties are more commercialized than those of improved sorghum. Additional income sources increase a farmer's purchasing power for improved maize seeds, thereby increasing farmers' probability of adopting them. 
Table 3.9: Determinants of adoption of improved varieties

\begin{tabular}{|c|c|c|c|c|c|c|}
\hline \multirow[t]{3}{*}{ Variable } & \multicolumn{3}{|l|}{ Sorghum } & \multicolumn{3}{|l|}{ Maize } \\
\hline & \multirow[t]{2}{*}{ Exposure } & \multicolumn{2}{|c|}{ Adoption } & \multirow[t]{2}{*}{ Exposure } & \multicolumn{2}{|c|}{ Adoption } \\
\hline & & Parametric & Classic & & Parametric & Classic \\
\hline $\begin{array}{l}\text { Sorghum network } \\
\text { degree1 }\end{array}$ & $\begin{array}{l}-0.027 \\
(0.106)\end{array}$ & $\begin{array}{c}0.432^{* * * *} \\
(0.122)\end{array}$ & $\begin{array}{l}0.336^{* * * *} \\
(0.184)\end{array}$ & & & \\
\hline $\begin{array}{l}\text { Sorghum network } \\
\text { degree } 2\end{array}$ & $\begin{array}{l}0.880^{* * * *} \\
(0.303)\end{array}$ & $\begin{array}{l}-0.219 \\
(0.192)\end{array}$ & $\begin{array}{l}-0.108 \\
(0.184)\end{array}$ & & & \\
\hline $\begin{array}{l}\text { Maize network } \\
\text { degree } 1\end{array}$ & & & & $\begin{array}{c}0.031 \\
(0.100)\end{array}$ & $\begin{array}{c}0.209 \\
(0.129)\end{array}$ & $\begin{array}{l}0.200^{* *} \\
(0.094)\end{array}$ \\
\hline $\begin{array}{l}\text { Maize network } \\
\text { degree2 }\end{array}$ & & & & $\begin{array}{c}0.101 \\
(0.194)\end{array}$ & $\begin{array}{l}-0.005 \\
(0.214)\end{array}$ & $\begin{array}{l}-0.068 \\
(0.194)\end{array}$ \\
\hline Admin link & $\begin{array}{c}0.017 \\
(0.011)\end{array}$ & $\begin{array}{c}0.003 \\
(0.010)\end{array}$ & $\begin{array}{c}0.002 \\
(0.009)\end{array}$ & $\begin{array}{c}0.010 \\
(0.009)\end{array}$ & $\begin{array}{l}-0.004 \\
(0.010)\end{array}$ & $\begin{array}{l}-0.004 \\
(0.010)\end{array}$ \\
\hline Extension link & $\begin{array}{l}-0.057 \\
(0.224)\end{array}$ & $\begin{array}{c}0.045 \\
(0.229)\end{array}$ & $\begin{array}{c}0.065 \\
(0.203)\end{array}$ & $\begin{array}{c}0.301 \\
(0.189)\end{array}$ & $\begin{array}{l}-0.247 \\
(0.252)\end{array}$ & $\begin{array}{l}-0.103 \\
(0.205)\end{array}$ \\
\hline Intesorg & & $\begin{array}{l}0.223^{* * *} \\
(0.094)\end{array}$ & $\begin{array}{c}0.480^{* * * *} \\
(0.082)\end{array}$ & & & \\
\hline Intemaiz & & & & & $\begin{array}{c}0.283^{* * * *} \\
(0.089)\end{array}$ & $\begin{array}{c}0.646^{* * *} \\
(0.087)\end{array}$ \\
\hline Mobile phone & $\begin{array}{l}0.517^{* *} \\
(0.233)\end{array}$ & $\begin{array}{l}-0.144 \\
(0.236)\end{array}$ & $\begin{array}{l}-0.094 \\
(0.214)\end{array}$ & $\begin{array}{c}0.280 \\
(0.201)\end{array}$ & $\begin{array}{l}-0.005 \\
(0.248)\end{array}$ & $\begin{array}{l}-0.067 \\
(0.205)\end{array}$ \\
\hline Radio & $\begin{array}{l}-0.369 \\
(0.248)\end{array}$ & $\begin{array}{c}0.272 \\
(0.244)\end{array}$ & $\begin{array}{c}0.140 \\
(0.218)\end{array}$ & $\begin{array}{c}0.258 \\
(0.208)\end{array}$ & $\begin{array}{c}0.265 \\
(0.276)\end{array}$ & $\begin{array}{c}0.180 \\
(0.227)\end{array}$ \\
\hline Leader & $\begin{array}{c}0.330 \\
(0.214)\end{array}$ & $\begin{array}{l}-0.176 \\
(0.214)\end{array}$ & $\begin{array}{l}-0.040 \\
(0.197)\end{array}$ & $\begin{array}{c}0.100 \\
(0.188)\end{array}$ & $\begin{array}{l}-0.050 \\
(0.216)\end{array}$ & $\begin{array}{l}-0.072 \\
(0.198)\end{array}$ \\
\hline Age & $\begin{array}{l}0.034^{* * * * *} \\
(0.012)\end{array}$ & $\begin{array}{l}-0.005 \\
(0.013)\end{array}$ & $\begin{array}{c}0.000 \\
(0.011)\end{array}$ & $\begin{array}{l}0.016^{*} \\
(0.009)\end{array}$ & $\begin{array}{l}-0.012 \\
(0.011)\end{array}$ & $\begin{array}{l}-0.004 \\
(0.010)\end{array}$ \\
\hline Female & $\begin{array}{l}-0.190 \\
(0.267)\end{array}$ & $\begin{array}{c}0.345 \\
(0.298)\end{array}$ & $\begin{array}{c}0.351 \\
(0.248)\end{array}$ & $\begin{array}{l}-0.396^{*} \\
(0.205)\end{array}$ & $\begin{array}{l}-0.116 \\
(0.267)\end{array}$ & $\begin{array}{l}-0.074 \\
(0.220)\end{array}$ \\
\hline Education & $\begin{array}{c}0.533 \\
(0.381)\end{array}$ & $\begin{array}{c}0.217 \\
(0.382)\end{array}$ & $\begin{array}{c}0.255 \\
(0.315)\end{array}$ & $\begin{array}{c}0.308 \\
(0.255)\end{array}$ & $\begin{array}{c}0.034 \\
(0.321)\end{array}$ & $\begin{array}{c}0.027 \\
(0.307)\end{array}$ \\
\hline Hhsize & & $\begin{array}{l}-0.001 \\
(0.055)\end{array}$ & $\begin{array}{l}-0.014 \\
(0.049)\end{array}$ & & $\begin{array}{l}-0.055 \\
(0.059)\end{array}$ & $\begin{array}{l}-0.043 \\
(0.050)\end{array}$ \\
\hline Fem1564 & & $\begin{array}{c}0.249^{*} \\
(0.143)\end{array}$ & $\begin{array}{c}0.230^{*} \\
(0.118)\end{array}$ & & $\begin{array}{l}0.105 \\
(0.139)\end{array}$ & $\begin{array}{c}0.050 \\
(0.124)\end{array}$ \\
\hline Mal1564 & & $\begin{array}{l}-0.096 \\
(0.109)\end{array}$ & $\begin{array}{l}-0.074 \\
(0.097)\end{array}$ & & $\begin{array}{l}0.256^{* * *} \\
(0.109)\end{array}$ & $\begin{array}{l}0.208^{* * *} \\
(0.099)\end{array}$ \\
\hline Nonfarm & $\begin{array}{c}0.057 \\
(0.206)\end{array}$ & $\begin{array}{l}-0.246 \\
(0.208)\end{array}$ & $\begin{array}{l}-0.199 \\
(0.193)\end{array}$ & $\begin{array}{l}0.464^{* *} \\
(0.181)\end{array}$ & $\begin{array}{l}0.402^{*} \\
(0.213)\end{array}$ & $\begin{array}{l}0.480^{* * *} \\
(0.192)\end{array}$ \\
\hline Land owned & $\begin{array}{c}0.005 \\
(0.021)\end{array}$ & $\begin{array}{c}0.009 \\
(0.020)\end{array}$ & $\begin{array}{c}0.002 \\
(0.019)\end{array}$ & $\begin{array}{l}-0.009 \\
(0.017)\end{array}$ & $\begin{array}{c}0.010 \\
(0.029)\end{array}$ & $\begin{array}{l}-0.002 \\
(0.017)\end{array}$ \\
\hline Poorsoil & & $\begin{array}{l}-0.006^{* * *} \\
(0.003)\end{array}$ & $\begin{array}{l}-0.005^{*} \\
(0.003)\end{array}$ & & $\begin{array}{l}-0.003 \\
(0.003)\end{array}$ & $\begin{array}{l}-0.003 \\
(0.003)\end{array}$ \\
\hline Sorgarea & & $\begin{array}{l}-0.028 \\
(0.110)\end{array}$ & $\begin{array}{l}-0.014 \\
(0.094)\end{array}$ & & & \\
\hline Maizarea & & & & & $\begin{array}{c}0.634^{* * * *} \\
(0.190)\end{array}$ & $\begin{array}{c}0.602^{* * * *} \\
(0.159)\end{array}$ \\
\hline Constant & $\begin{array}{l}-1.422 \\
(0.878)\end{array}$ & $\begin{array}{c}-0.774 \\
(0.864)\end{array}$ & $\begin{array}{c}-1.726^{* * *} \\
(0.726)\end{array}$ & $\begin{array}{c}-0.588 \\
(0.597)\end{array}$ & $\begin{array}{l}-0.103 \\
(0.826)\end{array}$ & $\begin{array}{l}-1.363^{*} \\
(0.744)\end{array}$ \\
\hline $\begin{array}{l}N \\
\text { Pseudo } R^{2}\end{array}$ & $\begin{array}{c}245 \\
0.170\end{array}$ & $\begin{array}{c}196 \\
0.194\end{array}$ & $\begin{array}{c}245 \\
0.229\end{array}$ & $\begin{array}{c}305 \\
0.127\end{array}$ & $\begin{array}{c}238 \\
0.181\end{array}$ & $\begin{array}{c}305 \\
0.357\end{array}$ \\
\hline
\end{tabular}

Notes: Figures are Probit coefficients, with robust standard errors in parenthesis. $* \mathrm{P}<10 \%, * * \mathrm{P}<5 \%, * * * \mathrm{P}<1 \%$. 
Soil characteristics also seem to matter for adoption of improved sorghum but not of improved maize varieties. Farmers with a high proportion of cultivated land that they perceive to have poor soil fertility have a lower probability of adopting improved sorghum varieties. This may be related to the fact that most improved varieties tend to be responsive to soil fertility status. The scale of production also affects adoption of improved maize varieties. We find that the probability of adoption increases with the size of land area allocated to maize. This may be so because the larger scale farmers tend to be wealthier and may therefore afford seeds, or they are more commercially oriented and hence exploiting the profitability advantage of improved varieties. It may also be the case that larger scale farmers can spare some land to 'experiment' with new varieties, or they are better able to cope with risks that may be associated with adopting new technologies. While the underlying reasons for the association between the cultivated area and adoption are ambiguous, it has been widely reported that farmers with a larger cropping area tend to adopt earlier than those with smaller ones (see reviews by Feder et al., 1985 and Geroski, 2000).

\subsubsection{Constraints to the adoption of ICVs}

After identifying the determinants of adoption of ICVs, we present the reasons stated by the farmers for the non-adoption of ICVs in this section. For farmers, who have never adopted sorghum and maize ICVs (never-adopters), the most limiting factor is seed availability, followed by perceived susceptibility to pests, both of which make close to three quarters of responses (Table 3.10). There are, however, significant differences between the two crops. About $56 \%$ of never-adopters of maize mentioned seed availability as a constraint, but just $44 \%$ of the sorghum never-adopters cited this as reason for non-adoption. Susceptibility to pests was mentioned by $30 \%$ of the sorghum never-adopters, while it was mentioned by only $16 \%$ of the maize never-adopters. The importance of reasons changes, if we only consider farmers who have adopted ICVs in the past but not in the last growing season. For sorghum ICVs, the most important constraint to adoption is pest susceptibility, followed by seed access problems. However, for maize ICVs, the most important constraint is low adaptation to local conditions; followed by again seed access problems. An important implication of this result is that adoption constraints may be different for those without previous adoption experience compared to those who have ever adopted them. 
Table 3.10: Stated reasons for non-adoption of known varieties (\% responses)

\begin{tabular}{|c|c|c|c|c|}
\hline \multirow[t]{2}{*}{ Reason } & \multicolumn{2}{|c|}{ Never adopted } & \multicolumn{2}{|c|}{$\begin{array}{l}\text { Ever adopted but did not } \\
\text { adopt in 2011/12 }\end{array}$} \\
\hline & Sorgh & Maize & Sorghum & Maize \\
\hline Seed constraints & 44.4 & $56.4^{* *}$ & 27.6 & 28.6 \\
\hline Pests, including birds & 30.7 & $15.7 * * *$ & 33.6 & $15.5 * * *$ \\
\hline Adaptation (low yields, takes long to mature) & 3.9 & $7.4^{*}$ & 6.0 & $29.1 * * *$ \\
\hline Post-harvest (markets, utilization) & 3.9 & $0.0 * *$ & 11.3 & $0.5^{* * *}$ \\
\hline Land constraints (small land, infertile soil) & 6.5 & 8.3 & 5.0 & $1.9 * *$ \\
\hline Other (weather, lack of interest, not specified) & 10.5 & 12.3 & 16.6 & $24.3 * *$ \\
\hline$N$ & 153 & 204 & 301 & 206 \\
\hline
\end{tabular}

\subsection{Conclusions}

This study analyzes the determinants of exposure, which is a precondition for adoption, and of adoption itself. We focus on the role of social networks on exposure and adoption of improved cereal technologies. In a departure from previous studies on the determinants of exposure to improved varieties, we assess the intensity of exposure, which is modeled as a discrete variable. Moreover, we compare technologies with largely missing seed markets (sorghum varieties and OPVs of maize) and those with considerably functional markets (maize hybrids). We also explicitly address the effect of intra- versus inter-village networks on exposure and adoption, which has, at least to our knowledge, not been done in previous studies. Using household survey data from 345 farmers living in Central Tanzania, we apply Poisson models to identify the role of social networks on exposure to improved varieties. The analysis of adoption is based on a methodology proposed by Diagne and Demont (2007), which is able to account for non-exposure bias.

Our results show that about $79 \%$ of the respondents are aware of at least one improved sorghum variety, while $74 \%$ of respondents know at least one maize variety. Farmer networks are found to be key sources of information on improved varieties. Exchange of information that exposes farmers to improved varieties within these networks is triggered mainly when a farmer sights a variety in a network member's field. Improved varieties of both crops are generally considered better than traditional ones by most farmers. Results for determinants of farmer exposure to improved varieties show that the size of a farmer's sorghum network positively influences their intensity of exposure to improved varieties of the crop. The size of maize network influences exposure to OPVs positively, but we do not find a 
significant effect on exposure to hybrids. We also find that farmers have substantial information networks outside their villages of residence, and it is these often understudied networks rather those inside the village, that determine the intensity of exposure to improved varieties. Important are also linkages to the village administrators in the case of sorghum and to the public extension officers in case of both crops.

After accounting for exposure, the estimated population adoption rate is $52 \%$ for sorghum and $71 \%$ for maize. Social networks for sorghum have a positive influence on variety adoption even after accounting for the role of social networks in exposure, and controlling for the number of improved varieties known by a farmer, indicating endogenous social effects. However, it is particularly the intra-village and not inter-village networks that produce this effect. This result implies that other than the social learning effects of social networks, social influence could also play a role in sorghum adoption. Households with more female adults are more likely to adopt improved sorghum, while those with more male adults are more likely to adopt improved maize. Poor soil fertility negatively affects adoption of improved sorghum, while non-farm income activities and size of maize farm positively influence adoption of maize varieties. Farmers mentioned seed availability followed by perceived susceptibility to pests as the most limiting factors to adoption. However, the importance of these reasons changes if we compare farmers without past adoption experience to those who have ever adopted.

These results raise a number of implications for policy and further research. First, there is still a substantial share of farmers, who are not aware of any improved varieties. To increase adoption, efforts directed towards improving the knowledge about ICVs need to be stepped up. Second, our results suggest that an important starting point of variety information flows in social networks is visibility of the varieties in other farmers' fields. Yet, focus group discussions held during the survey revealed that farmers were critical of the very small demo plots that are often used, arguing that it is difficult to judge the potential of the technologies from such small plots. This result underscores the need for well managed demo farms, positioned strategically for many farmers to see the technology being promoted. Third, farmer networks with extension officers need to be strengthened, for instance by improving the facilitation of extension officers' mobility. Fourth, the power of farmer networks with community leaders and village administrators can be exploited, which calls for research into the possibility of targeting the farms of these leaders for demonstration plots, and increasing their exposure to improved varieties through facilitated forums such as seminars, agricultural shows and meetings with seed traders. Fifth, the finding that inter-village networks matter for 
exposure to improved varieties points to the need for facilitated forums that enable farmers to exchange technological information across villages, such as tours to other villages. From a theoretical perspective, this result implies that inter-village networks cannot be generally ignored in studies on social networks. Studies on inter-village networks in the context of technology diffusion are rare and more studies are needed to enrich the debate on our findings. Sixth, the result shows that adoption increases with the number of improved varieties a farmer knows of. It is hence important to develop a set of ICVs, which are characterized by a range of crop attributes. This increases the chance that a farmer finds a variety that suits his/her requirements. Seventh, in the development of future sorghum varieties more emphasis should be placed on the performance on less fertile soils and reducing susceptibility to pests. Eighth, for the adoption of sorghum varieties it is crucial to target female farmers in extension activities because their level of exposure to improved varieties is generally lower than that of men although they are responsible for sorghum cultivation. Finally, the availability of improved varieties needs to be enhanced. The strategies, however, need to be adapted according to the source of seeds. Seeds of sorghum and non-hybrid maize ICVs, which are open pollinated, are usually obtained from fellow farmers. Distributing the seeds directly to farmers during field days and farmer field schools is hence a promising strategy. Another strategy would be to strengthen the initiative of producing quality declared seeds (QDS) by fellow farmers, which would bring the producer of seeds closer to the actual users. Moreover, popularizing the QDS farmers would be critical as the current ones are still unknown to many farmers, as was revealed during focus group discussions. For hybrid maize varieties, a different strategy needs to be applied, because they are usually obtained through local input dealers. It is hence important to improve the availability throughout the planting season in the local shops. This can only be achieved in collaboration with seed producers and retailers. 


\title{
4 Effects of social networks on technical efficiency in smallholder agriculture: The case of cereal producers Tanzania ${ }^{4}$
}

\begin{abstract}
The use of improved crop varieties is key to increasing food production, but in Sub-Saharan Africa traditional varieties still dominate smallholder farming. Lack of information is a major constraint to the adoption of improved varieties and the role of social networks in their diffusion is increasingly being studied. Social networks can, however, also affect the efficiency with which farmers use these technologies. In this paper we investigate the influence of social networks on technical efficiency of smallholder cereal producers. Using the case of Tanzania, we apply stochastic frontier analysis on plot-level data of sorghum and maize producers. Results show that the effects of social networks on efficiency differ by crop. Inter-village farmer-to-farmer networks positively influence technical efficiency of improved varieties of sorghum, but they have no effect in case of maize. We further find that links to public extension officers increase efficiency of improved maize varieties. Some wider research and policy implications are discussed.
\end{abstract}

Keywords: Improved varieties, social networks, information, technical efficiency, stochastic frontier.

\footnotetext{
4 This chapter is co-authored with Dr. Theda Gödecke and Dr. Stefan Schwarze (Assistant Professors, Department of Agricultural Economics and Rural Development, Georg-August-University Göttingen). The authors acknowledge the contribution of Prof. Dr. Bernhard Brümmer, Department of Agricultural Economics and Rural Development, Georg-August-University Göttingen.
} 


\subsection{Introduction}

Global demand for food and agricultural products is on the rise and there is need to increase production to meet this growing demand. Smallholders, who form the majority of farmers around the world, will play a significant role in this regard (FAO, 2014). The use of improved crop varieties (ICVs) has been identified as an important strategy by which smallholders can increase productivity and food production (World Bank, 2007). However, in most of SubSaharan Africa, traditional varieties still dominate smallholder production systems (Walker et al., 2014), limiting the envisaged output and productivity gains. Lack of agricultural information has been identified as a key constraint to ICV diffusion, and its role is increasingly being studied (Diagne and Demont, 2007; Simtowe et al., 2011; Kabunga, Dubois and Qaim, 2012). Based on this information constraint paradigm, a number of ICV diffusion studies (Matuschke and Qaim, 2009; Maertens and Barrett, 2013) have assessed the role of social ties and interactions, also known as social structures or social networks (Borgatti et al., 2009). This is anchored on the understanding that social networks are powerful informal institutions for information diffusion in farming communities, and that flows of information, beliefs and attitudes within social networks can influence farmers' technology adoption decisions (Baerenklau, 2005).

Social networks, however, can affect not only the adoption by farmers, but also the efficiency with which farmers use these technologies. Based on information obtained from network members, individual farmers adjust the type and timing of crop husbandry methods used (such as seedbed preparation, sowing, and management of soil fertility, pests and diseases), which then influences their technical efficiency. While there have been a number of studies assessing the impact of ICVs on efficiency and productivity (Huang and Bagi, 1984; Adesina and Djato, 1996; Sherlund, Barrett and Adesina, 2002; Aye and Mungatana, 2010), we are not aware of any study that has investigated explicitly the effect of farmer-tofarmer social networks. We hence add to the literature by investigating the role of these social networks for technical efficiency. We use data from 231 plots of sorghum and 287 of maize, collected from 345 cereal producers in Central Tanzania. Another interesting aspect of our study refers to the characteristics of social networks themselves. Past studies report that social networks cross geographical boundaries (De Weerdt, 2004; Fafchamps and Gubert, 2007), but previous studies of network effects primarily focus on intra-village links, ignoring inter- 
village networks that may play an important role in information dissemination. Hence, an attempt is made to assess the effects of social networks both within and across villages.

The rest of the paper is structured as follows. Section 2 discusses the methodology of our study. After describing the data and empirical models in Section 3, we present our results in Section 4. In Section 5, we conclude and discuss implications of the study for policy and future research.

\subsection{Methodology}

\subsubsection{Technical efficiency and its measurement}

Efficiency in resource allocation is the central concept in neoclassical theory of production, in which firms are assumed to be profit maximizing. According to Kumbhakar and Lovell (2000), we define technical efficiency (TE) of a farm as the ratio of its observed output to the maximum feasible output. Following Kumbhakar and Lovell (2000) and Greene (2008), we use stochastic frontier analysis to estimate the production frontier and to obtain measures of technical efficiency. The stochastic frontier model is specified as

$$
\ln Y_{i}=f\left(\boldsymbol{X}_{i}, \boldsymbol{\beta}\right)+v_{i}-u_{i}
$$

where $Y_{i}$ is the quantity of output produced by farm $i(\mathrm{i}=1,2, \ldots \mathrm{N}), \boldsymbol{X}_{\boldsymbol{i}}$ is a vector of inputs into the production process, and $\boldsymbol{\beta}$ is a vector of parameters to be estimated, $\left(v_{i}-u_{i}\right)$ is the composed error term, $\varepsilon_{i}$, with $v_{i}$ being the stochastic component that accounts for measurement errors, omitted variables, model (mis)specification and random variation across farms. This stochastic error is assumed to be normally distributed and can take negative, zero, or positive values. It is further assumed that $E\left(v_{i}\right)=0 ; \quad E\left(v_{i}^{2}\right)=\sigma_{v}^{2}$ and $E\left(v_{i} v_{j}\right)=0$ for all $i \neq j$ (Coelli et al., 2005). The term $u_{i} \geq 0$ represents the technical inefficiency, and captures the extent to which observed yield deviates from potential output, given inputs and production technology. This term is assumed to follow a half-normal, truncated-normal, exponential or gamma distribution. It is also assumed that $E\left(u_{i}^{2}\right)=\sigma_{u}^{2}$ and $E\left(u_{i} u_{j}\right)=0$ for all $i \neq j$ (Coelli et al., 2005). From this term, a farm's level of technical efficiency (TE) is calculated using equation 4.2. Jondrow et al. (1982) and Greene (2008) discuss the derivation of these terms is in detail.

$$
T E_{i}=\exp \left(-u_{i}\right)
$$

Letting technical inefficiency to be influenced by farm and management characteristics, then the inefficiency model can be specified as 


$$
u_{i}=\alpha_{0}+s_{i} \boldsymbol{\alpha}+z_{i} \delta+w_{i}
$$

where $\boldsymbol{\alpha}$ and $\boldsymbol{\delta}$ are vectors of parameters to be estimated, $\boldsymbol{s}$ represents a vector of social network characteristics of farmer $i, z_{i}$ is a vector of farm and farmer characteristics, and $w_{i}$ represents unobserved normally distributed random factors that influence inefficiency. Equations (4.1) and (4.3) are then estimated simultaneously by maximum likelihood methods (Kumbhakar and Lovell, 2000). We assume half-normal distribution and test for the presence of inefficiency (i.e., null hypothesis that $\lambda=0$, against the alternative that $\lambda>0$ ) using a special likelihood ratio test for on-boundary values described by Gutierrez, Carter and Drukker (2001).

\subsubsection{Information, social networks and technical efficiency}

The key sources of new agricultural information in our study area are seed and agro-chemical companies/dealers; government agricultural extension officers; non-governmental organizations; and public agricultural research and development organizations (Figure 4.1). Farmers obtain this information through two main channels. One, they may directly access the information by participating in the activities offered by these institutions such as farmer field days, on-farm trials and demo plots. The second pathway is informal, i.e., farmers obtain the information from other farmers, through their social networks. We define a social network as a set of actors or nodes (individuals or households) that have relationships or ties with one another (Marin and Wellman, 2011).

Social networks affect an individual farmer's behavior through social learning or social influence (Young, 2009; Hogset and Barrett, 2010). In the case of social learning, the farmer actively searches for information within his/her networks. The information obtained may in turn influence the farmers' decision to adopt a more efficient farming method. By contrast, social influence results from imitation or mimicry, which means that a farmer adjusts their farming practice mainly to conform to observed behavior of other farmers, and not necessarily based on any factual information about the motivation for their peers' adoption of the given farming method (Hedström, Sandell and Stern, 2000; Easley and Kleinberg, 2010). According to these pathways, we hypothesize that the information obtained from formal sources and from farmer-to-farmer networks influences individual farmers to adjust the type and timing of crop husbandry methods used (such as seedbed 
preparation, sowing, and management of soil fertility, pests and diseases), resulting to changes in technical efficiency.

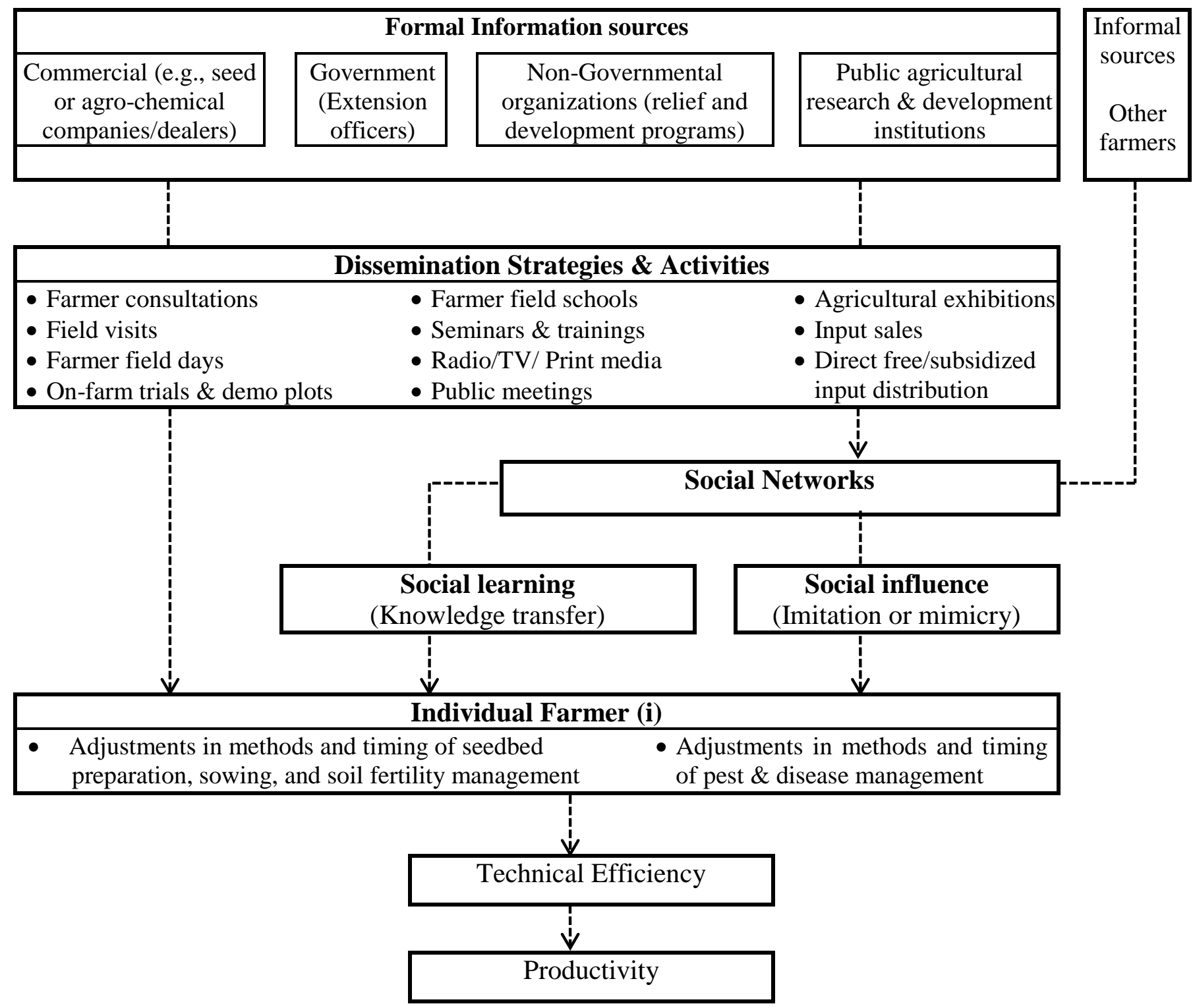

Figure 4.1: Information sources and pathways, and the role of social networks for technical efficiency. Source: Authors' impressions.

\subsubsection{Potential endogeneity in adoption of improved varieties}

The type of seed technology (improved or traditional varieties) used is an important factor influencing productivity. The adoption of improved varieties is, however, potentially endogenous. Mutter et al. (2013) argue that efficiency estimation procedures that do not account for endogeneity introduce bias in the results due to correlation between the endogenous variable and the composed error of the stochastic frontier. In our study, it is 
likely that endogeneity is present due to farmers self-selecting or being selected nonrandomly into adoption. Information on and seeds of improved varieties are often passed to farmers in a selective manner. For instance, agricultural research and extension staff often target particular geographic locations, individual farmers or groups of farmers (Diagne and Demont, 2007) for ICV research, extension and development activities. In the case of Tanzania, Monyo et al. (2004) and Lyimo et al. (2014) document heavy involvement of the public agricultural extension service and development organizations in disseminating improved varieties of sorghum and maize. Moreover, in our data, the seeds used in $26.3 \%$ of the improved sorghum plots were sourced from agricultural extension officers. It is therefore very likely that the adoption of improved varieties is non-random and that an endogeneity problem is present due to sample selection.

\subsubsection{Addressing endogeneity in variety adoption}

Recently, studies employing SFA have begun to address the problem of endogeneity in technology adoption (Solís, Bravo-Ureta and Quiroga, 2007; Rao, Brümmer and Qaim, 2012; Wollni and Brümmer, 2012). In this study, we use a matching method known as propensity score matching (PSM) (Rosenbaum and Rubin, 1983) to correct for potential endogeneity. This non-parametric method enables us to construct a group of plots sown with traditional varieties (control or counterfactual group) which is comparable to those plots sown with improved varieties (treatment or treated group). An advantage of this grouping is that it gives us the flexibility to analyze technical efficiency of the two groups separately. Technological differences between the improved and traditional varieties imply that production constraints and information needs are different, hence separate analyses are interesting. We implement PSM by first computing a propensity score, which is the probability to adopt an ICV, using a Logit model. Next we use kernel matching (for sorghum) and nearest neighbor matching (for maize) algorithms to construct the treatment and control groups within the region of common support (Caliendo and Kopeinig, 2008). One shortcoming of PSM is its reliance on observables to address confoundedness, but self-selection can also be influenced by unobserved variables, resulting in hidden bias (DiPrete and Gangl, 2004). The Rosenbaum bounding procedure (RBP) has been commonly used to assess the sensitivity of the results to unobservables (Rosenbaum, 2005). In this study, we follow DiPrete and Gangl (2004) to perform the RBP. For brevity, since we do not use the results of the matching directly, we do not show the matching models, but refer the reader to the cited references. 


\subsection{Data and empirical model}

\subsubsection{Data sources}

The data we use were collected in Singida Rural and Kondoa Districts in Central Tanzania between September and November 2012. Central Tanzania is mainly semi-arid, and farmers in the region cultivate mainly cereals (sorghum and maize are the staples), but also grow some pulses, oil, root and tuber crops, and keep livestock (United Republic of Tanzania, 2012). The data were collected through a household survey involving 345 farmers from 21 villages. In each district, 3 village clusters (2-5 villages each) were purposively selected. Each cluster consists of villages that are geographically close to each other and that share the same local agricultural extension officer. This approach was chosen because it enables us to investigate the effect of inter-village networks. In each village, households were then selected by simple random sampling, and their heads interviewed by enumerators using a pre-tested structured questionnaire. We collected information on respondent, household and farm characteristics, and plot-level data on crops cultivated in the 2011/12 season. Plot-level data was preferred to data for total area allocated to these crops because it is easier to remember for the respondent, given that the farmers do not keep formal records. To improve accuracy and reliability of labor data, respondents were asked to select only one plot of sorghum and maize, respectively, and recall the labor use by production activity for this plot.

To elicit data on social networks, we sampled pairs of the selected farmers using the random matching within sample approach (Conley and Udry, 2010; Maertens and Barrett, 2013). Each farmer $(i)$ was randomly paired with six other respondents $(j)$ from our sample: three from his/her village and three from neighboring villages ${ }^{5}$. The respondents were asked questions about their six random matches in this sequence: "Do you know $j$ (the match)?" If the answer was "no", no further network questions about the particular match were asked. If the answer was "yes", the respondent was asked: "Do you discuss sorghum (maize) farming issues with $j$ ?" Based on these answers, we interpret a "yes" response as presence of a network link for sorghum (maize), between the respondent and his/her match, and a "no" response as absence of such a link. Similar information about the respondent was not sought from his/her matches, implying that we use undirected network links. In addition to the farmer-to-farmer networks, respondents were asked about their frequency of interactions with

\footnotetext{
${ }^{5}$ When using the random matching approach, there is no explicit rule regarding the number of matches per respondent, which rarely exceeds seven in most studies.
} 
village administrators (chair or other executives at village or sub-village level) and public extension officers.

\subsubsection{Model specification}

The models used in this study are shown in equations (4.3) and (4.4). Different functional forms have been used for $f($.$) in equation (4.1), but the most common are Cobb-Douglas$ (CD) and Translog (TL). Although TL is usually preferred in empirical work due to its flexibility, we use the CD function in this paper, because it best fits our data. The dataset showed high multicollinearity between input variables and their cross-products, which rendered estimation of the frontier impossible, or to produce coefficients that were unstable or with counterintuitive signs. Such challenges have been reported in studies by Dawson, Lingard, and Woodford (1991) and Wilson, Hadley and Asby (2001).

Thus, our empirical production frontier takes the following form:

$$
\begin{gathered}
\text { InProduction }_{i c}=\beta_{0 c}+\sum_{x=1}^{X} \boldsymbol{\beta}_{x c} \text { Input }_{x i c}+\beta_{v c} \text { Variety }_{\text {vic }}+\sum_{e=1}^{E} \boldsymbol{\beta}_{e c} \text { Environment }_{\text {eic }} \\
+v_{i c}-u_{i c}
\end{gathered}
$$

where the subscripts $i$ and $c$ represent individual farmers and crops, respectively, and $\boldsymbol{\beta}$ are the parameters to be estimated. Input is a vector of discretionary inputs: land, labor and seeds. None of the farmers reported using fertilizers or irrigation in production of either crop, while the use of pesticides was negligible. This is consistent with minimal use of these inputs reported in recent national surveys (World Food Programme, 2010; United Republic of Tanzania 2012). Variety is a dummy variable representing the type of seed technology used (traditional or improved $^{6}$ ), and we hypothesize that improved varieties would have a positive effect on grain output. Environment is a vector of dummy variables controlling for the effect of physical production environment on crop output. Sherlund et al. (2002) show that omitting such environmental factors can bias efficiency estimates. Hence, we use soil types to control for differences in soil fertility (Sommer at al., 2013), distance from the homestead to the plots, to control for differences in other soil and environmental characteristics (Rowe et al., 2006) and crop management challenges associated with plots located away from the

\footnotetext{
${ }^{6}$ In this study, we categorize recycled seeds of improved varieties as improved, because from the perspective of the farmer, the varieties are still distinct from the traditional ones and failure to acquire fresh seeds may due to farmer or market constraints rather than their unwillingness to do so. Since recycled hybrid seeds tend to lose vigor over time, we acknowledge that this categorization could potentially underestimate their productivity.
} 
homestead (Tan, Kruseman and Heerink, 2007). A district dummy is also included to control for unobserved heterogeneity due to agro-climatic factors.

We estimate the determinants of inefficiency simultaneously with the production frontier, using the following model

$$
\begin{aligned}
& u_{i e}=\alpha_{0 c}+\sum_{k=1}^{K} \alpha_{k e} \text { Network } \boldsymbol{k}_{\text {kic }}+\sum_{m=1}^{M} \delta_{m e} z_{\text {mic }} \\
& \mathrm{i}=1,2, \ldots, \mathrm{N} ; \quad \mathrm{c}=1,2
\end{aligned}
$$

where subscripts $i$ and $c$ are as previously defined, and $\alpha$ and $\delta$ are coefficients to be estimated. Network is a vector of variables capturing the effect of different types of network links on efficiency. We use the total network degree (number of network links out of the six random matches) as a proxy for total farmer-to-farmer network size and further split it into intra-village and inter-village network degrees. The vector also includes variables measuring the link of farmers with village administrators and public agricultural extension officers. Our hypothesis is that farmers with a higher network degree or stronger ties with formal institutional actors are better placed to obtain more or higher quality production information, which may enhance technical efficiency. Finally, $z$ is a vector of control variables hypothesized to affect efficiency, such as farming experience, wealth-related variables, ownership of information asset such as radio, and membership to community associations that engage in agricultural activities.

\subsubsection{Descriptive statistics of model variables}

In this section we present descriptive statistics for the variables used in the frontier and inefficiency models. Additional variables that we use only for the estimation of the propensity scores are presented in Table A1 in the Appendix. Table 1 shows summary statistics of the plot-level variables disaggregated by crop and seed technology (traditional vs. improved). About $27 \%$ of sorghum plots are sown with improved varieties, while for maize, improved varieties occupy $63 \%$ of the plots. On average, plots of traditional sorghum varieties are significantly larger (0.78 ha) than those of improved varieties ( $0.57 \mathrm{ha})$, but for maize, it is the plots of improved varieties that are larger ( $0.85 \mathrm{ha})$ than those of traditional varieties (0.69 ha). Input use shows some significant differences only for sorghum, with farmers using more seeds and labor in plots sown with traditional varieties than in plots sown with improved varieties. Plots on sandy soil are the most common, followed by those on clay 
and loam soils, respectively. Most of the plots are located within the homestead or can be reached within 30 walking minutes. However, for a sizeable proportion of plots, farmers have to walk for a longer time to reach them and in this study we refer to them as "far plots". For maize, the proportion of far plots is significantly higher for improved than traditional varieties.

Table 4.1: Descriptive statistics for variables used in the production frontier models

\begin{tabular}{|c|c|c|c|c|c|}
\hline \multirow[t]{2}{*}{ Variable } & \multirow[t]{2}{*}{ Description } & \multicolumn{2}{|c|}{ Sorghum } & \multicolumn{2}{|c|}{ Maize } \\
\hline & & $\begin{array}{l}\text { Traditional } \\
(\mathrm{N}=169)\end{array}$ & $\begin{array}{l}\text { Improved } \\
(\mathrm{N}=62)\end{array}$ & $\begin{array}{l}\text { Traditional } \\
(\mathrm{N}=106)\end{array}$ & $\begin{array}{l}\text { Improved } \\
(\mathrm{N}=181)\end{array}$ \\
\hline \multirow{2}{*}{\multicolumn{6}{|c|}{ Variables used in the frontier model }} \\
\hline & & & & & \\
\hline Output & Grain output per plot (tons) & $\begin{array}{l}0.47 \\
(0.57)\end{array}$ & $\begin{array}{l}0.31 * * \\
(0.41)\end{array}$ & $\begin{array}{l}0.40 \\
(0.70)\end{array}$ & $\begin{array}{l}0.58 * * \\
(0.68)\end{array}$ \\
\hline \multicolumn{6}{|l|}{ Inputs } \\
\hline Land & Plot size (ha) & $\begin{array}{l}0.78 \\
(0.80)\end{array}$ & $\begin{array}{r}0.57 * * \\
(0.63)\end{array}$ & $\begin{array}{l}0.69 \\
(0.48)\end{array}$ & $\begin{array}{l}0.85 * * \\
(0.76)\end{array}$ \\
\hline Labor & Total labor used (Days) & $\begin{array}{l}113.9 \\
(95.4)\end{array}$ & $\begin{array}{l}87.8 * * \\
(72.3)\end{array}$ & $\begin{array}{l}82.0 \\
(57.0)\end{array}$ & $\begin{array}{l}79.9 \\
(76.8)\end{array}$ \\
\hline Seed & Total seed used (kg) & $\begin{array}{l}8.95 \\
(10.3)\end{array}$ & $\begin{array}{l}4.60 * * * \\
(5.67)\end{array}$ & $\begin{array}{l}10.0 \\
(10.4)\end{array}$ & $\begin{array}{l}10.6 \\
(12.4)\end{array}$ \\
\hline \multicolumn{6}{|c|}{ Production environment } \\
\hline Sand soil & $\begin{array}{l}\text { Soil type is mostly sandy }(1=\text { Yes, } \\
0=\text { otherwise })\end{array}$ & $\begin{array}{l}0.56 \\
(0.50)\end{array}$ & $\begin{array}{l}0.55 \\
(0.50)\end{array}$ & $\begin{array}{l}0.44 \\
(0.50)\end{array}$ & $\begin{array}{l}0.41 \\
(0.49)\end{array}$ \\
\hline Clay soil & Soil type is mostly clay ( $1=$ Yes, $0=$ otherwise $)$ & $\begin{array}{l}0.23 \\
(0.42)\end{array}$ & $\begin{array}{l}0.24 \\
(0.06)\end{array}$ & $\begin{array}{l}0.34 \\
(0.48)\end{array}$ & $\begin{array}{l}0.37 \\
(0.48)\end{array}$ \\
\hline Loam soil & Soil type is mostly loam ( $1=$ Yes, $0=$ otherwise $)$ & $\begin{array}{l}0.21 \\
(0.41)\end{array}$ & $\begin{array}{l}0.19 \\
(0.40)\end{array}$ & $\begin{array}{l}0.22 \\
(0.41)\end{array}$ & $\begin{array}{l}0.22 \\
(0.41)\end{array}$ \\
\hline Far plot & $\begin{array}{l}\text { Plot is located far from the homestead }(1=\text { Yes, } \\
0=\text { otherwise })\end{array}$ & $\begin{array}{l}0.12 \\
(0.32)\end{array}$ & $\begin{array}{l}0.13 \\
(0.34)\end{array}$ & $\begin{array}{l}0.12 \\
(0.33)\end{array}$ & $\begin{array}{l}0.22 * * \\
(0.42)\end{array}$ \\
\hline Kondoa & $\begin{array}{l}\text { Plot is in Kondoa district }(1=\text { Yes, } \\
0=\text { Otherwise })\end{array}$ & $\begin{array}{l}0.43 \\
(0.50)\end{array}$ & $\begin{array}{l}0.45 \\
(0.50)\end{array}$ & $\begin{array}{l}0.52 \\
(0.50)\end{array}$ & $\begin{array}{l}0.58 \\
(0.50)\end{array}$ \\
\hline
\end{tabular}

Note: Figures are mean values, with their standard deviations in parenthesis. *,**,*** differences in means between traditional and improved varieties are significant at 10,5 and $1 \%$ respectively.

Table 4.2 presents a summary of the social network, respondent, and household characteristics of our sample, disaggregated by crop and type of seed technology used. Social network data shows that the measures of crop network degree for sorghum are significantly different between growers of improved and traditional varieties. The total sorghum network degree is 1.9 for adopters of improved varieties and 1.1 for non-adopters. Similarly, both intra-village and inter-village network degrees are higher for adopters than for non-adopters. For maize, only the inter-village network degree differs significantly between adopters and non-adopters. The proportion of farmers with ties to extension officers is higher for growers of improved varieties than for growers of traditional varieties for both crops. For maize, adopters of improved varieties have more frequent communication with members of the 
village administration compared to non-adopters. Finally, the proportion of farmers with membership in a community group or association that engages in some agricultural activities is significantly higher for adopters of improved varieties of both crops.

Table 4.2: Descriptive statistics for variables used in the technical inefficiency models

\begin{tabular}{|c|c|c|c|c|c|}
\hline \multirow[t]{2}{*}{ Variable } & \multirow[t]{2}{*}{ Description } & \multicolumn{2}{|c|}{ Sorghum } & \multicolumn{2}{|c|}{ Maize } \\
\hline & & $\begin{array}{l}\text { Traditional } \\
(\mathrm{N}=169)\end{array}$ & $\begin{array}{l}\text { Improved } \\
(\mathrm{N}=62)\end{array}$ & $\begin{array}{l}\text { Traditional } \\
(\mathrm{N}=106)\end{array}$ & $\begin{array}{l}\text { Improved } \\
(\mathrm{N}=181)\end{array}$ \\
\hline \multicolumn{6}{|l|}{ Informal Networks } \\
\hline $\begin{array}{l}\text { Sorghum network } \\
\text { degree }\end{array}$ & $\begin{array}{l}\text { Total sorghum network degree (no. of links out of all } \\
\text { six random matches) }\end{array}$ & $\begin{array}{l}1.09 \\
(1.36)\end{array}$ & $\begin{array}{l}1.86^{* * * *} \\
(1.62)\end{array}$ & & \\
\hline $\begin{array}{l}\text { Sorghum network } \\
\text { degree1 }\end{array}$ & $\begin{array}{l}\text { Intra-village sorghum network degree (no. of links } \\
\text { out of three random matches within the village) }\end{array}$ & $\begin{array}{l}0.92 \\
(1.07)\end{array}$ & $\begin{array}{l}1.47 * * * \\
(1.10)\end{array}$ & & \\
\hline $\begin{array}{l}\text { Sorghum network } \\
\text { degree } 2\end{array}$ & $\begin{array}{l}\text { Inter-village sorghum network degree (no. of links } \\
\text { out of three random matches outside the village) }\end{array}$ & $\begin{array}{l}0.17 \\
(0.52)\end{array}$ & $\begin{array}{l}0.39 * * * \\
(0.84)\end{array}$ & & \\
\hline $\begin{array}{l}\text { Maize network } \\
\text { degree }\end{array}$ & $\begin{array}{l}\text { Total maize network degree (no. of links out of all } \\
\text { six random matches) }\end{array}$ & & & $\begin{array}{l}0.95 \\
(1.30)\end{array}$ & $\begin{array}{l}1.14 \\
(1.49)\end{array}$ \\
\hline $\begin{array}{l}\text { Maize network } \\
\text { degree } 1\end{array}$ & $\begin{array}{l}\text { Intra-village maize network degree (no. of links out } \\
\text { of three random matches within the village) }\end{array}$ & & & $\begin{array}{l}0.81 \\
(1.09)\end{array}$ & $\begin{array}{l}0.91 \\
(1.09)\end{array}$ \\
\hline $\begin{array}{l}\text { Maize network } \\
\text { degree } 2\end{array}$ & $\begin{array}{l}\text { Inter-village maize network degree (no. of links out } \\
\text { of three random matches outside the village) }\end{array}$ & & & $\begin{array}{l}0.14 \\
(0.45)\end{array}$ & $\begin{array}{l}0.24 * \\
(0.63)\end{array}$ \\
\hline $\begin{array}{l}\text { Association } \\
\text { membership }\end{array}$ & $\begin{array}{l}\text { Household head is a member of a community } \\
\text { association that engages in agricultural activities }\end{array}$ & $\begin{array}{l}0.10 \\
(029)\end{array}$ & $\begin{array}{l}0.21 * * * \\
(0.41)\end{array}$ & $\begin{array}{l}0.08 \\
(0.27)\end{array}$ & $\begin{array}{l}0.13^{*} \\
(0.34)\end{array}$ \\
\hline \multicolumn{6}{|l|}{ Formal Networks } \\
\hline Extension link & $\begin{array}{l}\text { Talks with public extension officer at least once per } \\
\text { month ( } 1=\text { Yes; } 0=\text { otherwise })\end{array}$ & $\begin{array}{l}0.65 \\
(0.48)\end{array}$ & $\begin{array}{l}0.74 * \\
(0.44)\end{array}$ & $\begin{array}{l}0.56 \\
(0.50)\end{array}$ & $\begin{array}{l}0.68 * * \\
(0.47)\end{array}$ \\
\hline Admin link & $\begin{array}{l}\text { Strength of links with village administration (no. of } \\
\text { contact days per month with a village administrator) }\end{array}$ & $\begin{array}{l}13.7 \\
(9.97)\end{array}$ & $\begin{array}{l}14.3 \\
(8.96)\end{array}$ & $\begin{array}{l}12.4 \\
(8.91)\end{array}$ & $\begin{array}{l}14.7 * * \\
(10.1)\end{array}$ \\
\hline \multicolumn{6}{|c|}{ Other farmer/farm characteristics } \\
\hline $\begin{array}{l}\text { Farming } \\
\text { experience }\end{array}$ & Experience in own farming activities (years) & $\begin{array}{l}25.6 \\
(11.5)\end{array}$ & $\begin{array}{l}24.6 \\
(9.86)\end{array}$ & $\begin{array}{l}25.3 \\
(12.5)\end{array}$ & $\begin{array}{l}26.1) \\
(10.8)\end{array}$ \\
\hline $\begin{array}{l}\text { Maize farming } \\
\text { experience }\end{array}$ & Maize farming experience (years) & & & $\begin{array}{l}21.9 \\
(12.1)\end{array}$ & $\begin{array}{l}22.7 \\
(11.5)\end{array}$ \\
\hline Land owned & Total land owned (Ha) & $\begin{array}{l}4.16 \\
(4.82)\end{array}$ & $\begin{array}{l}6.04 * * \\
(9.31)\end{array}$ & $\begin{array}{l}3.81 \\
(5.65)\end{array}$ & $\begin{array}{l}5.13 \\
(6.17)\end{array}$ \\
\hline Plots & Number of sorghum (maize) plots cultivated & $\begin{array}{l}1.54 \\
(0.76)\end{array}$ & $\begin{array}{l}1.66 \\
(0.70)\end{array}$ & $\begin{array}{l}1.14 \\
(0.51)\end{array}$ & $\begin{array}{l}1.50 * * * \\
(0.69)\end{array}$ \\
\hline Radio & Household owns a radio ( $1=$ yes; $0=$ otherwise) & $\begin{array}{l}0.75 \\
(0.43)\end{array}$ & $\begin{array}{l}0.69 \\
(0.47)\end{array}$ & $\begin{array}{l}0.68 \\
(0.47)\end{array}$ & $\begin{array}{l}0.79 * * \\
(0.41)\end{array}$ \\
\hline Nonfarm income & Household head earns a non-farm income & $\begin{array}{l}0.43 \\
(0.50)\end{array}$ & $\begin{array}{l}0.39 \\
(0.49)\end{array}$ & $\begin{array}{l}0.37 \\
(0.49)\end{array}$ & $\begin{array}{l}0.40 \\
(0.49)\end{array}$ \\
\hline Livestock wealth & $\begin{array}{l}\text { Total value of livestock owned (Millions of } \\
\text { Shillings. 1,560 Shillings=1USD during survey) }\end{array}$ & $\begin{array}{l}2.15 \\
(3.45)\end{array}$ & $\begin{array}{l}2.32 \\
(3.43)\end{array}$ & $\begin{array}{l}2.45 \\
(4.31)\end{array}$ & $\begin{array}{l}2.16 \\
(3.10)\end{array}$ \\
\hline Tech2011 & $\begin{array}{l}\text { Attended a technology/information dissemination } \\
\text { event in } 2011\end{array}$ & $\begin{array}{l}0.45 \\
(0.50)\end{array}$ & $\begin{array}{l}0.68 * * * \\
(0.47)\end{array}$ & $\begin{array}{l}0.39 \\
(0.49)\end{array}$ & $\begin{array}{l}0.50 * * \\
(0.50)\end{array}$ \\
\hline
\end{tabular}

Note: Figures are mean values, with their standard deviations in parenthesis. ${ }^{*}, * * * * *$ differences in means between traditional and improved varieties are significant at 10,5 and $1 \%$ respectively.

Turning to respondent and household characteristics, we find that farming experience of respondents is about 25 years and crop-specific farming experience does not differ much from overall experience. Furthermore, adopters of improved sorghum tend be wealthier - 
they own more land (6.0 ha) than growers of traditional varieties (4.2 ha). Adopters of improved maize have significantly more maize plots than non-adopters, but the difference in number of sorghum plots does not differ significantly between adopters and non-adopters of improved sorghum. Ownership of radios is higher among adopters for the case of maize, but does not differ between adopters and non-adopters of improved sorghum.

\subsection{Results}

\subsubsection{Results for the propensity score matching}

Results for the logit models are shown in Table A2 in the appendix. We summarize the matching quality in Table 4.3. The test for the balancing of covariates shows that the bias drops well below $10 \%$ after matching. The mean bias reduced by $83.5 \%$ for sorghum and $61 \%$ for maize. In addition, the Pseudo R-squared values of the Logit models were reduced to less than 5\%, while the LR Chi-squared values dropped to statistically insignificant levels, implying that matched improved and traditional variety plots do not differ systematically with respect to observable physical and management characteristics. The critical values of gamma at $10 \%$ level of significance are about 2.3 for sorghum and 2.0 for maize. This means, if there is an unobserved variable that is significantly influencing adoption of ICVs, then its value must at least double, to invalidate our results. We hence conclude that PSM substantially reduced covariate biases and is quite robust to hidden bias. The distribution of the propensity scores is shown in Figure 2 indicating sufficient common support. Detailed results on covariate balancing are reported in the Appendix (Table A3).

Table 4.3: Matching quality

\begin{tabular}{|c|c|c|c|c|c|c|}
\hline \multirow[t]{2}{*}{ Variable } & \multicolumn{3}{|l|}{ Sorghum } & \multicolumn{3}{|l|}{ Maize } \\
\hline & $\begin{array}{l}\text { Before } \\
\text { matching }\end{array}$ & $\begin{array}{l}\text { After } \\
\text { matching }\end{array}$ & $\begin{array}{l}\text { Bias } \\
\text { reduction }\end{array}$ & $\begin{array}{l}\text { Before } \\
\text { matching }\end{array}$ & $\begin{array}{l}\text { After } \\
\text { matching }\end{array}$ & $\begin{array}{l}\text { Bias } \\
\text { reduction }\end{array}$ \\
\hline \multicolumn{7}{|l|}{ Biases } \\
\hline Median bias (\%) & 21.3 & 5.9 & $72.3 \%$ & 17.7 & 8.0 & $53.2 \%$ \\
\hline Mean bias (\%) & 26.0 & 4.3 & $83.5 \%$ & 20.5 & 8.0 & $61.0 \%$ \\
\hline Pseudo $\mathrm{R}^{2}$ & 0.20 & 0.02 & & 0.23 & 0.04 & \\
\hline LR Chi squared & 54.5 & 3.20 & & 85.9 & 18.5 & \\
\hline p> Chi squared & 0.00 & 0.99 & & 0.00 & 0.49 & \\
\hline \multicolumn{7}{|l|}{ Bounding } \\
\hline Critical Gamma $(\Gamma)$ at $5 \%$ & & $1.9-2.0$ & & & $1.7-1.8$ & \\
\hline Critical Gamma $(\Gamma)$ at $10 \%$ & & $2.2-2.3$ & & & $1.9-2.0$ & \\
\hline
\end{tabular}




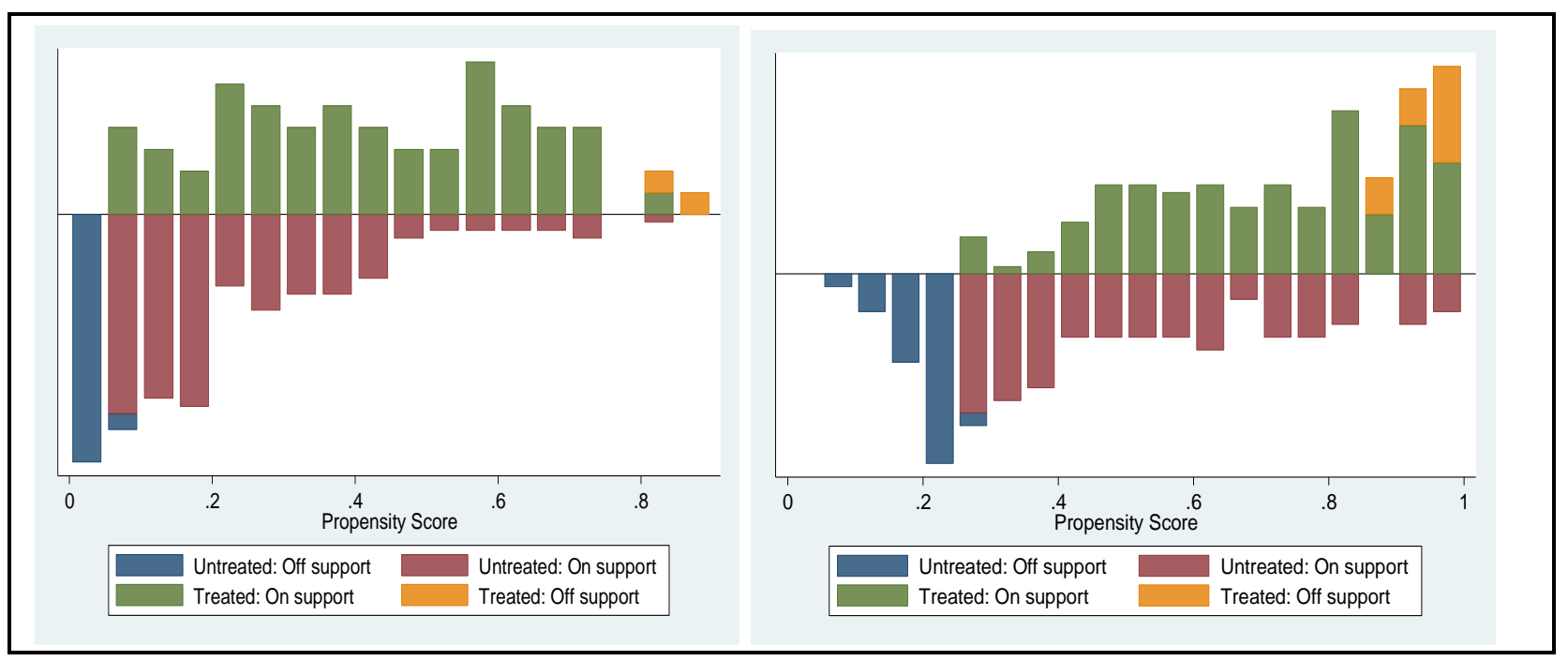

Figure 4.2: Distribution of propensity scores for sorghum (left) and maize (right), showing common support.

\subsubsection{Results for technical efficiency analysis}

For each crop, we estimated a pooled model and separate models for traditional and improved varieties using the matched samples. To test the effect of social networks, we included different proxies into the model. We begin our discussion with results of the frontier models presented in Table 4.4. The first three models of each crop (models 1-3 and 6-8) use the total crop (sorghum/maize) network degree, while in the last two models (4-5 and 9-10) we split the network into intra- and inter-village network degrees. Variance estimators provided at the bottom of the table show that $\lambda$ is greater than one, implying that variation of output is more due to inefficiency than random errors. Based on the likelihood ratio (LR) test statistics (chibar2) we reject the null hypotheses that $\sigma_{-} \mathrm{u}=0$ in all models, implying that the component of inefficiency in the composed error is significant. The estimated coefficients for all discretionary inputs (land, labor and seeds) have the expected positive signs in all models. The pooled models reveal that improved sorghum varieties have no significant effect on the yield, contrary to our hypothesis. Maredia, Byerlee and Pee (2000) demonstrate that in SubSaharan Africa, yield gains from use of improved sorghum varieties are likely to be marginal in drier regions, if, like in our study, other inputs especially inorganic fertilizers are not used. However, for maize, improved varieties produced about $43 \%$ more grain than traditional varieties, which is comparable to a nationally representative figure of 38\% (Lyimo, et al., 2014). Turning to the seed technology-specific models, results show that grain yields of improved varieties of both crops are more sensitive to environmental factors than traditional ones, suggesting that yields of traditional varieties are stable over a wider range of growing conditions than those of improved varieties. 
Table 4.4: Results of the production frontier models

\begin{tabular}{|c|c|c|c|c|c|c|c|c|c|c|}
\hline \multirow{3}{*}{ Variable } & \multicolumn{5}{|c|}{ Sorghum } & \multicolumn{5}{|l|}{ Maize } \\
\hline & \multicolumn{5}{|c|}{$\begin{array}{r}\text { Total sorghum network degree Intra- vs. inter- village } \\
\text { sorghum network degree }\end{array}$} & \multicolumn{3}{|c|}{ Total maize network degree } & \multicolumn{2}{|c|}{$\begin{array}{l}\text { Intra-vs. inter-village } \\
\text { maize network degree }\end{array}$} \\
\hline & $\begin{array}{l}\text { Pooled } \\
(1)\end{array}$ & $\begin{array}{l}\text { Traditional } \\
(2)\end{array}$ & $\begin{array}{l}\text { Improved } \\
\text { (3) }\end{array}$ & $\begin{array}{l}\text { Traditional } \\
(4)\end{array}$ & $\begin{array}{l}\text { Improved } \\
(5)\end{array}$ & $\begin{array}{l}\text { Pooled } \\
(6)\end{array}$ & $\begin{array}{l}\text { Traditional } \\
(7)\end{array}$ & $\begin{array}{l}\text { Improved } \\
(8)\end{array}$ & $\begin{array}{l}\text { Traditional } \\
(9)\end{array}$ & $\begin{array}{l}\text { Improved } \\
(10)\end{array}$ \\
\hline Land & $\begin{array}{l}0.46^{* * *} \\
(0.12)\end{array}$ & $\begin{array}{l}0.28^{* *} \\
(0.12)\end{array}$ & $\begin{array}{l}0.60^{* *} \\
(0.26)\end{array}$ & $\begin{array}{l}0.27^{* *} \\
(0.12)\end{array}$ & $\begin{array}{l}0.63^{\text {** }} \\
(0.26)\end{array}$ & $\begin{array}{l}0.47^{* * *} \\
(0.09)\end{array}$ & $\begin{array}{l}0.52^{* * *} \\
(0.11)\end{array}$ & $\begin{array}{l}0.47^{* * *} \\
(0.12)\end{array}$ & $\begin{array}{l}0.52^{* * *} \\
(0.11)\end{array}$ & $\begin{array}{l}0.44^{\text {*** }} \\
(0.13)\end{array}$ \\
\hline Labor & $\begin{array}{l}0.20^{* * *} \\
(0.07)\end{array}$ & $\begin{array}{l}0.35^{* * *} \\
(0.07)\end{array}$ & $\begin{array}{l}0.01 \\
(0.10)\end{array}$ & $\begin{array}{l}0.34^{* * *} \\
(0.07)\end{array}$ & $\begin{array}{l}0.06 \\
(0.11)\end{array}$ & $\begin{array}{l}0.09 \\
(0.08)\end{array}$ & $\begin{array}{l}0.01 \\
(0.13)\end{array}$ & $\begin{array}{l}0.07 \\
(0.12)\end{array}$ & $\begin{array}{l}0.01 \\
(0.13)\end{array}$ & $\begin{array}{l}0.10 \\
(0.12)\end{array}$ \\
\hline Seed & $\begin{array}{l}0.24^{* * * *} \\
(0.09)\end{array}$ & $\begin{array}{l}0.23^{* *} \\
(0.10)\end{array}$ & $\begin{array}{l}0.10 \\
(0.22)\end{array}$ & $\begin{array}{l}0.24^{* *} \\
(0.10)\end{array}$ & $\begin{array}{l}0.08 \\
(0.23)\end{array}$ & $\begin{array}{l}0.32^{* * * *} \\
(0.07)\end{array}$ & $\begin{array}{l}0.36^{* * *} \\
(0.12)\end{array}$ & $\begin{array}{l}0.30^{* * *} \\
(0.10)\end{array}$ & $\begin{array}{l}0.36^{* * *} \\
(0.12)\end{array}$ & $\begin{array}{l}0.31^{* * * *} \\
(0.10)\end{array}$ \\
\hline Improved & $\begin{array}{l}-0.14 \\
(0.14)\end{array}$ & & & & & $\begin{array}{l}0.43^{* * * *} \\
(0.11)\end{array}$ & & & & \\
\hline Clay soil & $\begin{array}{l}0.24 \\
(0.15)\end{array}$ & $\begin{array}{l}0.15 \\
(0.17)\end{array}$ & $\begin{array}{l}0.58^{* *} \\
(0.25)\end{array}$ & $\begin{array}{l}0.13 \\
(0.17)\end{array}$ & $\begin{array}{l}0.64^{* *} \\
(0.25)\end{array}$ & $\begin{array}{l}-0.02 \\
(0.12)\end{array}$ & $\begin{array}{l}0.02 \\
(0.21)\end{array}$ & $\begin{array}{l}0.14 \\
(0.16)\end{array}$ & $\begin{array}{l}0.02 \\
(0.21)\end{array}$ & $\begin{array}{l}0.11 \\
(0.16)\end{array}$ \\
\hline Loam soil & $\begin{array}{l}-0.09 \\
(0.17)\end{array}$ & $\begin{array}{l}0.14 \\
(0.17)\end{array}$ & $\begin{array}{l}-0.03 \\
(0.46)\end{array}$ & $\begin{array}{l}0.12 \\
(0.17)\end{array}$ & $\begin{array}{l}-0.06 \\
(0.47)\end{array}$ & $\begin{array}{l}0.12 \\
(0.14)\end{array}$ & $\begin{array}{l}0.23 \\
(0.25)\end{array}$ & $\begin{array}{l}0.28^{*} \\
(0.16)\end{array}$ & $\begin{array}{l}0.21 \\
(0.25)\end{array}$ & $\begin{array}{l}0.27^{*} \\
(0.16)\end{array}$ \\
\hline Far plot & $\begin{array}{l}-0.30 \\
(0.19)\end{array}$ & $\begin{array}{l}0.14 \\
(0.21)\end{array}$ & $\begin{array}{l}-1.21^{* * *} \\
(0.45)\end{array}$ & $\begin{array}{l}0.14 \\
(0.21)\end{array}$ & $\begin{array}{l}-1.12^{* * *} \\
(0.42)\end{array}$ & $\begin{array}{l}0.17 \\
(0.15)\end{array}$ & $\begin{array}{l}0.48 \\
(0.30)\end{array}$ & $\begin{array}{l}0.15 \\
(0.17)\end{array}$ & $\begin{array}{l}0.48 \\
(0.30)\end{array}$ & $\begin{array}{l}0.16 \\
(0.18)\end{array}$ \\
\hline Kondoa & $\begin{array}{l}0.19 \\
(0.16)\end{array}$ & $\begin{array}{l}-0.03 \\
(0.21)\end{array}$ & $\begin{array}{l}0.44 \\
(0.34)\end{array}$ & $\begin{array}{l}-0.04 \\
(0.21)\end{array}$ & $\begin{array}{l}0.44 \\
(0.34)\end{array}$ & $\begin{array}{l}-0.04 \\
(0.18)\end{array}$ & $\begin{array}{l}0.07 \\
(0.28)\end{array}$ & $\begin{array}{l}-0.27 \\
(0.23)\end{array}$ & $\begin{array}{l}0.07 \\
(0.28)\end{array}$ & $\begin{array}{l}-0.26 \\
(0.23)\end{array}$ \\
\hline Constant & $\begin{array}{l}-1.39^{* * *} \\
(0.42)\end{array}$ & $\begin{array}{l}-2.52^{* * *} \\
(0.39)\end{array}$ & $\begin{array}{l}-0.51 \\
(0.68)\end{array}$ & $\begin{array}{l}-2.49^{* * *} \\
(0.39)\end{array}$ & $\begin{array}{l}-0.72 \\
(0.73) \\
\end{array}$ & $\begin{array}{l}-1.24^{* * *} \\
(0.43)\end{array}$ & $\begin{array}{l}-1.14^{* *} \\
(0.51)\end{array}$ & $\begin{array}{l}-0.76 \\
(0.63)\end{array}$ & $\begin{array}{l}-1.14^{* *} \\
(0.51)\end{array}$ & $\begin{array}{l}-0.90 \\
(0.66)\end{array}$ \\
\hline $\mathrm{N}$ & 196 & 136 & 60 & 136 & 60 & 237 & 79 & 158 & 79 & 158 \\
\hline$\sigma_{u}$ & 1.49 & 0.98 & 2.03 & 0.98 & 2.03 & 1.38 & 1.60 & 1.33 & 1.60 & 1.33 \\
\hline$\sigma_{w}$ & 0.42 & 0.49 & 0.00 & 0.49 & 0.00 & 0.48 & 0.24 & 0.50 & 0.24 & 0.50 \\
\hline$\lambda$ & 3.58 & 2.01 & $1.88 \mathrm{e}+07$ & 2.01 & $1.88 \mathrm{e}+07$ & 2.90 & 6.64 & 2.65 & 6.64 & 2.65 \\
\hline Chibar2 & $21.27 * * *$ & * $3.40 * *$ & $19.89 * * *$ & $3.40 * *$ & $19.89 * * *$ & $22.74 * * *$ & $* 16.80 * * *$ & $9.18 * * *$ & $16.80 * * *$ & $9.18 * * *$ \\
\hline
\end{tabular}

Note: In brackets are robust standard errors. $* \mathrm{p}<0.1, * *, \mathrm{p}<0.05, * * * \mathrm{p}<0.01$.

Table 4.5 shows the results of the technical inefficiency models including the determinants and levels of technical efficiency. The model numbers correspond to those in Table 4.4. Since it is our aim to compare the effects of model covariates between improved and traditional varieties, we discuss the results for the seed technology-specific models only. The results show that for sorghum, the total social network degree does not have any significant effect on technical efficiency. However, by splitting the social network degree (models 4-5) we find that the inter-village network degree has a significant positive effect on technical efficiency for improved varieties, while the intra-village network degree has no significant effect. This implies that a bigger sorghum network with other farmers outside the village may be a more important source of information on productivity-enhancing farming practices than intra-village links. These results agree with Schaefer (2010) who argues that strong ties within an established network (for instance, those in intra-village networks) can make such networks conservative and less exposed to new ideas. In a similar vein, Rauch (2010) posits that bridging network clusters (for example, establishing network links to other 
villages) produces synergies that lead to higher outcomes. Moreover, Van den Broeck and Dercon (2011) report using data from a Tanzanian village that farming techniques that farmers learnt from others outside the village were more likely to be applied than those learnt from other farmers inside the village. As mentioned earlier, previous studies that investigated the effects of social networks on technology diffusion primarily focused on intra-village networks, thus the potentially important role of inter-village networks may have been missed.

The strength of links with village administrators had a small and insignificant effect. Having links to agricultural extension officers and attending technology and information dissemination events had a positive effect on technical efficiency of improved varieties and a negative effect on efficiency of traditional varieties, but these effects were statistically insignificant. Lack of evidence of positive effects of extension services on technical efficiency is often reported in developing countries (Coelli, Rahman and Thirtle, 2002; Theriault and Serra, 2014). Possible explanations for this is that due to some infrastructural, institutional or cultural challenges, extension messages are not disseminated effectively, or a number of farmers may find it difficult to apply recommendations from extension workers (Davis, 2008). We hypothesized that farmers linked to agricultural officers or attending their events would receive more information and hence achieve higher technical efficiency. However, since improved varieties of sorghum are OPVs, and many farmers obtain seeds from their networks, it seems that information from these networks is more important for technical efficiency than that from formal sources such as extension officers and events.

Results for maize show that, when controlling for other information sources and producer characteristics, the maize network degree has a negative and significant effect on technical efficiency of traditional varieties, but no effect on technical efficiency of improved varieties (models 7-8). By disaggregating the network degree into intra- and inter-village degree (models 9-10), we show that the effect for traditional varieties is driven by information received from farmers inside the village. This is rather surprising, but we hypothesize that since adoption of improved maize in our sample is quite high, discussions about maize farming mostly entail new farming methods associated with improved varieties. Some of the methods may be unsuitable for traditional varieties leading to lower technical efficiency. The strength of farmer links with members of the village administration did not have any significant effect on technical efficiency. We find, however, that links to public extension officers and attending information and technology dissemination events had significant positive effects on technical efficiency for improved but not traditional varieties. 
Chapter 4: Effects of social networks on technical efficiency in smallholder agriculture:

The case of cereal producers Tanzania

This finding is consistent with our hypothesis in section 4.2.2. It highlights that the information disseminated through formal sources is specific to improved varieties and underscores the complementarity between ties with extension officers and other formal information dissemination approaches such as extension meetings or farmer field days.

Table 4.5: Determinants of technical inefficiency and estimated technical efficiency scores

\begin{tabular}{|c|c|c|c|c|c|c|c|c|c|c|}
\hline \multirow[t]{3}{*}{ Variable } & \multicolumn{3}{|c|}{ Sorghum } & \multicolumn{6}{|c|}{ Maize } & \\
\hline & \multicolumn{3}{|c|}{ Total sorghum network degree } & \multicolumn{2}{|c|}{$\begin{array}{l}\text { Intra- vs. inter- village } \\
\text { sorghum network degree }\end{array}$} & \multicolumn{3}{|c|}{ Total maize network degree } & \multicolumn{2}{|c|}{$\begin{array}{l}\text { Intra-vs. inter-village } \\
\text { maize network degree }\end{array}$} \\
\hline & $\begin{array}{l}\text { Pooled } \\
(1)\end{array}$ & $\begin{array}{c}\text { Traditional } \\
(2)\end{array}$ & $\begin{array}{l}\text { Improved } \\
(3)\end{array}$ & $\begin{array}{l}\text { Traditional } \\
\text { (4) }\end{array}$ & $\begin{array}{l}\text { Improved } \\
(5)\end{array}$ & $\begin{array}{l}\text { Pooled } \\
(6)\end{array}$ & $\begin{array}{c}\text { Traditional } \\
(7)\end{array}$ & $\begin{array}{c}\text { Improved } \\
(8)\end{array}$ & $\begin{array}{c}\text { Traditional } \\
(9)\end{array}$ & $\begin{array}{c}\text { Improved } \\
(10)\end{array}$ \\
\hline $\begin{array}{l}\text { Sorghum network } \\
\text { degree }\end{array}$ & $\begin{array}{l}-0.01 \\
(0.08)\end{array}$ & $\begin{array}{l}-0.02 \\
(0.13)\end{array}$ & $\begin{array}{l}-0.11 \\
(0.11)\end{array}$ & & & & & & & \\
\hline $\begin{array}{l}\text { Sorghum network } \\
\text { degree1 } \\
\text { Sorghum network } \\
\text { degree2 }\end{array}$ & & & & $\begin{array}{c}-0.17 \\
(0.26) \\
0.39 \\
(0.45)\end{array}$ & $\begin{array}{c}0.26 \\
(0.30) \\
-0.58^{* *} \\
(0.29)\end{array}$ & & & & & \\
\hline $\begin{array}{l}\text { Maize network } \\
\text { degree }\end{array}$ & & & & & & $\begin{array}{c}0.02 \\
(0.08)\end{array}$ & $\begin{array}{l}0.43^{* *} \\
(0.22)\end{array}$ & $\begin{array}{l}-0.09 \\
(0.10)\end{array}$ & & \\
\hline $\begin{array}{l}\text { Maize network } \\
\text { degree } 1\end{array}$ & & & & & & & & & $\begin{array}{l}0.47^{*} \\
(0.25)\end{array}$ & $\begin{array}{c}0.01 \\
(0.17)\end{array}$ \\
\hline $\begin{array}{l}\text { Maize network } \\
\text { degree2 }\end{array}$ & & & & & & & & & $\begin{array}{c}0.24 \\
(0.48)\end{array}$ & $\begin{array}{l}-0.33 \\
(0.29)\end{array}$ \\
\hline $\begin{array}{l}\text { Association } \\
\text { membership }\end{array}$ & $\begin{array}{c}0.08 \\
(0.37)\end{array}$ & $\begin{array}{l}-0.88 \\
(0.58)\end{array}$ & $\begin{array}{l}0.93^{*} \\
(0.49)\end{array}$ & $\begin{array}{l}-1.00 \\
(0.62)\end{array}$ & $\begin{array}{c}0.63 \\
(0.53)\end{array}$ & $\begin{array}{l}-0.07 \\
(0.38)\end{array}$ & $\begin{array}{l}-1.28 \\
(0.91)\end{array}$ & $\begin{array}{l}-0.27 \\
(0.46)\end{array}$ & $\begin{array}{l}-1.22 \\
(0.88)\end{array}$ & $\begin{array}{l}-0.23 \\
(0.46)\end{array}$ \\
\hline Admin link & $\begin{array}{c}0.01 \\
(0.01)\end{array}$ & $\begin{array}{l}-0.01 \\
(0.01)\end{array}$ & $\begin{array}{c}0.02 \\
(0.02)\end{array}$ & $\begin{array}{l}-0.01 \\
(0.02)\end{array}$ & $\begin{array}{c}0.03 \\
(0.03)\end{array}$ & $\begin{array}{c}0.01 \\
(0.01)\end{array}$ & $\begin{array}{c}0.00 \\
(0.02)\end{array}$ & $\begin{array}{c}0.01 \\
(0.01)\end{array}$ & $\begin{array}{l}-0.00 \\
(0.02)\end{array}$ & $\begin{array}{c}0.02 \\
(0.01)\end{array}$ \\
\hline Extension link & $\begin{array}{c}0.17 \\
(0.26)\end{array}$ & $\begin{array}{c}0.29 \\
(0.45)\end{array}$ & $\begin{array}{l}-0.58 \\
(0.45)\end{array}$ & $\begin{array}{c}0.36 \\
(0.49)\end{array}$ & $\begin{array}{l}-0.46 \\
(0.46)\end{array}$ & $\begin{array}{l}-0.63^{* *} \\
(0.26)\end{array}$ & $\begin{array}{l}-0.35 \\
(0.38)\end{array}$ & $\begin{array}{l}-0.58^{* *} \\
(0.28)\end{array}$ & $\begin{array}{l}-0.34 \\
(0.39)\end{array}$ & $\begin{array}{l}-0.63^{* *} \\
(0.29)\end{array}$ \\
\hline Tech2011 & $\begin{array}{c}0.10 \\
(0.22)\end{array}$ & $\begin{array}{c}0.34 \\
(0.37)\end{array}$ & $\begin{array}{l}-0.04 \\
(0.38)\end{array}$ & $\begin{array}{c}0.38 \\
(0.41)\end{array}$ & $\begin{array}{l}-0.13 \\
(0.43)\end{array}$ & $\begin{array}{l}-0.49^{* *} \\
(0.25)\end{array}$ & $\begin{array}{c}0.68 \\
(0.52)\end{array}$ & $\begin{array}{c}-0.88^{* * *} \\
(0.31)\end{array}$ & $\begin{array}{c}0.70 \\
(0.51)\end{array}$ & $\begin{array}{c}-0.97^{* * * *} \\
(0.33)\end{array}$ \\
\hline Radio & $\begin{array}{l}-0.21 \\
(0.25)\end{array}$ & $\begin{array}{l}-0.26 \\
(0.41)\end{array}$ & $\begin{array}{l}-0.27 \\
(0.45)\end{array}$ & $\begin{array}{l}-0.28 \\
(0.42)\end{array}$ & $\begin{array}{l}-0.41 \\
(0.42)\end{array}$ & $\begin{array}{l}-0.08 \\
(0.22)\end{array}$ & $\begin{array}{c}0.01 \\
(0.42)\end{array}$ & $\begin{array}{l}-0.15 \\
(0.33)\end{array}$ & $\begin{array}{c}0.03 \\
(0.45)\end{array}$ & $\begin{array}{l}-0.14 \\
(0.32)\end{array}$ \\
\hline Farming experience & $\begin{array}{l}0.02^{*} \\
(0.01)\end{array}$ & $\begin{array}{c}0.00 \\
(0.01)\end{array}$ & $\begin{array}{l}0.07^{* *} \\
(0.03)\end{array}$ & $\begin{array}{c}0.00 \\
(0.01)\end{array}$ & $\begin{array}{l}0.08^{* * *} \\
(0.03)\end{array}$ & & & & & \\
\hline $\begin{array}{l}\text { Maize farming } \\
\text { experience }\end{array}$ & & & & & & $\begin{array}{l}0.01^{*} \\
(0.01)\end{array}$ & $\begin{array}{l}-0.02 \\
(0.02)\end{array}$ & $\begin{array}{l}0.02^{*} \\
(0.01)\end{array}$ & $\begin{array}{l}-0.02 \\
(0.02)\end{array}$ & $\begin{array}{l}0.02^{*} \\
(0.01)\end{array}$ \\
\hline Non-farm income & $\begin{array}{c}0.08 \\
(0.24)\end{array}$ & $\begin{array}{l}0.94^{* *} \\
(0.42)\end{array}$ & $\begin{array}{l}-0.70^{*} \\
(0.39)\end{array}$ & $\begin{array}{l}1.01^{* *} \\
(0.48)\end{array}$ & $\begin{array}{l}-0.69^{* *} \\
(0.34)\end{array}$ & $\begin{array}{c}0.12 \\
(0.22)\end{array}$ & $\begin{array}{c}0.33 \\
(0.41)\end{array}$ & $\begin{array}{c}0.10 \\
(0.32)\end{array}$ & $\begin{array}{l}0.35 \\
(0.42)\end{array}$ & $\begin{array}{c}0.11 \\
(0.31)\end{array}$ \\
\hline Land owned & $\begin{array}{c}-0.09^{* * * *} \\
(0.03)\end{array}$ & $\begin{array}{c}-0.28^{* * *} \\
(0.10)\end{array}$ & $\begin{array}{l}-0.09^{* *} \\
(0.04)\end{array}$ & $\begin{array}{c}-0.33^{* * *} \\
(0.13)\end{array}$ & $\begin{array}{l}-0.07^{*} \\
(0.04)\end{array}$ & & & & & \\
\hline No of plots & $\begin{array}{l}0.39^{* *} \\
(0.17)\end{array}$ & $\begin{array}{c}0.14 \\
(0.21)\end{array}$ & $\begin{array}{l}0.73^{* * * *} \\
(0.24)\end{array}$ & $\begin{array}{c}0.14 \\
(0.23)\end{array}$ & $\begin{array}{l}0.82^{* * *} \\
(0.21)\end{array}$ & $\begin{array}{l}-0.33^{*} \\
(0.18)\end{array}$ & $\begin{array}{l}-1.74^{* *} \\
(0.74)\end{array}$ & $\begin{array}{l}-0.24 \\
(0.20)\end{array}$ & $\begin{array}{l}-1.72^{* *} \\
(0.74)\end{array}$ & $\begin{array}{l}-0.24 \\
(0.20)\end{array}$ \\
\hline Livestock wealth & $\begin{array}{c}0.01 \\
(0.05)\end{array}$ & $\begin{array}{l}-0.16^{* *} \\
(0.07)\end{array}$ & $\begin{array}{c}0.05 \\
(0.06)\end{array}$ & $\begin{array}{l}-0.15^{* *} \\
(0.07)\end{array}$ & $\begin{array}{l}-0.01 \\
(0.08)\end{array}$ & $\begin{array}{l}-0.01 \\
(0.04)\end{array}$ & $\begin{array}{c}-0.37^{* *} \\
(0.15)\end{array}$ & $\begin{array}{c}0.00 \\
(0.05)\end{array}$ & $\begin{array}{l}-0.36^{* *} \\
(0.16)\end{array}$ & $\begin{array}{l}-0.00 \\
(0.05)\end{array}$ \\
\hline Kondoa & $\begin{array}{l}1.31^{* * *} \\
(0.32)\end{array}$ & $\begin{array}{l}2.15^{* * * *} \\
(0.57)\end{array}$ & $\begin{array}{l}1.65^{* * *} \\
(0.47)\end{array}$ & $\begin{array}{l}2.23^{* * * *} \\
(0.60)\end{array}$ & $\begin{array}{l}1.46^{* * *} \\
(0.47)\end{array}$ & $\begin{array}{c}0.39 \\
(0.30)\end{array}$ & $\begin{array}{l}1.30^{* * *} \\
(0.63)\end{array}$ & $\begin{array}{l}-0.16 \\
(0.39)\end{array}$ & $\begin{array}{l}1.26^{* *} \\
(0.62)\end{array}$ & $\begin{array}{l}-0.17 \\
(0.39)\end{array}$ \\
\hline Constant & $\begin{array}{l}-0.94^{*} \\
(0.54) \\
\end{array}$ & $\begin{array}{l}-1.08 \\
(1.20) \\
\end{array}$ & $\begin{array}{l}-1.87^{*} \\
(1.00) \\
\end{array}$ & $\begin{array}{l}-1.18 \\
(1.21) \\
\end{array}$ & $\begin{array}{l}-2.88^{* * *} \\
(1.41)\end{array}$ & $\begin{array}{l}0.92^{* *} \\
(0.41)\end{array}$ & $\begin{array}{l}1.92^{*} \\
(1.06) \\
\end{array}$ & $\begin{array}{l}1.10^{* *} \\
(0.52)\end{array}$ & $\begin{array}{l}1.88^{*} \\
(1.06) \\
\end{array}$ & $\begin{array}{l}1.09^{* * *} \\
(0.51)\end{array}$ \\
\hline $\begin{array}{l}\text { Mean Technical } \\
\text { Efficiency }\end{array}$ & $\begin{array}{l}0.45 \\
(0.24)\end{array}$ & $\begin{array}{c}0.63 \\
(0.22)\end{array}$ & $\begin{array}{c}0.42 * * * \\
(0.28)\end{array}$ & $\begin{array}{c}0.65 \\
(0.22)\end{array}$ & $\begin{array}{c}0.43 * * * \\
(0.28)\end{array}$ & $\begin{array}{c}0.46 \\
(0.22)\end{array}$ & $\begin{array}{c}0.50 \\
(0.26)\end{array}$ & $\begin{array}{c}0.48 \\
(0.22)\end{array}$ & $\begin{array}{c}0.50 \\
(0.25)\end{array}$ & $\begin{array}{c}0.48 \\
(0.22)\end{array}$ \\
\hline $\mathrm{N}$ & 196 & 136 & 60 & 136 & 60 & 237 & 79 & 158 & 79 & 158 \\
\hline
\end{tabular}


Predicted technical efficiency (TE) scores are shown at the bottom of Table 4.5. Assuming common production technology for each crop, the pooled models show almost equal mean TE scores of about $45 \%$ for sorghum and $46 \%$ for maize. When making comparisons between the seed technology-specific models, we find that the mean TE for sorghum is significantly higher for traditional varieties $(63 \%$ and $65 \%)$ than for improved ones (42\% and 43\%). For maize, the TE scores are higher for traditional varieties, but this difference is not significant. These overall low TE scores imply that opportunities exist for farmers to increase their technical efficiency and hence productivity.

\subsection{Conclusions and policy implications}

This paper has investigated the role of social networks for technical efficiency of smallholder farmers, using the case of cereal producers in Tanzania. Unlike previous social network studies, which mostly focused on cash crops, we have looked at sorghum and maize, which are grown mainly for home consumption. While previous studies concentrated primarily on intra-village social networks, we have extended the approach and have also considered intervillage networks. We applied stochastic frontier analysis to simultaneously estimate the production frontiers and the determinants of technical efficiency after correcting for potential self-selection in adoption of improved varieties using propensity score matching.

Our results show that for sorghum, while the total and intra-village network degrees (proxies for farmer-to-farmer network size) do not significantly influence technical efficiency, the inter-village sorghum network degree has a positive effect on technical efficiency of improved but not of traditional varieties. For the case of maize, we find no significant effect of maize network degree on technical efficiency of improved varieties. However, for traditional varieties, the intra-village network degree has a significant negative effect on technical efficiency. This demonstrates that social network effects on technical efficiency vary by crop and seed technology. The strength of ties with village administrators does not have any significant effect on technical efficiency of either crop. Consistent with our hypothesis, we find that having links to public extension officers and attending information and technology dissemination events organized through the officers has a positive effect on technical efficiency for improved varieties, which is significant only for maize. This result shows that efficiency-enhancing production information for the largely commercialized seed technologies may be much more technical, hence requiring more specialized dissemination, than for the less commercialized technologies. Further results show that the average technical 
efficiency scores are below $50 \%$ for both crops, meaning there is potential for farmers to more than double their productivity. The mean technical efficiency score of traditional varieties exceeds that of improved varieties, although this is significant for sorghum only. This implies that information or other production constraints that limit efficient utilization of production inputs are more severe for growers of improved than of traditional varieties.

These findings raise a number of implications for policy and further research. First, the finding that social networks are a key determinant of technical efficiency of improved sorghum varieties calls for further research into how these networks can be best used to raise technical efficiency and consequently crop productivity. Special emphasis should be given to inter-village networks, whose role for agricultural outcomes is rarely assessed. In addition, since this study assessed the effect of only one farmer network characteristic (degree) due to data limitations, future studies could consider the effects of other network characteristics as well. Secondly, from the findings on the positive effect of extension links and attendance of technology and information transfer events on technical efficiency, it is imperative that interactions between farmers and extension officers are increased, perhaps by facilitating their mobility into the villages and having more officers and extension activities at the lower administrative levels. However, more research may be necessary to identify the most costeffective ways of doing this. Thirdly, since technical efficiency scores of both crops and seed technologies are generally low, there is need to train farmers on farming practices that can raise their technical efficiency and hence productivity. One strategy would be to investigate the extent to which recommended crop management practices are currently being applied by farmers and focus farmer advisory services on practices that need more attention. 


\section{Conclusions and policy implications}

\subsection{Main findings}

Global demand for food and agricultural products is on the rise and there is need to increase production to meet this growing demand. Smallholders, who form the majority of farmers around the world, will play a significant role in this regard. The use of modern technologies such as improved crop varieties is seen as key to increasing agricultural productivity and production, but in Sub-Saharan Africa traditional varieties still dominate smallholder farming, limiting the envisaged output and productivity gains. Lack of agricultural information is a major constraint to adoption of improved varieties, and the role of social networks in information diffusion and variety adoption is increasingly being studied. However, several gaps still exist in the literature. First, while existing studies shows that social networks influence technology diffusion, the effects seem to be technology and context specific. For instance, most studies assessing the role of social networks in technology adoption focus on cash crops, and the few that have looked at staple cereals investigate hybrids that have functional private seed markets. Hence, it remains largely unknown what role social networks would play in situations where seed markets are weak or non-existent. Secondly, the concrete role of social networks in exposing farmers to improved technologies has not been investigated, yet exposure is a pre-condition for technology adoption. Thirdly, social networks have been shown to disseminate information that can potentially effect agricultural production, but no studies have investigated the role of social networks in productive efficiency of farms. Finally, although there is documented evidence that social networks cross geographical boundaries such as villages, most social network studies in agriculture focus on intra-village networks, ignoring inter-village networks that could play a significant role.

Thus, this study has contributed to the available literature by making at attempt to fill the above mentioned gaps, using data collected from 345 cereal growers Central Tanzania between September and November 2012, as an example. We focus on sorghum and maize, the staple cereals in the central region of the country. Sorghum ICVs available in Tanzania are purely open pollinated variety (OPV) technologies characterized by underdeveloped private seed markets, while those of maize are largely hybrids, for which functional private seed markets exist. 
The main results are graphically summarized in Figure 5.1, where the arrows indicate evidence of social network effects on various outcomes for sorghum and maize. Our first objective was to assess the factors that determine the existence of network links for the exchange of agricultural information between farmers. Using 948 pairs of farmers (dyads) randomly drawn from our sample, we found that even at the lowest administrative unit, the sub-village, not all farmers know each other. Yet, even in the cases where both farmers in a random dyad are familiar with each other, exchange of agricultural information occurs in only about one third of such dyads. Most of this exchange occurs if the farmers are from the same village, but $17 \%$ of these discussions occur across village boundaries. Dyadic regression results show that farmers are more likely to exchange relevant agricultural information if they have similar levels of education, different farm sizes, are members of the same community association, live in the same village, have known each other for a longer time, or have kinship ties. Moreover, the probability of exchanging farming information increases if a community leader is involved or if one of the farmers has a direct link to a public extension officer. These patterns are almost the same for sorghum and maize, meaning that if farmers exchange information about farming, they are unlikely to limit this information exchange to certain crops.

The second objective was to examine the role of social networks in exposing farmers to improved sorghum and maize varieties and hybrids. We found more pronounced differences between the two crops. While farmers gain first knowledge of sorghum varieties through their networks with other farmers in only $28 \%$ of the cases, they get exposed to maize varieties through such networks in $50 \%$ of the cases. However, controlling for personal characteristics of farmers such as education, age, gender, and ownership of information and communication assets, we find that increasing the social network degree (proxy for size of a farmer's social network) increases farmers' intensity of exposure (number of varieties known) to improved sorghum varieties, but not of improved maize varieties. Further disaggregation showed that for maize, the effect differs between OPVs and hybrids: while social networks play a positive and significant role in farmers' exposure to maize OPVs, the result remains insignificant for hybrids. Given that sorghum varieties are also OPVs, we conclude that the flow of information through informal networks is more important for seed technologies for which formal markets fail. Ownership of radio through which private seed markets commonly advertise their products increases exposure to maize hybrids, suggesting that for the more commercialized technologies, seed markets play a greater role than social networks in creating awareness. Strikingly, inter-village networks play a larger role in 
generating awareness about new varieties than intra-village networks. This confirms our proposition that a potential role of inter-village social networks may have been missed in past studies. By networking with public extension officers and village administrators, farmers increase their exposure considerably. The marginal effects of extension officers are much larger than those of the farmer network variables, suggesting that informal information channels complement, but do not substitute awareness creation through formal channels.

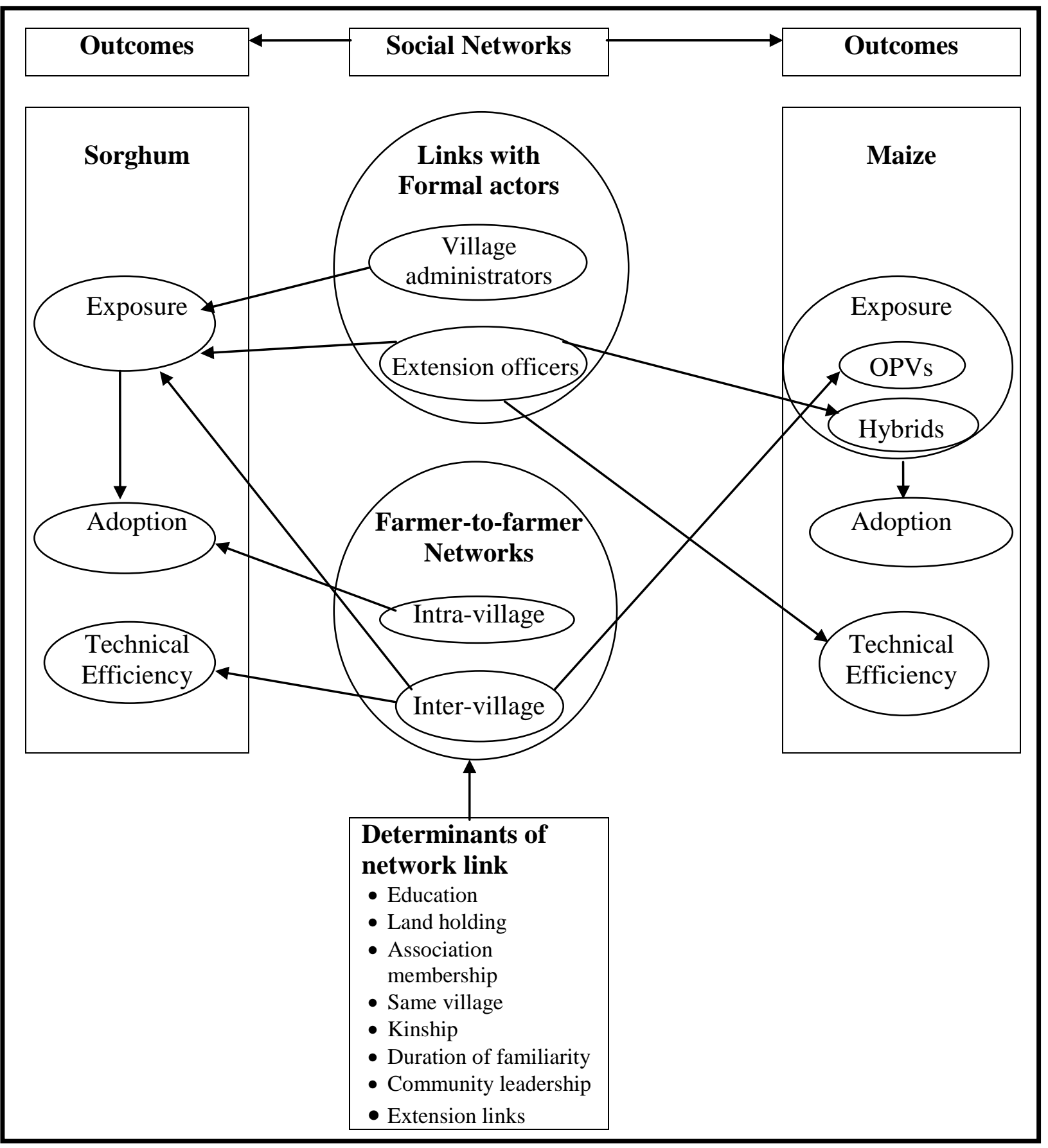

Figure 5.1: Effects of social networks on agricultural outcomes. Source: Author's impression from key results of the study. 
Having analyzed how farmers gain knowledge about improved varieties, and their level of exposure to them, our third objective was to analyze the determinants of adoption, focusing on the role of social networks. This was done based on the Diagne and Demont (2007) estimation framework that controls for non-exposure bias. We additionally control for household and farm characteristics such as demographic, wealth, and soil quality indicators. Results show that consistent with expectation, intensity of exposure positively influences adoption of improved varieties of both crops. Significant non-exposure biases confirm lack of exposure to be an important constraint to adoption. Results predict that adoption rates would increase by $9 \%-11 \%$, if all farmers were aware of the technologies. Interestingly, even after accounting for the role of social networks in exposure, and controlling for the intensity of exposure, we find that social networks for sorghum have a positive effect on variety adoption. This result implies that other than the learning effects of social networks (by which farmers expose each other to improved varieties), social influence could also play a role in sorghum adoption. Moreover, since improved sorghum varieties are not normally sold in formal seed markets, farmer networks could influence adoption by acting as seed sources for some farmers. We do not find significant social network effects on adoption of improved maize varieties, implying that influence of social networks on adoption is greater for improved varieties whose markets often fail. This is further supported by a positive influence of nonfarm income on adoption of improved maize, which implies that additional income from nonfarm activities could have been used to purchase seeds from formal markets as opposed to sourcing them from other farmers. Surprisingly, we find that contrary to the influence of social networks on exposure, it is the intra-village and not inter-village networks that produce this effect for sorghum. It means that while inter-village networks are more important for learning about new varieties as shown above, intra-village networks play a more important role in adoption, perhaps because it is easier to see and judge varieties grown inside than outside the village. Network links with village administrators or extension officers do not influence adoption once their role in exposure is controlled for, meaning that these communication channels are more relevant for raising awareness about the technologies.

The fourth objective of this study was to investigate the role of social networks in technical efficiency, which we compare between improved and traditional varieties. Using data from 231 plots of sorghum and 287 of maize, we applied stochastic frontier analysis after correcting for potential self-selection in adoption of improved varieties using propensity score matching. Our results show that for sorghum, while the total and intra-village network degrees (proxies for network size) do not significantly influence technical efficiency, the 
inter-village sorghum network degree has a positive effect on technical efficiency of improved but not of traditional varieties. For the case of maize, we find no significant effect of network degree on technical efficiency of improved varieties. However, for traditional varieties, the intra-village network degree has a significant negative effect on technical efficiency. This demonstrates social network effects on technical efficiency are dependent on crop and seed technology type. When comparing social network effects between improved varieties of the two crops, we conclude that the effects are more relevant for the varieties that do not have functioning private seed markets, consistent with the findings we discuss for exposure and adoption. Moreover, it shows that information from other villages may be much more novel for the respondent, than that coming from his/her village. Strength of ties with village administrators does not have any significant effect on technical efficiency of either crop. But consistent with our hypothesis, we find that having links to public extension officers and attending events organized through the officers has a positive effect on technical efficiency for improved varieties, which is significant only for maize. This shows that efficiency-enhancing production information for the largely commercialized seed technologies may be much more technical, hence requiring more specialized dissemination.

\subsection{Implications of the study}

This study has established that the levels of exposure, adoption and technical efficiency of improved varieties are still low and need to be addressed if full benefits of the technologies are to be realized. The findings raise a number of implications for policy and future research. First, social networks matter for the spread and efficient utilization of new agricultural technologies. Further, the role that social networks play for the spread and efficient utilization of new technologies differs by type of crop and technology: they seem to be more important for technologies that are not promoted by the private sector and for which formal markets fail. Technology dissemination programs should hence try to make use of such networks.

Second, the finding that inter-village networks matter for farmers' exposure to and technical efficiency of improved varieties points to the potential that facilitation of information exchange across village boundaries may have for awareness creation and the spread of new technologies. Follow-up studies should explicitly analyze the formation and functioning of inter-village social networks.

Third, farmers seem to discuss agricultural farming more with community leaders, while their links to village administrators in particular, play a role in creating awareness to improved varieties. Hence, the power of farmer networks with community leaders and village 
administrators can be exploited, which calls for research into the possibility of targeting the farms of these leaders for demonstration plots, and increasing their exposure to improved varieties through facilitated forums such as seminars, agricultural shows and meetings with seed traders.

Fourth, we find a positive effect of extension officers in facilitating discussions about crop farming, creating awareness and technical efficiency of improved technologies. This implies that formal extension programs can be complemented, but not replaced by social networks. Therefore, new extension models could be developed that explicitly build on the synergies between formal and informal information channels. Much more research is needed to establish what type of extension model is cost-effective in a particular situation. Our results suggest that an intensive training of lead farmers, who then pass on their knowledge to other farmers, may be more effective than assuming that snowball effects across multiple network nodes would occur automatically. Modeling this around farmer associations and well managed demonstration plots may be one promising approach.

\subsection{Limitations of the study and further research}

The results of this study have enabled us to draw important general implications as stated above. Nevertheless, we acknowledge some key limitations and suggest how they could be addressed in future. First, our results are from a case study which is not representative of the entire country or sorghum and maize growing areas. Rural Tanzania is ethnically and culturally diverse, meaning that formation and functioning of social networks may not follow the patterns discussed in this study, everywhere. More studies in other parts of the country can help to enrich our findings and in designing national agricultural extension policies that incorporate social networks. Second, our study is based on cross-sectional data and some of the results may have been influenced by prevailing weather conditions in the season studied. Panel studies could help to capture longer-term effects of social networks and further reduce unobserved heterogeneity caused by time invariant factors. Third, the farmer-to-farmer networks used here are only sampled and obviously do not reflect exactly what happens in the real networks themselves. It may be the case that some farmers rely on very specific networks which cannot be adequately captured by a sampled network. The methodology for sampling networks is still developing and future studies should pay attention on how to collect more data on these specific networks. Finally, this study did not assess the specific kind of farming information that farmers exchange, beyond the names of improved varieties. Studies in the future could investigate information exchange on key farming practices and 
perhaps the extent to which such information is applied. This may shed light on which information farmers can easily and effectively exchange, and which information requires specialized dissemination, perhaps by extension officers or other players in the pluralistic provision of farmer advisory services. 


\section{Bibliography}

Adesina, A.A., Djato, K.K., 1996. Farm size, relative efficiency and agrarian policy in Cote d'Ivoire: Profit function analysis of rice farms. Agricultural Economics 14, 93-102.

AGRA, 2010. Mid-term review of the Program for Africa's Seed Systems - Tanzania. The Alliance for a Green Revolution in Africa, Nairobi, Kenya. Accessed May 2013, available at http://www.agra.org/our-results/independent-evaluations.

Alene, A.D., Menkir, A., Ajala, S.O., Badu-Apraku, B., Olanrewaju, A.S., 2009. The economic and poverty impacts of maize research in West and Central Africa. Agricultural Economics 40(5), 535-550.

Alexandratos, N., Bruinsma, J., 2012. World agriculture towards 2030/2050: the 2012 revision. ESA Working Paper No. 12-03, Rome, Food and Agriculture Organization of the United Nations (FAO), Agricultural Development Economics Division.

Anandajayasekeram, P., Puskur, R., Workneh, S., Hoekstra, D., 2008. Concepts and practices in agricultural extension in developing countries: A source book. Washington, DC, International Food Policy Research Institute (IFPRI). Nairobi, Kenya, International Livestock Research Institute (ILRI).

Aye, G.C., Mungatana, E.D., 2010. Technical efficiency of traditional and hybrid maize farmers in Nigeria: Comparison of alternative approaches. African Journal of Agricultural Research 5(21), 2909-2917.

Baerenklau, K.A., 2005. Toward an understanding of technology adoption: Risk, learning, and neighborhood effects. Land Economics 81(1), 1-19.

Bandiera, O., Rasul, I., 2006. Social networks and technology adoption in Northern Mozambique. The Economic Journal 116, 869-902.

Barroga-Jamias, S., Brien, J.P., 1996. The Adoption of improved mungbean varieties in two rice-based villages in the Philippines: A network analysis. Philippine Journal of Crop Science 21(3), 93-104.

Bellon, M.R., Reeves, J., eds., 2002. Quantitative analysis of data from participatory methods in plant breeding. CIMMYT, Mexico, DF, Mexico. Accessed March 2013, available at http://repository.cimmyt.org/xmlui/handle/10883/909.

Besley, T., Case, A., 1993. Modeling technology adoption in developing countries. The American Economic Review 83(2), 396-402. 
Bindraban, P.S., Bulte, E., Giller, K., Meinke, H., Mol, A., van Oort, P., Oosterveer, P., van Keulen, H., Wollni, M., 2009. Beyond competition: Pathways for Africa's agricultural development. Report 242, Wageningen, Plant Research International.

Borgatti, S.P., 2005. Centrality and network flow. Social Networks 27, 55-71.

Borgatti, S.P., Mehra, A., Brass, D.J., Labianca, G., 2009. Network analysis in the social sciences. Science 323, 892-895.

Bruins, M., (2009). The evolution and contribution of plant breeding to global agriculture. In: UPOV, Responding to the challenges of a changing world: The role of new plant varieties and high quality seed in agriculture, Proceedings of the Second World Seed Conference held at the FAO Headquarters, Rome, September 8-10, 2009. Geneva, UPOV, pp 18-29.

Burt, R.S., 1987. Social contagion and innovation: Cohesion versus structural equivalence. American Journal of Sociology 92(6), 1287-1335.

Caliendo, M., Kopeinig, S., 2008. Some practical guidance for the implementation of propensity score matching. Journal of Economic Surveys 22(1), 31-72.

Cameron, A.C., Trivedi, P.K., 1998. Regression Analysis of Count Data. Cambridge University Press, New York, USA.

Cameron, A.C., Gelbach, J.B., Miller, D.L., 2011. Robust inference with multiway clustering. Journal of Business \& Economic Statistics 29(2), 238-249.

CGIAR, 2011. Forty findings on the impacts of CGIA R research, 1971-2011. Washington, D.C., USA: Consultative Group on International Agricultural Research (CGIAR) Fund Office, World Bank.

Chandrasekhar, A., Lewis, R., 2011. Econometrics of sampled networks. Unpublished manuscript, MIT. Accessed July 2012, Available at http://stanford.edu/ arungc/CL.pdf.

Christoplos, I., 2010. Mobilizing the Potential of Rural and Agricultural Extension. Rome, Italy, Food and Agriculture Organization of the United Nations (FAO), Office of Knowledge Exchange, Research and Extension, the Global Forum for Rural Advisory Services.

Coelli, T., Rahman, S., Thirtle, C., 2002. Technical, allocative, cost and scale efficiencies in Bangladesh rice cultivation: A non-parametric approach. Journal of Agricultural Economics 53(3), 607-626.

Coelli, T.J., Prasada Rao, D.S., O’Donnell, C.J., Battese, G.E., 2005. An Introduction to Efficiency and Productivity Analysis, $2^{\text {nd }}$ Edition. Springer, New York. 
Conley, T.G., Udry, C.R., 2010. Learning about a new technology: Pineapple in Ghana. American Economic Review 100(1), 35-69.

Crehan, K., 1997. The Fractured Community: Landscapes of Power and Gender in Rural Zambia. Berkeley and Los Angeles, California, University of California Press.

Davis, K.E., 2008. Extension in Sub-Saharan Africa: Overview and assessment of past and current models, and future prospects. Journal of International Agricultural and Extension Education 15(3): 15-28.

Dawson, P.J., Lingard, J., Woodford, C.H., 1991. A generalized measure of farm-specific technical efficiency. American Journal of Agricultural Economics 73(4), 1098-1104.

De Weerdt, J., 2004. Risk sharing and endogenous network formation. In: S. Dercon, ed., Insurance against Poverty. Oxford: Oxford University Press, pp 197-216.

Diagne, A., 2006. Diffusion and adoption of Nerica rice varieties in Côte d'Ivoire. The Developing Economies 44(2), 208-31.

Diagne, A., Demont, M., 2007. Taking a new look at empirical models of adoption: Average treatment effect estimation of adoption rate and its determinants. Agricultural Economics 37, 201-210.

Diagne, A., Sogbossi, M.-J., Simtowe, F., Diawara, S., Diallo, A.S., Barry, A.B., 2009. Estimation of actual and potential adoption rates and determinants of a new technology not universally known in the population: The case of NERICA rice varieties in Guinea. Contributed Paper prepared for presentation at the International Association of Agricultural Economists' 2009 Conference, Beijing, China, August 16-22 2009. Accessed January 2014, Available at http://purl.umn.edu/51644.

Dibba L., Diagne, A., Fialor, S.C., Nimoh, F., 2012. Diffusion and adoption of new rice varieties for Africa (Nerica) in The Gambia. African Crop Science Journal 20(1), 141153.

Dimara, E., Skuras, D., 2003. Adoption of agricultural innovations as a two-stage partial observability process. Agricultural Economics 28, 187-196.

DiPrete, T.A., Gangl, M., 2004. Assessing bias in the estimation of causal effects: Rosenbaum bounds on matching estimators and instrumental variables estimation with imperfect instruments. Sociological Methodology 34(1), 271-310.

Doss, C. R., Mwangi, W., Verkuijl, H., de Groote, H., 2003. Adoption of maize and wheat technologies in Eastern Africa: A Synthesis of the findings of 22 case studies. CIMMYT Economics Working Paper 03-06, Mexico, D.F., International Maize and Wheat Improvement Center (CIMMYT). 
Dufhues, T., Buchenrieder, G., Euler, D.G., Munkung, N., 2011. Network based social capital and individual loan repayment performance. Journal of Development Studies 47(8), 1199-1215.

Easley, D., Kleinberg, J., 2010. Networks, Crowds, and Markets: Reasoning About a Highly Connected World. Cambridge University Press, New York, USA.

Erenstein, O., Kassie, G.T., Langyintuo, A., Mwangi, W., 2011. Characterization of maize producing households in drought prone regions of Eastern Africa. CIMMYT. Socioeconomics Working Paper 1, Mexico, D.F., International Maize and Wheat Improvement Center (CIMMYT).

Fafchamps, M., Gubert, F., 2007. The formation of risk sharing networks. Journal of Development Economics 83, 326-350.

FAO, 2002. World Agriculture: Towards 2015/30. Summary report, Rome, Italy, Food and Agricultural Organization of the United Nations (FAO).

FAO, 2014. The State of Food and Agriculture: Innovation in Family Farming. Rome, Italy, Food and Agricultural Organization of the United Nations (FAO).

Feder, G., Just, R.E., Zilberman, D., 1985. Adoption of agricultural innovations in developing countries: A survey. Economic Development and Cultural Change 33(2), 255-298.

Fried, H.O., Lovell, C.A.K., Schmidt, S.S., 2008. Efficiency and productivity. In: H.O. Fried, C.A.K. Lovell and S.S. Schmidt, eds., The Measurement of Productive Efficiency and Productivity Growth. Oxford University Press, Oxford, pp. 3-91

Geroski, P.A. 2000. Models of technology diffusion. Research Policy 29, 603-625.

Gollin, D., Morris, M., Byerlee, D., 2005. Technology adoption in intensive post-green revolution systems. American Journal of Agricultural Economics 87(5), 1310-1316.

Goswami, R., Basu, D., 2010. Does information network affect technology diffusion? A study on the spread of banana and guava cultivation among farmers of Nadia District, West Bengal, India. Research Journal of Agriculture and Biological Sciences 6(6), 701707.

Granovetter, M. S., 1973. The strength of weak ties. American Journal of Sociology 78(6), 1360-1380.

Granovetter, M., 2005. The impact of social structure on economic outcomes. Journal of Economic Perspectives 19(1), 33-50.

Greene, W.H., 2008. The econometric approach to efficiency analysis. In: H.O. Fried, C.A.K. Lovell and S.S. Schmidt, eds., The Measurement of Productive Efficiency and Productivity Growth. Oxford University Press, Oxford, pp. 92-250. 
Greene, W.H., 2012. Econometric analysis. Pearson Education Limited, Essex, Great Britain.

Gutierrez, R. G., Carter, S., Drukker, D.M., 2001. On boundary-value likelihood-ratio tests. Stata Technical Bulletin 60, 15-18.

Handcock, M.S., Gile, K.J., 2010. Modeling social networks from sampled data. The Annals of Applied Statistics 4(1), 5-25.

Hanneman, R.A., Riddle, M., 2005. Introduction to social network methods. Riverside, CA: University of California, Riverside (published in digital form at http://www.faculty.ucr.edu/ hanneman/nettext/). Accessed in June 2012.

Hedström, P., Sandell, R., Stern, C., 2000. Mesolevel networks and the diffusion of social movements: The case of the Swedish social democratic party. American Journal of Sociology 106(1), 145-72 145.

Heinrich, G.M., Mgonja, M.A., 2002. Sorghum and Millet Improvement Program (SMIP) midterm review. International Sorghum and Millets Newsletter 43, 1-3.

Hogset, H., Barrett, C.B., 2010. Social learning, social influence, and projection bias: A caution on inferences based on proxy reporting of peer behavior. Economic Development and Cultural Change 589(3), 563-589.

Hossain, M., Jaim, W.M.H., Paris, T.R., Hardy, B., eds, 2012. Adoption and diffusion of modern rice varieties in Bangladesh and eastern India. Los Baños, Philippines, International Rice Research Institute.

House, L., Mullady, J., Lobb, A., House, M., 2007. The influence of culture on the impact of recommendations on product adoption: A cross-cultural social network study. Selected paper prepared for presentation at the American Agricultural Economics Association Annual Meeting, Portland, Oregon, July 29-31, 2007.

Huang, C.J., Bagi, F.S., 1984. Technical efficiency on individual farms in Northwest India. Southern Economic Journal 51(1), 108-115.

Jondrow, J., Lovell, C.A.K., Materov, I.S., Schmidt, P., 1982. On the estimation of technical inefficiency in the stochastic frontier production function model. Journal of Econometrics 19, 233-238.

Kabunga, N.S., Dubois, T., Qaim, M., 2012. Heterogeneous information exposure and technology adoption: The case of tissue culture bananas in Kenya. Agricultural Economics 43, 1-13.

Kijima, Y., Otsuka, K., Sserunkuuma, D., 2011. An inquiry into constraints on a Green Revolution in Sub-Saharan Africa: The case of NERICA rice in Uganda. World Development 39(1), 77-86. 
Krishna, V.V., Qaim, M., 2008. Potential impacts of Bt eggplant on economic surplus and farmers' health in India. Agricultural Economics 38, 167-180.

Kumbhakar, S.C., Lovell, C.A.K., 2000. Stochastic Frontier Analysis. Cambridge University Press, Cambridge, UK.

Lyimo, S., Mduruma, Z., De Groote, H., 2014. The use of improved maize varieties in Tanzania. African Journal of Agricultural Research 9(7), 643-657.

Maertens, A., Barrett, C.B., 2013. Measuring social networks effects on agricultural technology adoption. American Journal of Agricultural Economics 95(2), 353-359.

Mal, P., Anik, A.R., Bauer, S., Schmitz, P.M., 2012. Bt cotton adoption: A double-hurdle approach for North Indian farmers. AgBioForum 15(3), 294-302.

Maredia, M.K., Byerlee, D., Pee, P., 2000. Impacts of food crop improvement research: Evidence from sub-Saharan Africa. Food Policy 25, 531-559.

Marin, A., Wellman, B., 2011. Social network analysis: An introduction. In: P. Carrington and J. Scott, eds., The SAGE Handbook of Social Network Analysis. London: Sage Publications, pp 11-25.

Matuschke, I., Qaim, M., 2009. The impact of social networks on hybrid seed adoption in India. Agricultural Economics 40, 493-505.

Mgonja, M.A., Monyo, E.S., 2002. Field days in Tanzania enhance regional spillover of models and technology developed in SMIP pilot countries. International Sorghum and Millets Newsletter 43, 4-6.

Monyo E.S., Ngereza J., Mgonja, M.A., Rohrbach, D.D., Saadan, H.M., Ngowi, P., 2004. Adoption of Improved Sorghum and Pearl Millet Technologies in Tanzania. Bulawayo, Zimbabwe, International Crops Research Institute for the Semi-Arid Tropics ICRISAT).

Mutter, R.L., Greene, W.H., Spector, W., Rosko, M.D., Mukamel, D.B., 2013. Investigating the impact of endogeneity on inefficiency estimates in the application of stochastic frontier analysis to nursing homes. Journal of Productivity Analysis 39:101-110.

Newman, M.J., 2010. Networks: An Introduction. Oxford University Press Inc., New York.

Nguezet, P.M.D., Diagne, A., Okoruwa, V.O., Ojehomon, V., 2011. Impact of improved rice technology (NERICA varieties) on income and poverty among rice farming households in Nigeria: A local average treatment effect (LATE) approach. Quarterly Journal of International Agriculture 50(3), 267-291. 
Ngwediagi, P., Maeda, E., Kimomwe, H., Kamara, R., Massawe S., Akonaay, H.B., Mapunda, L.N.D., 2010. Tanzania report on the state of plant genetic resources for food and agriculture 2009, Prepared for The Second Report on the State of the World's Plant Genetic Resources for Food and Agriculture. Rome, Italy, Food and Agricultural organization of the United Nations (FAO). Accessed October 2014, Available at www.fao.org/docrep/013/i1500e/i1500e01.htm.

Petersen, M.A., 2009. Estimating standard errors in finance panel data sets: Comparing approaches. The Review of Financial Studies 22 (1), 435-480.

Rakotoarisoa, M., Iafrate, M., Paschali, M., 2012. Why has Africa become a net food importer?: Explaining Africa's agriculture and food trade deficits. Rome, Italy, The Food and Agriculture Organization (FAO), Trade and Markets Division.

Ransom, J.K., Paudyal, K., Adhikari, K., 2003. Adoption of improved maize varieties in the hills of Nepal. Agricultural Economics 29, 299-305.

Rao, E.J.O., Brümmer, B., Qaim, M., 2012. Farmer participation in supermarket channels, production technology, and efficiency: The case of vegetables in Kenya. American Journal of Agricultural Economics 94(4), 891-912.

Rauch, J.E., 2010. Does network theory connect to the rest of us? A review of Matthew O. Jackson's Social and Economic Networks. Journal of Economic Literature 48(4), 980986.

Rosenbaum, P.R., 2005. Sensitivity analysis in observational studies. In: B.S. Everitt, and D.C. Howell, eds., Encyclopedia of Statistics in Behavioral Science 4, 1809-1814. John Wiley \& Sons Ltd, Chichester.

Rosenbaum, P.R., Rubin, D.B., 1983. The central role of the propensity score in observational studies for causal effects. Biometrika 70(1), 41-55.

Rowe, E.C., van Wijk, M.T., de Ridder, N., Giller, K.E., 2006. Nutrient allocation strategies across a simplified heterogeneous African smallholder farm. Agriculture, Ecosystems and Environment 116, 60-71.

Rubin, D.B., 1973. Matching to remove bias in observational studies. Biometrics 29, 159183.

Rusike, J., Twomlow, S., Freeman, H.A., Heinrich, G.M., 2006. Does farmer participatory research matter for improved soil fertility technology development and dissemination in Southern Africa? International Journal of Agricultural Sustainability 4(3), 176-192. 
Saha, L., Alan, L. H., Robert, S., 1994. Adoption of emerging technologies under output uncertainty. American Journal of Agricultural Economics 76, 836-846.

Saka, A.R., Mtukuso, A.P., Mbale, B.J., Phiri, I.M.G., 2008. The role of research-extensionfarmer linkages in vegetable production and development in Malawi. In: M.L. Chadha, M.O. Oluoch, A.R. Saka, A.P. Mtukuso, A.T. Daudi, eds, Vegetable Research and Development in Malawi, Review and Planning Workshop Proceedings, September 2324, 2003, Lilongwe Malawi. Shanhua, Taiwan, AVRDC - The World Vegetable Center, AVRDC Publication No. 08-705, pp. 71-86.

Santos, P., Barrett, C.B., 2008. What do we learn about social networks when we only sample individuals? Not much. Accessed June 2012, available at http://dx.doi.org/10.2139/ssrn.1141838.

Santos, P., Barrett, C.B., 2010. Interest, identity and information search in a dynamic rural economy. World Development 38(12), 1788-1796.

Schaefer, D.R., 2010. A Configurational approach to homophily using lattice visualization. Connections 30(2), 21-40.

Sherlund, S.M., Barrett, C.B., Adesina, A.A., 2002. Smallholder technical efficiency controlling for environmental production conditions. Journal of Development Economics 69, 85-101.

Shiferaw, B.A, Kebede, T.A., You, L., 2008. Technology adoption under seed access constraints and the economic impacts of improved pigeonpea varieties in Tanzania. Agricultural Economics 39, 309-323.

Simtowe, F., Kassie, M., Diagne, A., Asfaw, S., Shiferaw, B., Silim, S., Muange, E., 2011. Determinants of agricultural technology adoption: The case of improved pigeonpea varieties in Tanzania. Quarterly Journal of International Agriculture 50(4), 325-345.

Smale, M., Byerlee, D., Jayne, T., 2011. Maize Revolutions in Sub-Saharan Africa. Policy Research Working Paper 5659, Washington DC, The World Bank, Development Research Group, Agriculture and Rural Development Team.

Smith, K.P., Christakis, N.A., 2008. Social networks and health. Annual Review of Sociology 34, 405-429.

Solís, D., Bravo-Ureta, B.E., Quiroga, R.E., 2007. Soil conservation and technical efficiency among hillside farmers in Central America: A switching regression model. The Australian Journal of Agricultural and Resource Economics 51, 491-510. 
Sommer, R., Bossio, D., Desta, L., Dimes, J., Kihara, J., Koala, S., Mango, N., Rodriguez, D., Thierfelder, C., Winowiecki, L., 2013. Profitable and sustainable nutrient management systems for East and Southern African smallholder farming systems challenges and opportunities: A synthesis of the Eastern and Southern Africa situation in terms of past experiences, present and future opportunities in promoting nutrients use in Africa. Cali (Colombia), CIAT; The University of Queensland; QAAFI; CIMMYT.

Tan, S., Kruseman, G., Herrink, N., 2007. Land fragmentation and Smallholder rice farm's production costs in Jiangxi Province, China. In: M. Spoor, N. Heerink and F. Qu, Dragons With Clay Feet? Transition, Sustainable Land Use and Rural Environment in China and Vietnam. Lexington Books, Plymouth, UK, pp. 211-228.

Tatlonghari, G., Paris, T., Pede, V., Siliphouthone, I., Suhaeti, R., 2012. Seed and information exchange through social networks: The case of rice farmers of Indonesia and Lao PDR. Sociology Mind 2(2), 169-176.

Theriault, V., Serra, R., 2014. Institutional environment and technical efficiency: A stochastic frontier analysis of cotton producers in West Africa. Journal of Agricultural Economics 65(2), 383-405.

Tripp, R., 2006. Strategies for seed system development in Sub-Saharan Africa: A study of Kenya, Malawi, Zambia, and Zimbabwe. SAT eJournal 2(1), 1 - 60. Accessed Oct 2014, Available at http://ejournal.icrisat.org/mpiirpaper2.1.htm.

Udry, C.R., Conley, T.G., 2004. Social networks in Ghana. Center Discussion Paper No. 888, New Haven, CT, Yale University, Economic Growth Center.

Uiaene, R.N., 2011. Determinants of agricultural technology adoption in Mozambique. In: Proceedings of the $10^{\text {th }}$ African Crop Science Conference, From Soil to Soul: Crop Production for Improved African Livelihoods and a Better Environment for Future Generations, 10-13 October 2011, Maputo, Mozambique. Entebbe, Uganda, African Crop Science Society.

United Republic of Tanzania, 2012. National Sample Census of Agriculture 2007/2008. Ministry of Agriculture, Food Security and Cooperatives, Ministry of Livestock Development and Fisheries, Ministry of Water and Irrigation, Ministry of Agriculture, Livestock and Environment, Zanzibar, Prime Minister's Office, Regional Administration and Local Governments, Ministry of Industries, Trade and Marketing, The National Bureau of Statistics and the Office of the Chief Government Statistician, Zanzibar, (volumes Va, Vm). 
van den Broeck, K., Dercon, S., 2011. Information flows and social externalities in a Tanzanian banana growing village. Journal of Development Studies 47, 231-52.

Walker, T., Alene, A., Ndjeunga, J., Labarta, R., Yigezu, Y., Diagne, A., Andrade, R., Muthoni Andriatsitohaina, R., De Groote, H., Mausch, K., Yirga, C., Simtowe, F., Katungi, E., Jogo, W., Jaleta, M., Pandey, S., 2014. Measuring the effectiveness of crop improvement research in Sub-Saharan Africa from the perspectives of varietal output, adoption, and change: 20 crops, 30 countries, and 1150 cultivars in farmers' fields. Report of the Standing Panel on Impact Assessment (SPIA), Rome, Italy, CGIAR Independent Science and Partnership Council (ISPC) Secretariat.

Wilson, P., Hadley, D., Asby, C., 2001. The influence of management characteristics on the technical efficiency of wheat farmers in eastern England. Agricultural Economics 24, $329-338$.

Wollni, M., Brümmer, B., 2012. Productive efficiency of specialty and conventional coffee farmers in Costa Rica: Accounting for technological heterogeneity and self-selection. Food Policy 37(1), 67-76.

Wooldridge, J.M., 2010. Econometric Analysis of Cross Section and Panel Data. Second Edition. The MIT Press, Cambridge, Massachusetts.

World Bank, 2007. World Development Report 2008: Agriculture for Development. Washington DC, The World Bank.

World Food Programme, 2010. United Republic of Tanzania 2009/10 Comprehensive Food Security and Vulnerability Analysis (CFSVA). Rome, Italy, World Food Programme (WFP), ODXF Food Security Analysis.

Young, H.P., 2009. Innovation diffusion in heterogeneous populations: Contagion, social influence, and social learning. American Economic Review 99(5), 1899-1924. 


\section{Appendices}

\section{Appendix A: Additional tables}

Table A1: Additional variables used in the logit models

\begin{tabular}{|c|c|c|c|c|c|}
\hline \multirow[t]{2}{*}{ Variable } & \multirow[t]{2}{*}{ Description } & \multicolumn{2}{|c|}{ Sorghum } & \multicolumn{2}{|c|}{ Maize } \\
\hline & & $\begin{array}{l}\text { Traditional } \\
(\mathrm{N}=169)\end{array}$ & $\begin{array}{l}\text { Improved } \\
(\mathrm{N}=62)\end{array}$ & $\begin{array}{l}\text { Traditional } \\
(\mathrm{N}=106)\end{array}$ & $\begin{array}{l}\text { Improved } \\
(\mathrm{N}=181)\end{array}$ \\
\hline Striga plot & $\begin{array}{l}\text { Plot gets infested with strig } a \text { weeds }(1=\text { Yes, } \\
0=\text { Otherwise })\end{array}$ & $\begin{array}{l}0.28 \\
(0.45)\end{array}$ & $\begin{array}{l}0.11 * * * \\
(0.32)\end{array}$ & $\begin{array}{l}0.20 \\
(0.40)\end{array}$ & $\begin{array}{l}0.16 \\
(0.36)\end{array}$ \\
\hline Female & Respondent is a female $(1=y e s ; 0=$ otherwise $)$ & $\begin{array}{l}0.27 \\
(0.44)\end{array}$ & $\begin{array}{l}0.19 \\
(0.40)\end{array}$ & $\begin{array}{l}0.32 \\
(0.47)\end{array}$ & $\begin{array}{l}0.23 * * \\
(0.42)\end{array}$ \\
\hline Education & $\begin{array}{l}\text { Respondent has more than four years of formal } \\
\text { education ( } 1=\text { yes; } 0=\text { otherwise) }\end{array}$ & $\begin{array}{l}0.84 \\
(0.37)\end{array}$ & $\begin{array}{l}0.90 \\
(0.30)\end{array}$ & $\begin{array}{l}0.79 \\
(0.41)\end{array}$ & $\begin{array}{l}0.83 \\
(0.38)\end{array}$ \\
\hline $\begin{array}{l}\text { Sorghum farming } \\
\text { experience }\end{array}$ & Sorghum farming experience (years) & $\begin{array}{l}23.6 \\
(12.4)\end{array}$ & $\begin{array}{l}21.1 * \\
(12.1)\end{array}$ & & \\
\hline Exposure & $\begin{array}{l}\text { Level of exposure to improved varieties (number } \\
\text { of sorghum/maize varieties known) }\end{array}$ & $\begin{array}{l}1.44 \\
(1.30)\end{array}$ & $\begin{array}{l}2.34 * * * \\
(1.23)\end{array}$ & $\begin{array}{l}0.94 \\
(1.29)\end{array}$ & $\begin{array}{l}2.51 * * * \\
(1.53)\end{array}$ \\
\hline Ever adopted & $\begin{array}{l}\text { Ever adopted an improved sorghum (maize) } \\
\text { variety ( } 1=\text { Yes, } 0=\text { otherwise) }\end{array}$ & $\begin{array}{l}0.54 \\
(0.50)\end{array}$ & $\begin{array}{l}0.82 \\
(0.39)\end{array}$ & $\begin{array}{l}0.26 \\
(0.44)\end{array}$ & $\begin{array}{l}0.91 * * * \\
(0.29)\end{array}$ \\
\hline Extension strength & $\begin{array}{l}\text { Strength of links with public extension officer } \\
\text { (no. of contact days per month) }\end{array}$ & $\begin{array}{l}3.36 \\
(5.98)\end{array}$ & $\begin{array}{l}4.11 \\
(5.79)\end{array}$ & $\begin{array}{l}3.05 \\
(5.84)\end{array}$ & $\begin{array}{l}4.12 * \\
(6.25)\end{array}$ \\
\hline Muslim & $\begin{array}{l}\text { Respondent is Muslim ( } 1=y e s ; 0=\text { otherwise }- \\
\text { mostly Christian) }\end{array}$ & $\begin{array}{l}0.49 \\
(0.50)\end{array}$ & $\begin{array}{l}0.50 \\
(0.50)\end{array}$ & $\begin{array}{l}0.53 \\
(0.50)\end{array}$ & $\begin{array}{l}0.62^{*} \\
(0.49)\end{array}$ \\
\hline Mobile phone & $\begin{array}{l}\text { Household owns a mobile phone (1=yes; } \\
0=\text { otherwise) }\end{array}$ & $\begin{array}{l}0.68 \\
(0.47)\end{array}$ & $\begin{array}{l}0.71 \\
(0.46)\end{array}$ & $\begin{array}{l}0.61 \\
(0.49)\end{array}$ & $\begin{array}{l}0.74 * * \\
(0.44)\end{array}$ \\
\hline
\end{tabular}

Note: Figures are mean values, with their standard deviations in parenthesis. $*$,**,*** differences in means

between traditional and improved varieties are significant at 10,5 and $1 \%$ respectively.

Table A2: Logit results for the estimation of propensity scores

\begin{tabular}{|c|c|c|c|c|c|c|c|c|}
\hline \multirow[t]{2}{*}{ Variable } & \multicolumn{2}{|c|}{ Coefficient } & \multirow[t]{2}{*}{ Variable } & \multicolumn{2}{|c|}{ Coefficient } & \multirow[t]{2}{*}{ Variable } & \multicolumn{2}{|c|}{ Coefficient } \\
\hline & sorghum & Maize & & sorghum & Maize & & sorghum & Maize \\
\hline Constant & $\begin{array}{l}-2.15 * * * \\
(0.83)\end{array}$ & $\begin{array}{l}-0.67 \\
(0.71)\end{array}$ & $\begin{array}{l}\text { Ever } \\
\text { adopted }\end{array}$ & $\begin{array}{l}1.19 * * * \\
(0.45)\end{array}$ & & Striga plot & $\begin{array}{l}-1.40 * * * \\
(0.51)\end{array}$ & $\begin{array}{l}-0.41 \\
(0.36)\end{array}$ \\
\hline $\begin{array}{l}\text { Sorghum network } \\
\text { degree } 1\end{array}$ & $\begin{array}{l}0.39 * * \\
(0.18)\end{array}$ & & Exposure & & $\begin{array}{l}0.81 * * * \\
(0.16)\end{array}$ & Village cluster 2 & $\begin{array}{l}-0.30 \\
(0.63)\end{array}$ & $\begin{array}{l}-0.37 \\
(0.52)\end{array}$ \\
\hline $\begin{array}{l}\text { Sorghum network } \\
\text { degree } 2\end{array}$ & $\begin{array}{l}0.11 \\
(0.33)\end{array}$ & & Radio & $\begin{array}{l}-0.48 \\
(0.41)\end{array}$ & $\begin{array}{l}0.07 \\
(0.37)\end{array}$ & Village cluster 3 & $\begin{array}{l}-1.73 * * \\
(0.72)\end{array}$ & $\begin{array}{l}-0.35 \\
(0.49)\end{array}$ \\
\hline $\begin{array}{l}\text { Maize network } \\
\text { degree } 1\end{array}$ & & $\begin{array}{l}0.02 \\
(0.14)\end{array}$ & Mobile phone & & $\begin{array}{l}0.09 \\
(0.32)\end{array}$ & Village cluster4 & $\begin{array}{l}-0.56 \\
(0.65)\end{array}$ & $\begin{array}{l}-0.02 \\
(0.49)\end{array}$ \\
\hline $\begin{array}{l}\text { Maize network } \\
\text { degree } 2\end{array}$ & & $\begin{array}{l}0.26 \\
(0.33)\end{array}$ & Education & $\begin{array}{l}0.88 * \\
(0.54)\end{array}$ & & Village cluster5 & $\begin{array}{l}-0.43 \\
(0.72)\end{array}$ & $\begin{array}{l}0.02 \\
(0.63)\end{array}$ \\
\hline Admin link & & $\begin{array}{l}-0.08 \\
(0.06)\end{array}$ & Female & $\begin{array}{l}-0.36 \\
(0.41)\end{array}$ & & Village cluster6 & $\begin{array}{l}-1.39^{*} \\
(0.78)\end{array}$ & $\begin{array}{l}-0.47 \\
(0.50)\end{array}$ \\
\hline Admin link & & 0.00 & Muslim & -0.22 & -0.20 & & & \\
\hline squared & & $(0.00)$ & & $(0.40)$ & $(0.34)$ & Mean propensity & 0.27 & 0.63 \\
\hline Extension & & -0.00 & Land owned & 0.01 & $0.23 * * *$ & score & $(0.21)$ & $(0.25)$ \\
\hline strength & & $(0.03)$ & & $(0.03)$ & $(0.08)$ & Pseudo R-squared & 0.20 & 0.24 \\
\hline Tech2011 & $0.84 * *$ & & Land owned & & $-0.01 * *$ & $\mathrm{~N}$ & 231 & 287 \\
\hline $\begin{array}{l}\text { Farming } \\
\text { experience }\end{array}$ & & $\begin{array}{l}-0.01 \\
(0.01)\end{array}$ & $\begin{array}{l}\text { squared } \\
\text { Livestock } \\
\text { wealth }\end{array}$ & & $\begin{array}{l}(0.00) \\
-0.09 * \\
(0.05)\end{array}$ & $\begin{array}{l}\text { Robust standard er } \\
* \mathrm{p}<0.1, * * p<0.0\end{array}$ & $\begin{array}{l}\text { ors in bra } \\
* * * p<0\end{array}$ & \\
\hline
\end{tabular}


Table A3: Covariate balancing before and after matching

\begin{tabular}{|c|c|c|c|c|c|c|c|c|c|}
\hline \multirow[t]{3}{*}{ Variable } & \multirow[t]{3}{*}{ Sample } & \multicolumn{4}{|c|}{ Sorghum } & \multicolumn{4}{|c|}{ Maize } \\
\hline & & \multicolumn{2}{|c|}{ Mean } & \multirow{2}{*}{$\begin{array}{c}\text { \% reduction } \\
\text { in |bias| }\end{array}$} & \multirow{2}{*}{$\begin{array}{l}\text { t-test } \\
p>|t|\end{array}$} & \multicolumn{2}{|c|}{ Mean } & \multirow{2}{*}{$\begin{array}{c}\text { \% reduction } \\
\text { in |bias| }\end{array}$} & \multirow{2}{*}{$\begin{array}{l}\mathrm{t} \text {-test } \\
\mathrm{p}>|\mathrm{t}|\end{array}$} \\
\hline & & Treated & Control & & & Treated & Control & & \\
\hline \multirow[t]{2}{*}{ Village cluster 1} & Unmatched & 0.18 & 0.10 & & 0.11 & 0.33 & 0.19 & & 0.01 \\
\hline & Matched & 0.17 & 0.12 & 33.6 & 0.43 & 0.30 & 0.23 & 55.9 & 0.20 \\
\hline \multirow[t]{2}{*}{ Village cluster2 } & Unmatched & 0.19 & 0.13 & & 0.23 & 0.14 & 0.17 & & 0.55 \\
\hline & Matched & 0.18 & 0.18 & 99.4 & 1.00 & 0.15 & 0.23 & -215 & 0.06 \\
\hline \multirow[t]{2}{*}{ Village cluster 3} & Unmatched & 0.08 & 0.20 & & 0.04 & 0.10 & 0.16 & & 0.13 \\
\hline & Matched & 0.08 & 0.09 & 99.0 & 0.98 & 0.10 & 0.08 & 58.4 & 0.43 \\
\hline \multirow[t]{2}{*}{ Village cluster 4} & Unmatched & 0.29 & 0.26 & & 0.65 & 0.20 & 0.25 & & 0.36 \\
\hline & Matched & 0.30 & 0.33 & 11.6 & 0.76 & 0.22 & 0.27 & -9.20 & 0.29 \\
\hline \multirow[t]{2}{*}{ Village cluster5 } & Unmatched & 0.16 & 0.15 & & 0.80 & 0.12 & 0.10 & & 0.75 \\
\hline & Matched & 0.17 & 0.19 & -45.8 & 0.78 & 0.12 & 0.07 & -313 & 0.13 \\
\hline \multirow[t]{2}{*}{ Village cluster6 } & Unmatched & 0.10 & 0.17 & & 0.19 & 0.11 & 0.13 & & 0.59 \\
\hline & Matched & 0.10 & 0.10 & 95.0 & 0.95 & 0.12 & 0.13 & 70.7 & 0.87 \\
\hline \multirow[t]{2}{*}{ Striga plot } & Unmatched & 0.11 & 0.28 & & 0.01 & 0.16 & 0.20 & & 0.35 \\
\hline & Matched & 0.12 & 0.12 & 99.1 & 0.98 & 0.17 & 0.22 & -16.6 & 0.25 \\
\hline Sorghum network & Unmatched & 1.47 & 0.92 & & 0.00 & & & & \\
\hline degree1 & Matched & 1.42 & 1.43 & 97.0 & 0.94 & & & & \\
\hline Sorghum network & Unmatched & 0.39 & 0.17 & & 0.02 & & & & \\
\hline degree 2 & Matched & 0.32 & 0.46 & 35.5 & 0.34 & & & & \\
\hline Maize network & Unmatched & 1.47 & 0.92 & & 0.00 & 0.91 & 0.81 & & 0.48 \\
\hline degree 1 & Matched & 1.42 & 1.43 & 97.0 & 0.94 & 0.91 & 1.00 & -0.20 & 0.45 \\
\hline Maize network & Unmatched & 0.39 & 0.17 & & 0.02 & 0.24 & 0.14 & & 0.17 \\
\hline degree 2 & Matched & 0.32 & 0.46 & 35.5 & 0.34 & 0.18 & 0.22 & 67.1 & 0.64 \\
\hline Radio & Unmatched & 0.69 & 0.75 & & 0.38 & 0.79 & 0.68 & & 0.05 \\
\hline & Matched & 0.70 & 0.67 & 49.0 & 0.73 & 0.79 & 0.77 & 82.0 & 0.69 \\
\hline Muslim & Unmatched & 0.50 & 0.49 & & 0.84 & 0.62 & 0.53 & & 0.13 \\
\hline & Matched & 0.48 & 0.48 & 62.7 & 0.95 & 0.59 & 0.65 & 30.1 & 0.25 \\
\hline Tech2011 & Unmatched & 0.68 & 0.45 & & 0.00 & & & & \\
\hline & Matched & 0.68 & 0.69 & 99.0 & 0.98 & & & & \\
\hline Ever adopted & Unmatched & 0.82 & 0.54 & & 0.00 & & & & \\
\hline & Matched & 0.82 & 0.76 & 79.9 & 0.46 & & & & \\
\hline Education & Unmatched & 0.90 & 0.84 & & 0.23 & & & & \\
\hline & Matched & 0.90 & 0.91 & 82.8 & 0.84 & & & & \\
\hline Female & Unmatched & 0.20 & 0.27 & & 0.26 & & & & \\
\hline & Matched & 0.20 & 0.17 & 56.9 & 0.66 & & & & \\
\hline Land owned & Unmatched & 6.04 & 4.16 & & 0.05 & 5.13 & 3.81 & & 0.07 \\
\hline & Matched & 4.89 & 5.83 & 49.8 & 0.50 & 4.77 & 4.79 & 98.6 & 0.98 \\
\hline Land owned squared & Unmatched & & & & & 64.1 & 46.2 & & 0.50 \\
\hline & Matched & & & & & 56.2 & 57.3 & 94.2 & 0.97 \\
\hline Livestock wealth & Unmatched & & & & & 2.16 & 2.45 & & 0.51 \\
\hline & Matched & & & & & 2.27 & 1.86 & -39.9 & 0.32 \\
\hline Admin link & Unmatched & & & & & 14.7 & 12.4 & & 0.06 \\
\hline & Matched & & & & & 14.2 & 14.2 & 97.2 & 0.96 \\
\hline Admin link squared & Unmatched & & & & & 316 & 233 & & 0.03 \\
\hline & Matched & & & & & 303 & 317 & 84.2 & 0.74 \\
\hline Extension strength & Unmatched & & & & & 4.12 & 3.05 & & 0.15 \\
\hline & Matched & & & & & 3.98 & 3.48 & 52.9 & 0.47 \\
\hline Exposure & Unmatched & & & & & 2.51 & 0.93 & & 0.00 \\
\hline & Matched & & & & & 2.24 & 2.22 & 98.9 & 0.91 \\
\hline Mobile phone & Unmatched & & & & & 0.74 & 0.61 & & 0.03 \\
\hline & Matched & & & & & 0.72 & 0.78 & 48.0 & 0.20 \\
\hline Farming experience & Unmatched & & & & & 26.1 & 25.34 & & 0.60 \\
\hline & Matched & & & & & 26.2 & 26.23 & 94.9 & 0.98 \\
\hline
\end{tabular}




\title{
Appendix B: Survey Questionnaire
}

\author{
HOPE: Early Adoption Survey Instrument - Tanzania 2012 \\ ICRISAT/DRD/University of Goettingen
}

\subsection{Survey quality control}

Date of interview: Day:.... Month. Year:

Interviewed by:

Starting time:

Ending time:

Date entered:

Day:

Month: Year:

Entered by:

\section{Introductory Statement}

We are researchers from the DRD (Ministry of Agriculture), Dodoma, collaborating with a number of organizations to improve productivity and incomes of our farmers in line with the Kilimo Kwanza Policy. As part of this initiative, we interviewed among others your household two years ago, and are now doing a follow up to assess changes as well as challenges that still need to be addressed, especially in sorghum, finger millet and maize farming. We would like to talk to the person responsible for production of sorghum, finger millet and maize.

All the information gathered will be kept strictly confidential and solely used for research purposes.

If you are ready, may we now begin?

\subsection{Respondent and site identification}

1. Household ID:

2. Name of Household head:

3. Village location: Treatment area.

Diffusion area....

Control area.

4. District

5. Ward

6. Village

7. Sub Village

8. GPS readings (i) Eastings $\mathbf{E}$.

ii) Southings $\mathbf{S}$

iii)Elevation (m)

9. Respondent name

10. Respondent sex

0 male

1 female

11. Number of years the respondent is living in the village.

12. Experience (years) in own farming activities

13. Experience (years) in cultivating: i) Sorghum

ii) Finger millet.

iii) Maize

14. Community responsibility of household head

[0=None; $\mathbf{1}=$ Cell leader $\mathbf{2}=$ Sub-village leader $\mathbf{3}=$ Village Chairman $\mathbf{4}=$ Village Executive Officer $\mathbf{5}=$ Village government member $\mathbf{6}=$ Ward Executive Officer $\mathbf{7}=$ Councilor $\mathbf{8}=$ Political party leader $\mathbf{9}=$ Youth leader; $\mathbf{1 0}=$ Women's leader; $\mathbf{1 1}=$ Religious leader $\mathbf{1 2}=$ Other, specify. 


\subsection{Household information}

2.1 Household composition and occupation of members (Please fill the table for all household members who were in the last 12 month living in your household, fill also for non-permanent members eg. Temporary migrants, children living away at school)

\begin{tabular}{|c|c|c|c|c|c|c|c|c|c|c|c|c|c|c|c|c|}
\hline \multicolumn{2}{|c|}{$\begin{array}{l}\text { Name of } \mathrm{HH} \text { member (start } \\
\text { with respondent) }\end{array}$} & $\begin{array}{c}\text { Relation to } \\
\text { HH head } \\
\text { Code A }\end{array}$ & $\begin{array}{c}\text { Gender } \\
(\mathbf{0 = m a l e ;} \\
\mathbf{1}=\text { female })\end{array}$ & $\begin{array}{c}\text { Age } \\
\text { (years) }\end{array}$ & $\begin{array}{c}\text { Marital } \\
\text { status } \\
\text { Code B }\end{array}$ & $\begin{array}{c}\text { Education } \\
\text { level } \\
\text { Code } \mathbf{C}\end{array}$ & $\begin{array}{l}\text { Religion } \\
\text { Code D }\end{array}$ & \begin{tabular}{|c} 
Number of \\
month s/he \\
was living in \\
the hh
\end{tabular} & $\begin{array}{r}\text { Farm la } \\
\text { particip } \\
\text { Codes }\end{array}$ & $\begin{array}{l}\text { bour } \\
\text { ation } \\
\mathbf{E}\end{array}$ & $\begin{array}{c}\text { Main } \\
\text { occupation } \\
\text { Code F }\end{array}$ & \begin{tabular}{|c|} 
Yearly net \\
income in TSh \\
if NOT farming
\end{tabular} & $\begin{array}{c}2^{\text {nd }} \text { important } \\
\text { occupation } \\
\text { Code } \mathbf{F}\end{array}$ & $\begin{array}{c}\text { Yearly net } \\
\text { income in TSh } \\
\text { if NOT farming }\end{array}$ & \begin{tabular}{|c|} 
Other \\
income \\
sources \\
Code G \\
\end{tabular} & $\begin{array}{c}\text { Yearly net } \\
\text { income from } \\
\text { other sources } \\
\text { (TSh) }\end{array}$ \\
\hline \multicolumn{17}{|l|}{1.} \\
\hline \multicolumn{17}{|l|}{2.} \\
\hline \multicolumn{17}{|l|}{3.} \\
\hline \multicolumn{17}{|l|}{4.} \\
\hline \multicolumn{17}{|l|}{5.} \\
\hline \multicolumn{17}{|l|}{6.} \\
\hline \multicolumn{17}{|l|}{7.} \\
\hline \multicolumn{17}{|l|}{8.} \\
\hline \multicolumn{17}{|l|}{9.} \\
\hline \multicolumn{17}{|l|}{10.} \\
\hline \multicolumn{17}{|l|}{11.} \\
\hline \multicolumn{17}{|l|}{12.} \\
\hline \multicolumn{17}{|l|}{13.} \\
\hline \multicolumn{17}{|l|}{14.} \\
\hline $\begin{array}{l}\text { A } \\
\text { sehold head } \\
\text { use } \\
\text { /daughter } \\
\text { ent } \\
\text { /daughter in-law } \\
\text { nd child } \\
\text { er relative } \\
\text { er, specify....... }\end{array}$ & $\begin{array}{l}\text { Codes B } \\
1 \text { Married livi } \\
2 \text { Married but } \\
3 \text { Divorced/se } \\
4 \text { Widow/widc } \\
5 \text { Never marri } \\
6 \text { Other, speci }\end{array}$ & $\begin{array}{l}\text { ing with spouse } \\
\text { t spouse away } \\
\text { parated } \\
\text { ower } \\
\text { ed } \\
\text { fy............ }\end{array}$ & $\begin{array}{l}\text { Code C } \\
0 \text { None (i } \\
1 \text { Basic }( \\
2 \text { Lower } 1 \\
3 \text { Upper } 1 \\
4 \text { Second } \\
5 \text { High ed } \\
6 \text { College } \\
7 \text { Vocatio } \\
8 \text { Not app } \\
9 \text { Other, s }\end{array}$ & $\begin{array}{l}\text { lliterate) } \\
\text { can write } \\
\text { primary (1 } \\
\text { orimary (5 } \\
\text { ary (9-12) } \\
\text { lucation (1 } \\
\text { nal trainin } \\
\text { plicable } \\
\text { specify ... }\end{array}$ & $\begin{array}{l}\text { and read) } \\
1-4) \\
5-7) \\
(13-14) \\
\text { ing }\end{array}$ & $\begin{array}{l}\text { Codes D } \\
0 \text { No religic } \\
\text { 1 Moslem } \\
2 \text { Christian } \\
3 \text { Other, spe }\end{array}$ & ion & $\begin{array}{l}\text { ode E } \\
\text { None } \\
\text { Full time } \\
\text { Part-time } \\
\text { Weekends and h } \\
\text { Other, please sp } \\
\text {..................... }\end{array}$ & $\begin{array}{l}\text { holidays } \\
\text { pecify }\end{array}$ & $\begin{array}{l}\text { Cod } \\
0 \mathrm{No} \\
1 \mathrm{Fa} \\
\text { lives } \\
3 \mathrm{He} \\
4 \mathrm{Ho} \\
5 \mathrm{Ca} \\
\text { anotl } \\
6 \mathrm{No} \\
\text { (shol }\end{array}$ & $\begin{array}{l}\text { es F } \\
\text { occupation } \\
\text { rming (crop an } \\
\text { tock) } \\
\text { erdsboy/girl } \\
\text { pusekeeping } \\
\text { sual labourer } \\
\text { her farm } \\
\text { on-farm busine } \\
\text { ps, trade, tailor }\end{array}$ & $\begin{array}{l}\text { nd/or } \\
\text { on } \\
\text { ess } \\
\text { r, etc) }\end{array}$ & $\begin{array}{l}\text { ed employment } \\
\text { r, specify.......... } \\
\text { ent }\end{array}$ & $\begin{array}{l}\text { Codes G } \\
\text { 1 Rented out lan } \\
\text { 2 Rented out ox } \\
\text { ploughing } \\
\text { 3 Sale of dung c } \\
\text { 4 Sale of own tr } \\
\text { (firewood, etc) } \\
5 \text { Sale of own br } \\
6 \text { Pension incom }\end{array}$ & $\begin{array}{l}\text { ind } \\
\text { xen for } \\
\text { cake for fuel } \\
\text { rees } \\
\text { orewed drinks } \\
\text { me }\end{array}$ & $\begin{array}{l}7 \text { Drought relief } \\
8 \text { Remittances (sent } \\
\text { from non-resident } \\
\text { family and relatives) } \\
9 \text { Marriage gifts } \\
\text { (e.g., dowry) } \\
10 \text { Other, specify } \\
\text {....................... }\end{array}$ \\
\hline
\end{tabular}




\subsection{Knowledge and adoption of sorghum, finger millet and maize varieties}

3.1 Please fill the following Table for all varieties of sorghum, finger millet and maize the farmer knows (also those s/he does not plant her/himself)

\begin{tabular}{|c|c|c|c|c|c|c|c|c|c|c|c|c|c|c|c|c|}
\hline \multirow[b]{2}{*}{$\begin{array}{l}\text { Crop } \\
\text { 1=Sorghum; } \\
\text { 2=F/Millet; } \\
\text { 3=Maize }\end{array}$} & \multirow[b]{2}{*}{$\begin{array}{l}\text { Varieties } \\
\text { known } \\
\text { (Variety } \\
\text { Codes) }\end{array}$} & \multirow[b]{2}{*}{$\begin{array}{l}\text { Type of } \\
\text { variety } \\
(\mathbf{0}=\text { Local; } \\
\text { 1=Modern })\end{array}$} & \multirow{2}{*}{$\begin{array}{l}\text { When (year) } \\
\text { did you first } \\
\text { hear about } \\
\text { the variety? }\end{array}$} & \multirow{2}{*}{$\begin{array}{l}\text { From whom } \\
\text { did you first } \\
\text { hear about it? } \\
\text { rank up to } \\
\text { three Code A }\end{array}$} & \multicolumn{6}{|c|}{$\begin{array}{l}\text { If Main source of variety information was another farmer, fill in the following } \\
\text { details at the time information was first acquired }\end{array}$} & \multirow{2}{*}{\begin{tabular}{|c|} 
Ever \\
planted the \\
variety? \\
$(\mathbf{0 = n o}$ \\
$\mathbf{1 = y e s})$
\end{tabular}} & \multicolumn{5}{|c|}{ If NO } \\
\hline & & & & & $\begin{array}{l}\text { Name of the } \\
\text { farmer from } \\
\text { which } \\
\text { information } \\
\text { was sourced }\end{array}$ & $\begin{array}{l}\text { What was your } \\
\text { relationship } \\
\text { with the } \\
\text { farmer? } \\
\text { (Relationship } \\
\text { codes) }\end{array}$ & $\begin{array}{l}\text { Had you } \\
\text { known the } \\
\text { farmer } \\
\text { before? } \\
(\mathbf{0 = N o} \\
\mathbf{1 = Y e s )}\end{array}$ & $\begin{array}{l}\text { How far dic } \\
\text { the farmer } \\
\text { live } \\
\text { (walking } \\
\text { minutes) }\end{array}$ & $\begin{array}{l}\text { Which year } \\
\text { did the } \\
\text { farmer first } \\
\text { grow the } \\
\text { variety? }\end{array}$ & $\begin{array}{l}\text { If this variety } \\
\text { is modern, } \\
\text { how did you } \\
\text { learn about } \\
\text { it? (Codes B) }\end{array}$ & & \begin{tabular}{|c} 
Give \\
reasons \\
(Code C, \\
rank 3)
\end{tabular} & $\begin{array}{l}\text { Ever seen } \\
\text { the variety } \\
\text { growing? } \\
(\mathbf{0}=\mathrm{No} ; \\
\mathbf{1}=\mathrm{Yes})\end{array}$ & $\begin{array}{l}\text { Ever tasted any } \\
\text { meal or } \\
\text { beverage made } \\
\text { from the } \\
\text { variety? }(\mathbf{0}=\mathrm{No} \\
\mathbf{1 = Y e s )}\end{array}$ & $\begin{array}{l}\text { Will you } \\
\text { plant } \\
\text { variety in } \\
\text { future? } \\
;\left(\begin{array}{l}\text { =no; } \\
1=\text { yes })\end{array}\right.\end{array}$ & $\begin{array}{c}\text { If } N O, \\
\text { why not? } \\
\text { (Code C, } \\
\text { rank3) }\end{array}$ \\
\hline & & & & & & & & & & & & & & & & \\
\hline & & & & & & & & & & & & & & & & \\
\hline & & & & & & & & & & & & & & & & \\
\hline & & & & & & & & & & & & & & & & \\
\hline & & & & & & & & & & & & & & & & \\
\hline & & & & & & & & & & & & & & & & \\
\hline & & & & & & & & & & & & & & & & \\
\hline & & & & & & & & & & & & & & & & \\
\hline & & & & & & & & & & & & & & & & \\
\hline & & & & & & & & & & & & & & & & \\
\hline & & & & & & & & & & & & & & & & \\
\hline & & & & & & & & & & & & & & & & \\
\hline & & & & & & & & & & & & & & & & \\
\hline
\end{tabular}

\section{Variety Codes}

Sorghum

2. Pato

3. Macia

4. Tegemeo

5. Local variety

(unspecified)

6. Sila

7. Serena

8. Udo (Local)
9. KARI Mtama1 25. Pannar 34. Katumani $\begin{aligned} & \text { Code A } \\ & 1 \text { Govern }\end{aligned}$

10 Modern variety 26. Pioneer 35. Modern 2 Farmer club (unspecified)

11. Other sorghum variety

27. DK variety

Maize

28. Honga (unspecified) 4 Research centre

29. Staha 36. Local

21. America (Local) 31. Seedo variety

(Local) 31. SeedCo (unspecified) 6 Seed/grain stockist

32. Situka 37. Other

7 Another farmer/neig

24. Hybrid
3 NGO

5.On-farm trials/demos/field me about it then I

days

\section{Codes B}

1. I saw it in the plot and asked the farmer asked for details 3. The farmer told me about it and

invited me to see it 4. Other. ...
Relationship Codes

$1=$ Parent 2=Child 3=Brother/sister

4=Grandparent

$\mathbf{5}=$ Grandchild

$\mathbf{6}=$ Nephew/Niece

$7=$ Uncle/aunt

8=Cousin

$\mathbf{9 = S a m e ~ f a m i l y ~}$

9 Other, specify.........

lineage
Code C

$\mathbf{1 0}=$ Mother/father in-law $\mathbf{1}$ Cannot get seed at all $\quad 9$ Poor prices

11=Brother/sister in-law 2 Lack of cash to buy seed $\mathbf{1 0}$ No market

12=Other relative $\quad 3$ Susceptible to field 11 Requires high

13=Fellow villager/

pests/diseases

skills

Friend/Neigh

4 Susceptible to bird attack12 Seeds are

14=Professional/busines

colleague

$\mathbf{1 5}=$ Other, specify

pests

expensive
13 Requires more

..............

6 Poor taste

rainfall

7 Cannot get credit

14 Other, specify

8 Low yielding variety 


\subsection{For all MODERN varieties ever planted in Table 3.1, please fill the following table}

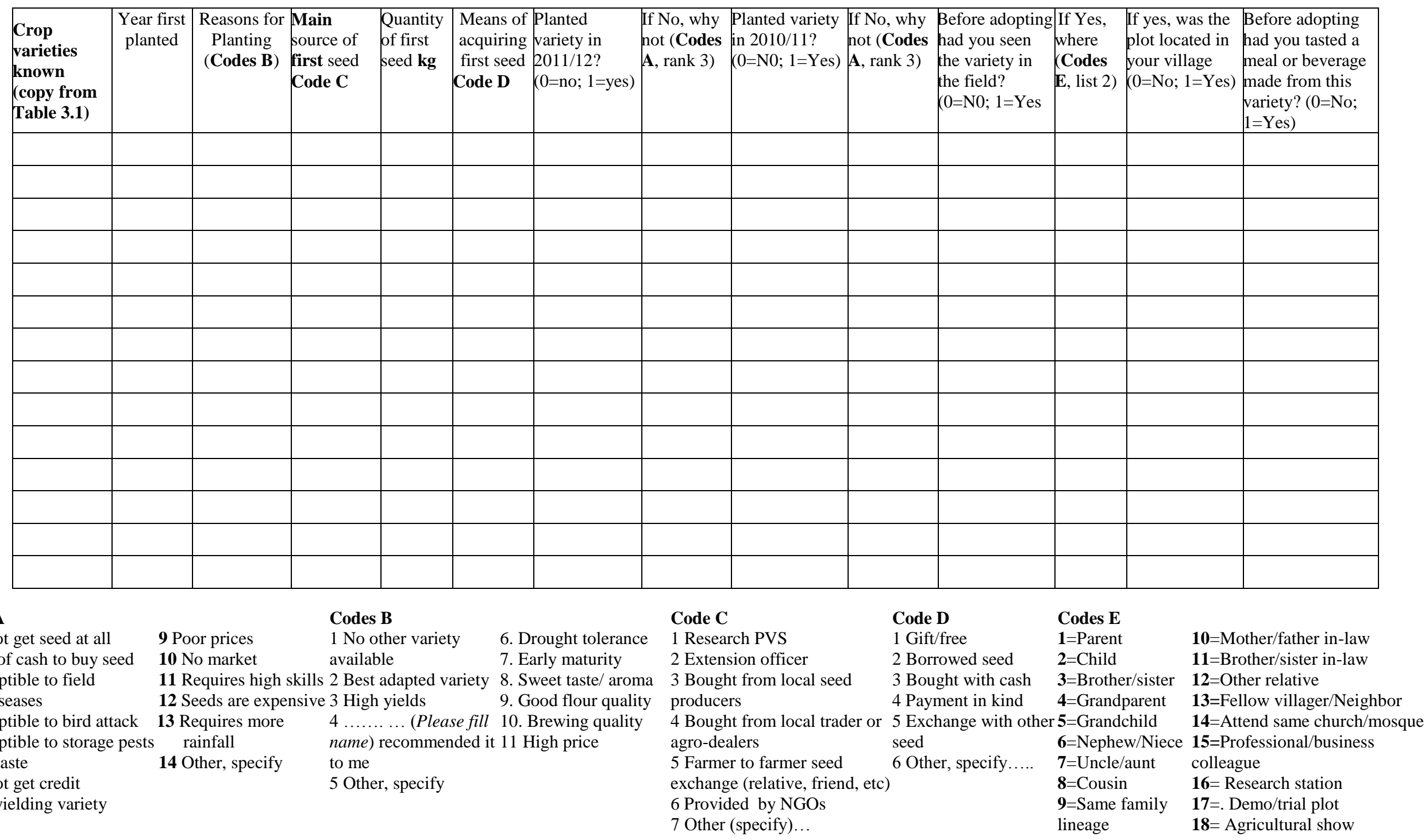

Code A

1 Cannot get seed at all

2 Lack of cash to buy seed

3 Susceptible to fiel

pests/disease

4 Susceptible to bird attack

6 Susceptib

7 Cannot get credit

$\mathbf{8}$ Low yielding variety
7 Other (specify)... 
3.3. Farmers' perception of characteristics of known modern sorghum, finger millet and maize variety compared with farmer's best local variety. [Let the farmer mention the best local sorghum, finger millet and maize varieties, and the best known modern varieties for comparison. For those who do not know any specific modern variety, or those who think all modern varieties are the same, get their perception on modern varieties in general only]

3.3.1 Name of best local variety: Sorghum

Finger millet.

Maize

3.3.2 Name of best modern variety: Sorghum

Finger millet.

Maize

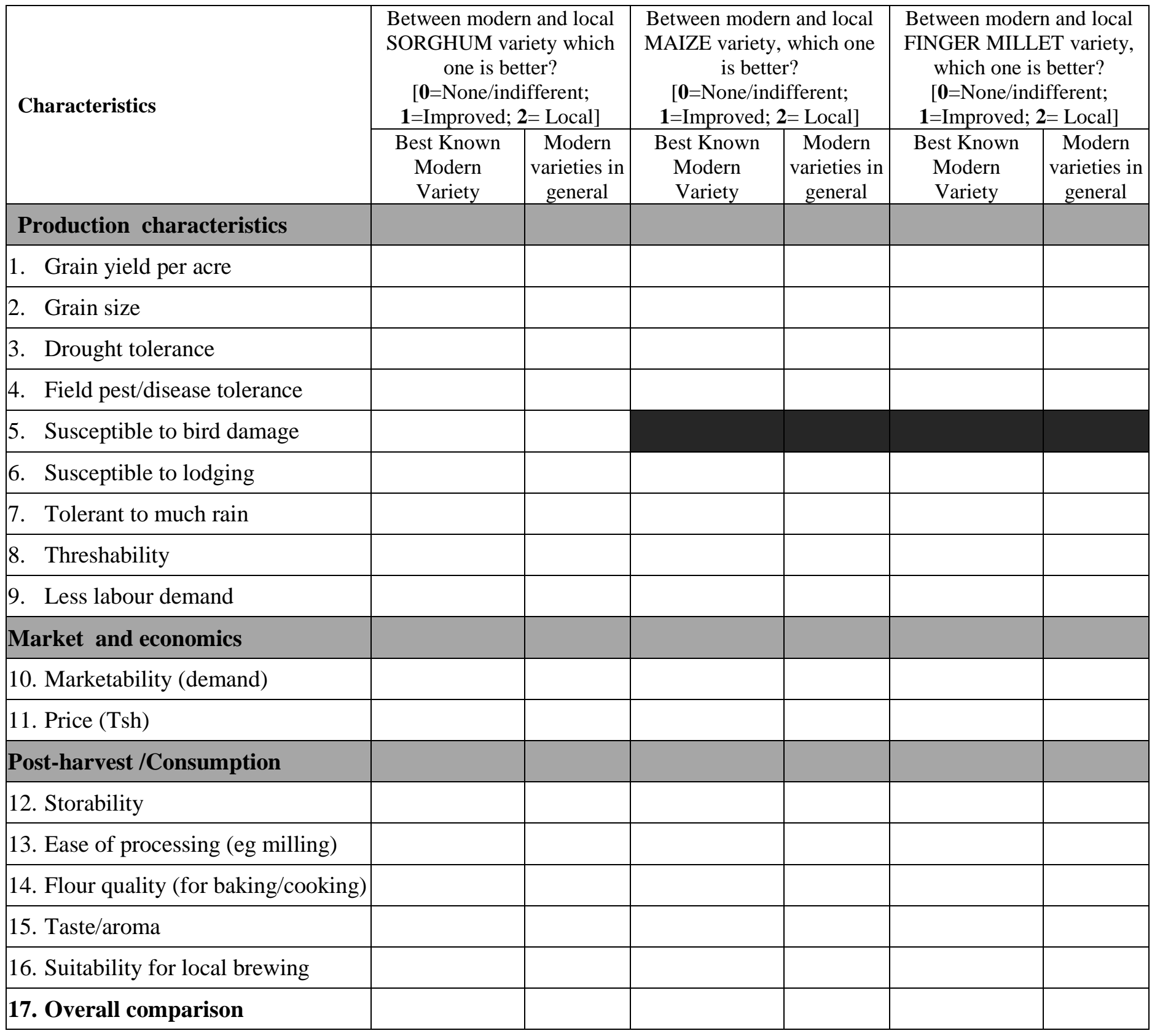




\subsection{Information on informal sorghum, finger millet \&maize seed production and exchanges}

\subsubsection{Seed saving/sharing practice}

\section{Seed saving/sharing}

1. How often do you save grain for seed? $(\mathbf{0}=$ Never; $\mathbf{1}=$ Sometimes; 2=Always)

2. How often is this saved seed adequate for your requirements? $(\mathbf{0}=$ Never; $\mathbf{1}=$ Sometimes; $\mathbf{2}=$ Always)

3. How often do you share your own produced seed with relatives? (0=Never; $\mathbf{1}=$ =Sometimes; $2=$ =Always $)$

4. How often do you share your own produced seed with non-relatives? (0=Never; $\mathbf{1}=$ Sometimes; $\mathbf{2}=$ Always)

5. What are the seed exchange terms for relatives? $(\mathbf{0}=$ Free; $\mathbf{1}=$ Cash; $\mathbf{2}=$ with seed/grain of other crops; $\mathbf{3}=$ with other items; $\mathbf{4}=$ with farm labour $)$

6. What are the seed exchange terms for non-relatives? $(\mathbf{0}=$ Free; $\mathbf{1}=$ Cash; $\mathbf{2}=$ with seed/grain of other crops; $\mathbf{3}=$ with other items; $\mathbf{4}=$ with labour $)$

7. Do you have any formal training on seed production? $(\mathbf{0}=\mathrm{No} ; \mathbf{1}=\mathrm{Yes})$

\subsubsection{Seed saving/sharing during the 2011/2012 planting season}

\begin{tabular}{|c|c|c|c|c|c|c|}
\hline & \multicolumn{2}{|c|}{ Sorghum varieties } & \multicolumn{2}{|c|}{ Maize varieties } & \multirow{2}{*}{\multicolumn{2}{|c|}{\begin{tabular}{|l|} 
Finger Millet \\
Local Modern \\
\end{tabular}}} \\
\hline & Local & Modern & Local & Modern & & \\
\hline $\begin{array}{l}\text { 1. How much own saved seed did you have } \\
\text { at the start of the season }(\mathrm{Kg}) \text { ? }\end{array}$ & & & & & & \\
\hline $\begin{array}{l}\text { 2. Was this amount enough for your needs? } \\
(0=\mathrm{No} ; 1=\text { Yes })\end{array}$ & & & & & & \\
\hline $\begin{array}{l}\text { 3. If No, did you seek seed from other } \\
\text { farmers? }(0=\mathrm{No} ; \quad \quad \quad 1=\text { Yes })\end{array}$ & & & & & & \\
\hline
\end{tabular}

5. If Yes, to which farmers did you give your own seeds? (fill details below)

\begin{tabular}{|c|c|c|c|c|c|c|c|c|c|c|c|c|}
\hline \multirow{3}{*}{ Name of the farmer } & \multirow{3}{*}{$\begin{array}{l}\text { Relationship } \\
\text { (Codes A) }\end{array}$} & \multirow{3}{*}{$\begin{array}{l}\text { Residence } \\
\text { (Codes B) }\end{array}$} & \multicolumn{4}{|c|}{ Sorghum } & \multicolumn{4}{|c|}{ Maize } & \multirow{2}{*}{\multicolumn{2}{|c|}{ Finger Millet }} \\
\hline & & & \multicolumn{2}{|r|}{ Local } & \multicolumn{2}{|c|}{ Modern } & \multicolumn{2}{|r|}{ Local } & \multicolumn{2}{|c|}{ Modern } & & \\
\hline & & & $\mathrm{Kg}$ & \begin{tabular}{|l}
$\begin{array}{l}\text { Price } \\
(\mathrm{TSh} / \mathrm{kg})\end{array}$ \\
\end{tabular} & $\mathrm{Kg}$ & \begin{tabular}{|l|} 
Price \\
$(\mathrm{TSh} / \mathrm{kg})$
\end{tabular} & $\mathrm{Kg}$ & $\begin{array}{l}\text { Price } \\
(\mathrm{TSh} / \mathrm{kg})\end{array}$ & $\mathrm{Kg}$ & $\begin{array}{l}\text { Price } \\
(\mathrm{TSh} / \mathrm{kg})\end{array}$ & $\mathrm{Kg}$ & \begin{tabular}{|l}
$\begin{array}{l}\text { Price } \\
(\mathrm{TSh} / \mathrm{kg})\end{array}$ \\
\end{tabular} \\
\hline 1. & & & & & & & & & & & & \\
\hline 2. & & & & & & & & & & & & \\
\hline 3. & & & & & & & & & & & & \\
\hline 4. & & & & & & & & & & & & \\
\hline 5. & & & & & & & & & & & & \\
\hline 6. & & & & & & & & & & & & \\
\hline
\end{tabular}

\section{Codes A}

1=Parent; $\mathbf{2}=$ Child; $\mathbf{3}=$ Brother/sister; $\mathbf{4}=$ Grandparent; $\mathbf{5}=$ Grandchild; $\mathbf{6}=$ Nephew $/$ Niece; $\mathbf{7}=$ Uncle/aunt; $\mathbf{8}=$ Cousin; $\mathbf{9}=$ Same family lineage; 10=Mother/father in-law; 11=Brother/sister in-law;12=Other relative; 13=Fellow villager/Neighbor; 14=Attend same church/ mosque; 15=Professional/business colleague; 16=Other, specify.......

Codes B $\quad \mathbf{1}=$ In this village $\quad 2=$ Outside this village 


\subsection{Social Networks}

Now I want to ask you questions about your interactions with a number of farmers, as well as key individuals (officers and organizations) who promote farming activities in this village. [Fill in $\mathbf{1}$ for all YES responses, $\boldsymbol{0}$ for all NO responses and $\mathbf{9 9 9}$ for DON'T KNOW/NOT SURE]

\subsection{Relationships and Interactions}

\begin{tabular}{|c|c|c|c|c|c|c|c|c|c|c|c|c|c|c|c|c|c|}
\hline $\begin{array}{l}\text { Farmers/External } \\
\text { agent }(X)\end{array}$ & $\begin{array}{l}\text { House } \\
\text { hold ID }\end{array}$ & $\begin{array}{l}\text { Do } \\
\text { you } \\
\text { know } \\
(\mathrm{X})\end{array}$ & $\begin{array}{l}\text { Since } \\
\text { when } \\
(\text { Year) } \\
\text { have } \\
\text { you } \\
\text { known } \\
(X) ?\end{array}$ & $\begin{array}{l}\text { How is } \\
\text { (X) } \\
\text { related } \\
\text { to you? } \\
\text { (Relati } \\
\text { onship } \\
\text { codes) }\end{array}$ & 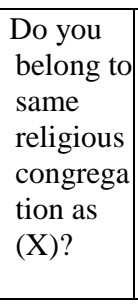 & $\begin{array}{l}\text { Do you } \\
\text { belong to } \\
\text { the same } \\
\text { association } \\
\text { with }(\mathrm{X}) \text { ? } \\
\text { (fill in all } \\
\text { that apply, } \\
\text { Codes A) }\end{array}$ & $\begin{array}{l}\text { Have } \\
\text { you } \\
\text { ever } \\
\text { talked } \\
\text { to }(\mathrm{X}) \text { ? }\end{array}$ & $\begin{array}{l}\text { If yes, how } \\
\text { many times } \\
\text { per month } \\
\text { on average } \\
\text { do you talk } \\
\text { to }(\mathrm{X}) \text { ? }\end{array}$ & $\begin{array}{l}\text { Have } \\
\text { you } \\
\text { ever } \\
\text { visited } \\
\text { the } \\
\text { home } \\
\text { of }(\mathrm{X}) \text { ? }\end{array}$ & $\begin{array}{l}\text { If yes, how } \\
\text { many times } \\
\text { per month on } \\
\text { average do } \\
\text { you visit the } \\
\text { home of }(\mathrm{X}) \text { ? }\end{array}$ & $\begin{array}{l}\text { Is }(X) \text { 's } \\
\text { field/ } \\
\text { plot } \\
\text { adjace } \\
\text { nt to } \\
\text { yours? }\end{array}$ & $\begin{array}{l}\text { Have } \\
\text { you ever } \\
\text { passed } \\
\text { by the } \\
\text { field of } \\
\text { (X)? }\end{array}$ & $\begin{array}{l}\text { If Yes, how } \\
\text { many times } \\
\text { per month do } \\
\text { you pass by } \\
\text { the field of } \\
(\mathrm{X}) \text { ? }\end{array}$ & 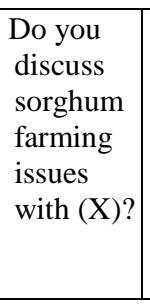 & 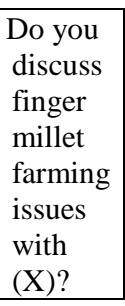 & $\begin{array}{l}\text { Do you } \\
\text { discuss } \\
\text { maize } \\
\text { farming } \\
\text { issues } \\
\text { with } \\
(\mathrm{X}) ?\end{array}$ & $\begin{array}{l}\text { Does }(\mathrm{X}) \\
\text { inform } \\
\text { you of } \\
\text { Agric. } \\
\text { meetings? }\end{array}$ \\
\hline \multicolumn{18}{|c|}{ Farmers from same village } \\
\hline \multicolumn{18}{|l|}{1.} \\
\hline \multicolumn{18}{|l|}{2.} \\
\hline \multirow{2}{*}{\multicolumn{18}{|c|}{\begin{tabular}{|l|l}
3. & \\
\end{tabular}}} \\
\hline & & & & & & & & & & & & & & & & & \\
\hline \multicolumn{18}{|l|}{4.} \\
\hline \multicolumn{18}{|l|}{5.} \\
\hline \multirow{2}{*}{\multicolumn{18}{|c|}{ lage Chairman, 8. Village Chairman, 9.Village Executive) }} \\
\hline & & & & & & & & & & & & & & & & & \\
\hline \multicolumn{18}{|c|}{ o tha } \\
\hline \multicolumn{18}{|l|}{8.} \\
\hline \multirow{2}{*}{\multicolumn{18}{|c|}{$\begin{array}{l}9 . \\
\text { External A oents }\end{array}$}} \\
\hline & & & & & & & & & & & & & & & & & \\
\hline \multicolumn{18}{|c|}{ Agricultural Ext. Officer } \\
\hline \multicolumn{18}{|l|}{ Research- } \\
\hline \multicolumn{18}{|l|}{ NGO- } \\
\hline \multicolumn{18}{|l|}{ Input dealer-- } \\
\hline Grain buyer-- & & & & & & & & & & & & & & & & & \\
\hline
\end{tabular}

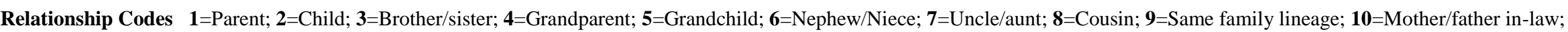

$\mathbf{1 1 = B r o t h e r / s i s t e r ~ i n - l a w ; 1 2 = O t h e r ~ r e l a t i v e ; ~ 1 3 = F e l l o w ~ v i l l a g e r / N e i g h b o r ; ~ 1 4 = A t t e n d ~ s a m e ~ c h u r c h / ~ m o s q u e ; ~ 1 5 = P r o f e s s i o n a l / b u s i n e s s ~ c o l l e a g u e ; ~ 1 6 = O t h e r , ~ s p e c i f y . . . . . . . ~}$

Codes A： $\mathbf{0}=$ No; $\mathbf{1 = F a r m i n g ~ g r o u p ; ~} \mathbf{2}=$ Self-help group; $\mathbf{3}=$ Merry go round; $\mathbf{4}=$ =Savings and Credit; $\mathbf{5}=$ Other (Specify) 


\subsection{Information and Resource Sharing among Social Network Members}

\begin{tabular}{|c|c|c|c|c|c|c|c|c|c|c|c|c|c|c|c|c|c|c|c|c|c|c|c|c|c|c|}
\hline \multirow{3}{*}{$\begin{array}{l}\text { Farmers/External } \\
\text { agent }(X)-\text { From } \\
\text { Table } 4.1\end{array}$} & \multicolumn{26}{|c|}{$\begin{array}{l}\text { Have you ever sought (abbreviated } S) \text { any of the following from }(\mathrm{X}) ?(0=\text { No; } 1=\text { Yes }) \text {. } \\
\text { If YES, did you ever receive (abbreviated R)? }(0=\text { No; } 1=\text { Yes }) .\end{array}$} \\
\hline & \multicolumn{2}{|c|}{$\begin{array}{c}\text { Information } \\
\text { on modern } \\
\text { sorghum } \\
\text { varieties }\end{array}$} & \multicolumn{2}{|c|}{$\begin{array}{l}\text { Seeds of } \\
\text { modern } \\
\text { sorghum } \\
\text { varieties }\end{array}$} & \multicolumn{2}{|c|}{$\begin{array}{l}\text { Seeds of } \\
\text { local } \\
\text { sorghum } \\
\text { varieties }\end{array}$} & \multicolumn{2}{|c|}{$\begin{array}{l}\text { Labor for } \\
\text { sorghum } \\
\text { activities }\end{array}$} & \multicolumn{2}{|c|}{\begin{tabular}{|c|}
$\begin{array}{c}\text { Information } \\
\text { on sorghum } \\
\text { marketing }\end{array}$ \\
\end{tabular}} & \multicolumn{2}{|c|}{$\begin{array}{c}\text { Information } \\
\text { on modern } \\
\text { maize } \\
\text { varieties }\end{array}$} & \multicolumn{2}{|c|}{$\begin{array}{c}\text { Seeds of } \\
\text { modern } \\
\text { maize } \\
\text { varieties }\end{array}$} & \multicolumn{2}{|c|}{$\begin{array}{c}\text { Seeds of } \\
\text { local maize } \\
\text { varieties }\end{array}$} & \multicolumn{2}{|c|}{$\begin{array}{l}\text { Labor for } \\
\text { maize } \\
\text { activities }\end{array}$} & \multicolumn{2}{|c|}{$\begin{array}{c}\text { Information } \\
\text { on maize } \\
\text { marketing }\end{array}$} & \multicolumn{2}{|c|}{$\begin{array}{c}\text { Seeds of } \\
\text { finger millet }\end{array}$} & \multicolumn{2}{|c|}{$\begin{array}{l}\text { Land to } \\
\text { cultivate }\end{array}$} & \multicolumn{2}{|c|}{$\begin{array}{c}\text { Financial } \\
\text { Assistance }\end{array}$} \\
\hline & $\mathbf{S}$ & $\mathbf{R}$ & $\mathbf{S}$ & $\mathbf{R}$ & $\mathbf{S}$ & $\mathbf{R}$ & $\mathbf{S}$ & $\mathbf{R}$ & $\mathbf{S}$ & $\mathbf{R}$ & $\mathbf{S}$ & $\mathbf{R}$ & $\mathbf{S}$ & $\mathbf{R}$ & $\mathbf{S}$ & $\mathbf{R}$ & $\mathbf{S}$ & $\mathbf{R}$ & $\mathbf{S}$ & $\mathbf{R}$ & $\mathbf{S}$ & $\mathbf{R}$ & $\mathbf{S}$ & $\mathbf{R}$ & $\mathbf{S}$ & $\mathbf{R}$ \\
\hline
\end{tabular}

\section{Farmers from same village}

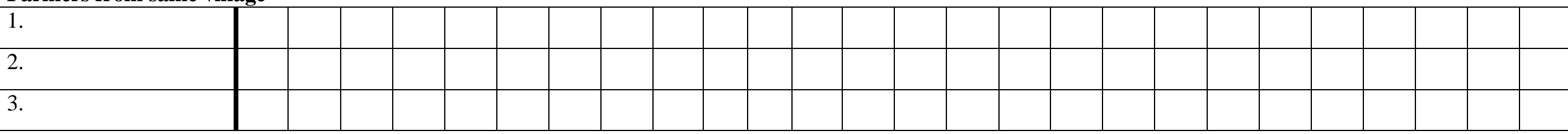

Farmers from same cluster
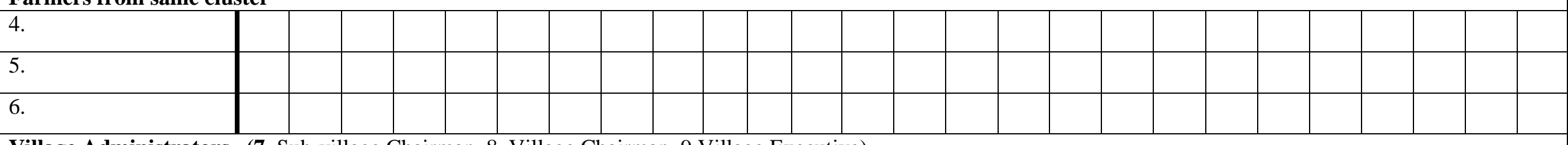

Village Administrators (7. Sub-village Chairman, 8. Village Chairman, 9.Village Executive)

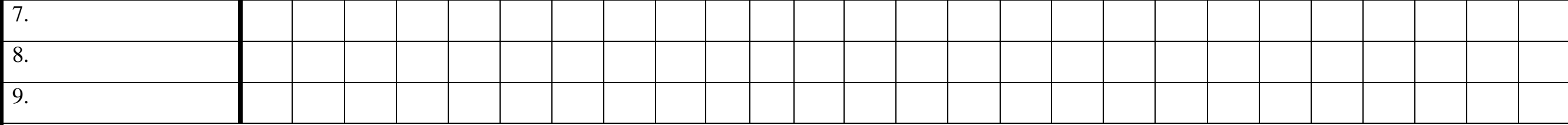

External Agents

Agricultural Ext. Officer

Research-

NGO-

Input dealer--

Grain buyer--
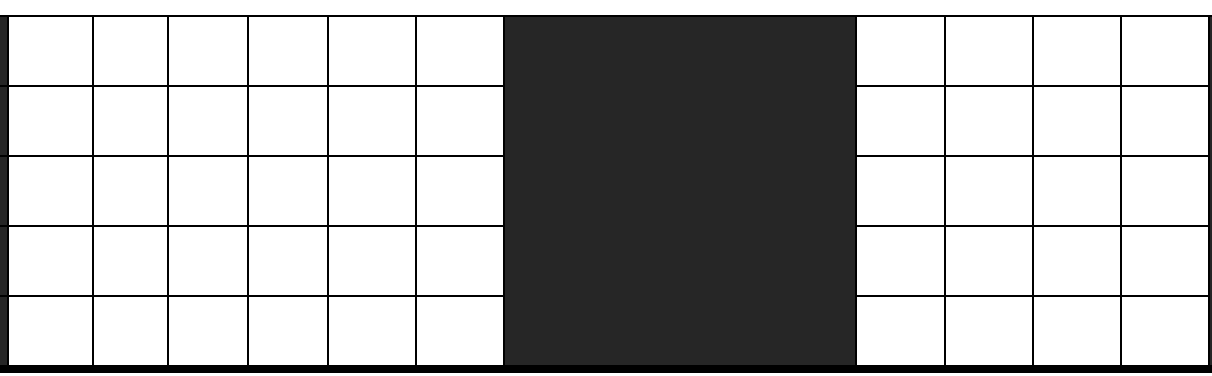


\subsection{Social Learning in Sorghum Farming}

\begin{tabular}{|c|c|c|c|c|c|c|c|c|c|}
\hline \multirow[b]{3}{*}{$\begin{array}{l}\text { Farmers }(X) \text { - From Table } \\
4.1\end{array}$} & \multicolumn{9}{|c|}{ Tell me about the following sorghum farming activities of $(X)$ during the $2011 / 12$ season } \\
\hline & \multirow{2}{*}{$\begin{array}{l}\text { Did }(X) \\
\text { cultivate } \\
\text { sorghum } \\
(\text { Codes A) }\end{array}$} & \multicolumn{8}{|c|}{ If $(X)$ cultivated sorghum } \\
\hline & & $\begin{array}{l}\text { Sorghum } \\
\text { varieties } \\
\text { cultivated } \\
\text { (Variety } \\
\text { Codes, Record } \\
\text { all reported) }\end{array}$ & $\begin{array}{l}\text { Which of the } \\
\text { varieties were } \\
\text { of modern } \\
\text { type? (Variety } \\
\text { Codes) }\end{array}$ & $\begin{array}{l}\text { From where } \\
\text { did }(X) \text { get } \\
\text { seeds of } \\
\text { modern } \\
\text { varieties? } \\
\text { (Codes B) }\end{array}$ & $\begin{array}{l}\text { From where } \\
\text { did }(X) \text { get } \\
\text { seeds of } \\
\text { local } \\
\text { varieties? } \\
\text { (Codes B) } \\
\end{array}$ & $\begin{array}{l}\text { Did (X) use } \\
\text { manure/fert } \\
\text { ilizer on } \\
\text { sorghum } \\
\text { plot? } \\
\text { (Codes A) }\end{array}$ & $\begin{array}{l}\text { How much } \\
\text { sorghum did } \\
\text { (X) harvest } \\
\text { (kg)? -99 for } \\
\text { don't know }\end{array}$ & $\begin{array}{l}\text { Did }(\mathrm{X}) \text { sell } \\
\text { part of } \\
\text { sorghum } \\
\text { harvest? } \\
\text { (Codes A) }\end{array}$ & $\begin{array}{l}\text { If yes, at what } \\
\text { price (TShs/kg)? - } \\
99=\text { don't know }\end{array}$ \\
\hline \multicolumn{10}{|l|}{ Farmers in same Village } \\
\hline \multicolumn{10}{|l|}{1.} \\
\hline \multicolumn{10}{|l|}{2.} \\
\hline \multicolumn{10}{|l|}{3.} \\
\hline \multicolumn{10}{|l|}{ Farmers in same Cluster } \\
\hline \multicolumn{10}{|l|}{4.} \\
\hline \multicolumn{10}{|l|}{5.} \\
\hline \multicolumn{10}{|l|}{6.} \\
\hline \multicolumn{10}{|c|}{ Village Administrators (7. Sub-village Chairman, 8. Village Chairman, 9.Village Executive) } \\
\hline \multicolumn{10}{|l|}{7.} \\
\hline \multicolumn{10}{|l|}{8.} \\
\hline 9. & & & & & & & & & \\
\hline
\end{tabular}

Codes A: 0=No; 1=Yes; $-\mathbf{9 9}=$ Don't know

Codes B: 1=Voucher system; 2=Another farmer; $\mathbf{3}=$ =Farmer's Club; $\mathbf{4 = L o c a l ~ t r a d e r ~ o r ~ a g r o - d e a l e r s ; ~} \mathbf{5}=$ NGO; $\mathbf{6}=$ Extension officer; $7=$ Research PVS; $8=$ Local seed producers; $\mathbf{9 = O w n}$ storage; 10=Other, specify.........-99= Don't know 
4.4 Social Learning in Finger millet Farming

\begin{tabular}{|c|c|c|c|c|c|c|c|c|c|}
\hline \multirow[b]{3}{*}{$\begin{array}{l}\text { Farmers }(X) \text { - From Table } \\
4.1\end{array}$} & \multicolumn{9}{|c|}{ Tell me about the following Finger millet farming activities of $(X)$ during the 2011/12 season } \\
\hline & \multirow[b]{2}{*}{$\begin{array}{l}\text { Did }(\mathrm{X}) \\
\text { cultivate } \\
\text { Finger } \\
\text { millet } \\
\text { (Codes A) }\end{array}$} & \multicolumn{8}{|c|}{ If $(X)$ cultivated Finger millet } \\
\hline & & $\begin{array}{l}\text { Finger millet } \\
\text { varieties } \\
\text { cultivated } \\
\text { (Variety } \\
\text { Codes, Record } \\
\text { all reported) }\end{array}$ & $\begin{array}{l}\text { Which of the } \\
\text { varieties were } \\
\text { of modern } \\
\text { type? (Variety } \\
\text { Codes) }\end{array}$ & $\begin{array}{l}\text { From where } \\
\text { did }(X) \text { get } \\
\text { seeds of } \\
\text { modern } \\
\text { varieties? } \\
(\text { Codes B) }\end{array}$ & $\begin{array}{l}\text { From where } \\
\text { did }(X) \text { get } \\
\text { seeds of } \\
\text { local } \\
\text { varieties? } \\
\text { (Codes B) }\end{array}$ & \begin{tabular}{|l|} 
Did $(X)$ use \\
manure/fert \\
ilizer on \\
Finger \\
millet plot? \\
(Codes A) \\
\end{tabular} & $\begin{array}{l}\text { How much } \\
\text { Finger millet } \\
\text { did }(\mathrm{X}) \\
\text { harvest }(\mathrm{kg}) \text { ? } \\
\mathbf{- 9 9} \text { for don't } \\
\text { know }\end{array}$ & $\begin{array}{l}\text { Did }(\mathrm{X}) \text { sell } \\
\text { part of } \\
\text { Finger } \\
\text { millet } \\
\text { harvest? } \\
\text { (Codes A) }\end{array}$ & 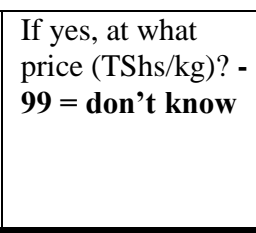 \\
\hline \multicolumn{10}{|l|}{ Farmers in same Village } \\
\hline \multicolumn{10}{|l|}{1.} \\
\hline \multicolumn{10}{|l|}{2.} \\
\hline \multicolumn{10}{|l|}{3.} \\
\hline \multicolumn{10}{|l|}{ Farmers in same Cluster } \\
\hline \multicolumn{10}{|l|}{4.} \\
\hline \multicolumn{10}{|l|}{5.} \\
\hline \multicolumn{10}{|l|}{6.} \\
\hline \multicolumn{10}{|c|}{ Village Administrators (7. Sub-village Chairman, 8. Village Chairman, 9.Village Executive) } \\
\hline \multicolumn{10}{|l|}{7.} \\
\hline \multicolumn{10}{|l|}{8.} \\
\hline 9. & & & & & & & & & \\
\hline
\end{tabular}

Codes A: 0=No; 1=Yes; -99=Don't know

Codes B: 1=Voucher system; 2=Another farmer; $\mathbf{3}=$ =Farmer's Club; $\mathbf{4 = L o c a l ~ t r a d e r ~ o r ~ a g r o - d e a l e r s ; ~} \mathbf{5}=$ NGO; $\mathbf{6}=$ Extension officer; $7=$ Research PVS; 8=Local seed producers; $\mathbf{9 = O w n}$ storage; 10=Other, specify.........-99= Don't know 


\subsection{Social Learning in Maize Farming}

\begin{tabular}{|c|c|c|c|c|c|c|c|c|c|}
\hline \multirow[b]{3}{*}{$\begin{array}{l}\text { Farmers }(X) \text { - From Table } \\
4.1\end{array}$} & \multicolumn{9}{|c|}{ Tell me about the following maize farming activities of $(X)$ during the 2011/12 season } \\
\hline & \multirow{2}{*}{$\begin{array}{l}\text { Did }(X) \\
\text { cultivate } \\
\text { maize } \\
(\text { Codes A })\end{array}$} & \multicolumn{8}{|c|}{ If $(X)$ cultivated maize } \\
\hline & & $\begin{array}{l}\text { Maize varieties } \\
\text { cultivated } \\
\text { (Variety } \\
\text { Codes, Record } \\
\text { all reported) }\end{array}$ & $\begin{array}{l}\text { Which of the } \\
\text { varieties were } \\
\text { of modern } \\
\text { type? (Variety } \\
\text { Codes) }\end{array}$ & $\begin{array}{l}\text { From where } \\
\text { did }(X) \text { get } \\
\text { seeds of } \\
\text { modern } \\
\text { varieties? } \\
(\text { Codes B) }\end{array}$ & $\begin{array}{l}\text { From where } \\
\text { did }(X) \text { get } \\
\text { seeds of } \\
\text { local } \\
\text { varieties? } \\
\text { (Codes B) }\end{array}$ & \begin{tabular}{|l} 
Did $(X)$ use \\
manure/fert \\
ilizer on \\
maize plot? \\
$($ Codes A)
\end{tabular} & $\begin{array}{l}\text { How much } \\
\text { maize did }(X) \\
\text { harvest }(\mathrm{kg}) \text { ? } \\
\mathbf{- 9 9} \text { for don't } \\
\text { know }\end{array}$ & $\begin{array}{l}\text { Did }(\mathrm{X}) \text { sell } \\
\text { part of } \\
\text { maize } \\
\text { harvest? } \\
\text { (Codes A) }\end{array}$ & 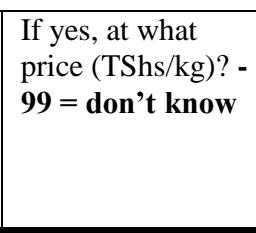 \\
\hline \multicolumn{10}{|l|}{ Farmers in same Village } \\
\hline \multicolumn{10}{|l|}{1.} \\
\hline \multicolumn{10}{|l|}{2.} \\
\hline \multicolumn{10}{|l|}{3.} \\
\hline \multicolumn{10}{|l|}{ Farmers in same Cluster } \\
\hline \multicolumn{10}{|l|}{4.} \\
\hline \multicolumn{10}{|l|}{5.} \\
\hline \multicolumn{10}{|l|}{6.} \\
\hline \multicolumn{10}{|c|}{ Village Administrators (7. Sub-village Chairman, 8. Village Chairman, 9.Village Executive) } \\
\hline \multicolumn{10}{|l|}{7.} \\
\hline \multicolumn{10}{|l|}{8.} \\
\hline 9. & & & & & & & & & \\
\hline
\end{tabular}

Codes A: $\mathbf{0 = N o}$; $1=Y e s ;-99=D o n ' t$ know

Codes B: $\mathbf{1}=$ Voucher system; $\mathbf{2}=$ Another farmer; $\mathbf{3}=$ Farmer's Club; $\mathbf{4}=$ Local trader or agro-dealers; $\mathbf{5}=\mathrm{NGO}$; $\mathbf{6}=$ Extension officer; $\mathbf{7}=$ Research PVS; $\mathbf{8}=$ Local seed producers; $\mathbf{9 =}$ =Own storage; $\mathbf{1 0}=$ Other, specify..........99= Don't know 


\subsection{Agricultural production}

5.1. Please fill the following Table about land holdings during the 2011/2012 planting season (in acres)

\begin{tabular}{|l|l|l|l|l|l|c|}
\hline \multicolumn{2}{|c|}{} & Total & $\begin{array}{c}\text { Cultivated } \\
\text { land }\end{array}$ & $\begin{array}{c}\text { Fallow } \\
\text { land }\end{array}$ & $\begin{array}{c}\text { Rented/borrowed } \\
\text { out }\end{array}$ & $\begin{array}{c}\text { Other, } \\
\text { specify** }\end{array}$ \\
\hline $\begin{array}{l}\text { Land } \\
\text { ownership }\end{array}$ & Own & & & & & \\
\cline { 2 - 7 } & Rented/borrowed in & & & & & \\
\hline
\end{tabular}

**Specification

If no land is rented/borrowed out skip to 5.2.

\subsubsection{If land was rented/borrowed /out, please fill out the following details}

\begin{tabular}{|c|c|c|c|}
\hline \multirow[t]{2}{*}{ Plot details } & \multicolumn{3}{|c|}{ Rented/Borrowed out } \\
\hline & Plot1 & Plot2 & Plot3 \\
\hline \multicolumn{4}{|l|}{ Who (Name) did you rent it to? } \\
\hline \multicolumn{4}{|c|}{ What is your relationship with the tenant? (Codes A) } \\
\hline \multicolumn{4}{|c|}{ Does tenant reside in this village? $(0=\mathrm{No} ; 1=$ Yes $)$} \\
\hline \multicolumn{4}{|l|}{ What was the size of the plot (acres)? } \\
\hline How much rent was received (TSh)? & & & \\
\hline
\end{tabular}

\section{Codes A}

$\mathbf{1}=$ Parent; 2=Child; 3=Brother/sister; 4= Grandparent; 5=Grandchild; 6=Nephew/Niece; 7=Uncle/aunt 8=Cousin; 9=Same family lineage; 10=Mother/father in-law; 11=Brother/sister in-law; 12=Other relative; 13=Fellow villager/Friend/Neighbor; 14=Professional/business colleague; $\mathbf{1 5}=$ Other, specify .......

\subsection{Key crops and purpose for cultivation}

4.1.3 Over the last 10 years, tell me about the area under sorghum, finger millet and maize on your farm.

$\begin{array}{llll}\text { Sorghum: } & 0 \text { constant } & 1 \text { increasing } & 2 \text { decreasing } \\ \text { Finger millet : } & 0 \text { constant } & 1 \text { increasing } & 2 \text { decreasing } \\ \text { Maize : } & 0 \text { constant } & 1 \text { increasing } & 2 \text { decreasing }\end{array}$

4.1.4 If both sorghum and maize areas increased/decreased, which one increased/decreased more?

(1=Sorghum; $2=$ Maize $)$

4.1.5 What are the reasons for this decision?

4.1.6 If both finger millet and maize areas increased, which one increased more?

(1=Finger millet; $2=$ Maize)

4.1.7 What are the reasons for this decision? 
5.3 Characteristics of all plots cultivated in the 2011/2012 planting season

\begin{tabular}{|c|c|c|c|c|c|c|c|c|c|c|c|c|c|c|}
\hline \multirow[b]{2}{*}{$\begin{array}{c}\text { Plot Number } \\
\text { (number starting } \\
\text { from nearest plot } \\
\text { to house) }\end{array}$} & \multirow[b]{2}{*}{ Plot name } & \multirow[b]{2}{*}{$\begin{array}{c}\text { Plot } \\
\text { location } \\
(\text { Codes A) }\end{array}$} & \multirow[b]{2}{*}{$\begin{array}{l}\text { If plot is not } \\
\text { within } \\
\text { homestead, } \\
\text { walking time } \\
\text { to plot (min) }\end{array}$} & \multirow[b]{2}{*}{$\begin{array}{l}\text { Plot } \\
\text { size } \\
\text { (acre) }\end{array}$} & \multirow[b]{2}{*}{$\begin{array}{c}\text { Plot } \\
\text { ownership } \\
\text { Code B }\end{array}$} & \multicolumn{3}{|c|}{ If plot is not own } & \multirow[b]{2}{*}{$\begin{array}{c}\text { Soil } \\
\text { fertility } \\
\text { Codes D }\end{array}$} & \multirow[b]{2}{*}{$\begin{array}{c}\text { Soil } \\
\text { type } \\
\text { Code E }\end{array}$} & \multirow[b]{2}{*}{$\begin{array}{l}\text { Slope } \\
\text { Code F }\end{array}$} & \multirow[b]{2}{*}{$\begin{array}{c}\text { Soil water } \\
\text { conservation } \\
(\mathbf{0 = n o ;} \\
\mathbf{1 = y e s})\end{array}$} & \multirow[b]{2}{*}{$\begin{array}{c}\text { Nater logging } \\
\text { on plot } \\
\mathbf{0 = n o} ; \mathbf{1}=\mathbf{y e s})\end{array}$} & \multirow[b]{2}{*}{$\begin{array}{c}\text { Striga } \\
\text { severity } \\
\text { (0=No striga; } \\
\text { 1=Low; } \\
\text { 2=Average; } \\
\text { 3=High) }\end{array}$} \\
\hline & & & & & & $\begin{array}{c}\text { what is your } \\
\text { relationship } \\
\text { with the owner } \\
\text { (Codes C) }\end{array}$ & $\begin{array}{c}\text { Does owner } \\
\text { reside in this } \\
\text { village } \\
(0=\mathrm{No} ; \\
1=\text { Yes? } \\
\end{array}$ & $\begin{array}{c}\text { How } \\
\text { much rent } \\
\text { did you } \\
\text { pay } \\
\text { (TSh)? }\end{array}$ & & & & & & \\
\hline 1. & & & & & & & & & & & & & & \\
\hline 2. & & & & & & & & & & & & & & \\
\hline 3. & & & & & & & & & & & & & & \\
\hline 4. & & & & & & & & & & & & & & \\
\hline 5. & & & & & & & & & & & & & & \\
\hline 6. & & & & & & & & & & & & & & \\
\hline 7. & & & & & & & & & & & & & & \\
\hline 8. & & & & & & & & & & & & & & \\
\hline 9. & & & & & & & & & & & & & & \\
\hline 10. & & & & & & & & & & & & & & \\
\hline
\end{tabular}

\section{Codes A}

1. Within the homestead

2. Outside the homestead, same village

3. Outside the homestead, different village

\section{Codes B Codes $\mathrm{C}$}

1 Own 1=Parent

2 Borrowed 2=Child

3 Rented in $3=$ Brother/sister

4=Grandparent

$\mathbf{5}=$ Grandchild

6=Nephew/Niece

7=Uncle/aunt

$8=$ Cousin
9=Same family lineage

$\mathbf{1 0}=$ Mother/father in-law

$\mathbf{1 1}=$ Brother/sister in-law

12=Other relative

13=Fellow villager/Neighbor

14=Attend same church/mosque

15=Professional/business colleague

16 $=$ Other, specify .......

\section{Codes D Codes E}

1 Poor

2 Medium

3 Good

1 Finyanzi (clay)

2 Tifutifu (loam)

3 Kichanga (sandy)

4 Other, specify

\section{Codes F}

1 Gentle slope (flat)

2 Medium slope

3 Steep slope 
5.4 Characteristics of crop production in the 2011/2012 planting season (information has to be filled per plot and variety for the previous planting season. Each plot and each variety at the same plot have a separate row)

\begin{tabular}{|c|c|c|c|c|c|c|c|c|c|c|c|c|c|c|c|c|c|c|c|c|c|}
\hline \multirow[b]{2}{*}{$\begin{array}{c}\text { Plot name } \\
\text { (From Table } \\
5.3 \text { ) }\end{array}$} & \multirow{2}{*}{$\begin{array}{l}\text { Crops } \\
\text { grown } \\
\text { Crop } \\
\text { codes }\end{array}$} & \multicolumn{2}{|c|}{$\begin{array}{l}\text { If crop grown is sorghum, } \\
\text { finger millet or maize }\end{array}$} & \multirow[b]{2}{*}{$\begin{array}{l}\text { Area } \\
\text { cultivated } \\
\text { (acres) }\end{array}$} & \multicolumn{2}{|c|}{$\begin{array}{l}\text { Time of } \\
\text { Sowing }\end{array}$} & \multirow{2}{*}{$\begin{array}{c}\text { Inter } \\
\text { cropping } \\
\text { (0=no; } \\
\text { 1=yes) }\end{array}$} & \multirow{2}{*}{\begin{tabular}{|c|} 
If inter \\
cropping: \\
With which \\
crop? \\
Crop codes
\end{tabular}} & \multirow[b]{2}{*}{$\begin{array}{c}\text { Irrigated } \\
(0=\text { no; } \\
1=\text { yes })\end{array}$} & \multicolumn{2}{|c|}{$\begin{array}{c}\text { Onset of } \\
\text { rains }\end{array}$} & \multicolumn{2}{|c|}{\begin{tabular}{|l|} 
Time of \\
Harvest
\end{tabular}} & \multicolumn{3}{|c|}{ Total amount harvested } & \multicolumn{3}{|c|}{ Total amount sold } & \multicolumn{2}{|c|}{ Revenue } \\
\hline & & $\begin{array}{l}\text { Name of } \\
\text { Variety } \\
\text { (Variety } \\
\text { codes) }\end{array}$ & $\begin{array}{l}\text { Type of } \\
\text { variety } \\
\text { (1=Local; } \\
2=\text { Modern }\end{array}$ & & Month & Week & & & & Month & Week & Month & Week & $\begin{array}{c}\text { Bags } \\
(120 \mathrm{~kg})\end{array}$ & $\begin{array}{c}\text { Tins } \\
(20 \mathrm{~kg})\end{array}$ & $\mathrm{kg}$ & $\begin{array}{c}\text { Bags } \\
(120 \mathrm{~kg})\end{array}$ & $\left|\begin{array}{c}\text { Tins } \\
(20 \mathrm{~kg})\end{array}\right|$ & $\mathrm{kg}$ & $\begin{array}{c}\text { Average } \\
\text { Price } \\
\text { (TShs/Kg }\end{array}$ & $\begin{array}{c}\text { Gross sales } \\
\text { (TSh) }\end{array}$ \\
\hline & & & & & & & & & & & & & & & & & & & & & \\
\hline & & & & & & & & & & & & & & & & & & & & & \\
\hline & & & & & & & & & & & & & & & & & & & & & \\
\hline & & & & & & & & & & & & & & & & & & & & & \\
\hline & & & & & & & & & & & & & & & & & & & & & \\
\hline & & & & & & & & & & & & & & & & & & & & & \\
\hline & & & & & & & & & & & & & & & & & & & & & \\
\hline & & & & & & & & & & & & & & & & & & & & & \\
\hline & & & & & & & & & & & & & & & & & & & & & \\
\hline & & & & & & & & & & & & & & & & & & & & & \\
\hline & & & & & & & & & & & & & & & & & & & & & \\
\hline & & & & & & & & & & & & & & & & & & & & & \\
\hline
\end{tabular}

\section{Crop Codes}

1. Sorghum

2. Finger Millet

3. Maize

6. Pigeonpea

7. Cowpea

8. Groundnut

4. Pearl/bulrush millet

5. Sunflower

9. Bambara nut

10. Simsim

11. Other, specify......

Variety Codes 5. Local variety Sorghum

1. Langalanga

2. Pato

3. Macia

4. Tegemeo

$$
\text { (unspecified) }
$$

6. Sila

7. Serena

8. Udo

9. KARI Mtama1
Maize

10. Modern variety 21. America (Local) 27. DK (unspecified)

11. Other sorghum variety.. $\begin{array}{lll}\text { 22. } & \text { Kiseku (local) } & \text { 28. } \\ \text { Ilonga }\end{array}$

23. Kitumbiri (local) 29. Staha

24. Hybrid 30. Kilima,

25. Pannar

26. Pioneer
32. Situka

33. Cargil,

34. Katumani

35. Modern variety (unspecified)

36. Local variety (unspecified)

37. Other maize variety ........... 
5.4.1 Crop production inputs in the 2011/2012 planting season (Please ask for all inputs per plot and crop level).

\begin{tabular}{|c|c|c|c|c|c|c|c|c|c|c|c|c|c|c|c|}
\hline \multirow{3}{*}{$\begin{array}{c}\begin{array}{c}\text { Plot } \\
\text { name }\end{array} \\
\text { (from } \\
\text { Table } \\
5.3)\end{array}$} & \multirow{3}{*}{$\begin{array}{c}\text { Crop } \\
\text { (from } \\
\text { Table } \\
5.4)\end{array}$} & \multirow{3}{*}{$\begin{array}{c}\text { Variety } \\
\text { (Codes } \\
\text { from } \\
\text { Table } \\
\text { 5.4) } \\
\end{array}$} & \multicolumn{3}{|c|}{ Seeds } & \multicolumn{6}{|c|}{ Fertilizer } & \multicolumn{3}{|c|}{ Manure/ Compost } & \multirow{3}{*}{$\begin{array}{c}\text { Pesticides } \\
\text { Total } \\
\text { Expenditure } \\
\text { TSh } \\
\end{array}$} \\
\hline & & & \multirow{2}{*}{$\begin{array}{l}\text { Own } \\
\text { /gift } \\
(\mathrm{kg}) \\
\end{array}$} & \multicolumn{2}{|c|}{ Bought } & \multicolumn{2}{|c|}{ DAP } & \multicolumn{2}{|c|}{ Urea } & \multicolumn{2}{|c|}{ TSP } & \multirow{2}{*}{$\begin{array}{l}\text { Own/ } \\
\text { gift } \\
\text { (ox- } \\
\text { cart) }\end{array}$} & \multicolumn{2}{|c|}{ Bought } & \\
\hline & & & & $\mathrm{kg}$ & $\begin{array}{l}\text { Price in } \\
\text { TSh/kg }\end{array}$ & $\mathrm{kg}$ & $\left|\begin{array}{l}\text { Price in } \\
\text { TSh} / \mathrm{kg}\end{array}\right|$ & $\mathrm{kg}$ & $\begin{array}{l}\text { Price in } \\
\text { TSh } / \mathrm{kg}\end{array}$ & $\mathrm{Kg}$ & $\begin{array}{l}\text { Price in } \\
\mathrm{TSh} / \mathrm{kg}\end{array}$ & & Ox-cart & $\begin{array}{l}\text { Price in } \\
\text { TSh/cart }\end{array}$ & \\
\hline & & & & & & & & & & & & & & & \\
\hline & & & & & & & & & & & & & & & \\
\hline & & & & & & & & & & & & & & & \\
\hline & & & & & & & & & & & & & & & \\
\hline & & & & & & & & & & & & & & & \\
\hline & & & & & & & & & & & & & & & \\
\hline & & & & & & & & & & & & & & & \\
\hline & & & & & & & & & & & & & & & \\
\hline & & & & & & & & & & & & & & & \\
\hline & & & & & & & & & & & & & & & \\
\hline & & & & & & & & & & & & & & & \\
\hline & & & & & & & & & & & & & & & \\
\hline & & & & & & & & & & & & & & & \\
\hline & & & & & & & & & & & & & & & \\
\hline
\end{tabular}

\section{Crop Codes}

1. Sorghum

2. Finger Millet

3. Maize

4. Pearl/bulrush millet

5. Sunflower

6. Pigeonpea

7. Cowpea

8. Groundnut
Variety Codes

9. Bambara nut Sorghum

10. Simsim 1. Langalanga

11. Other,

specify
2. Pato

3. Macia

4. Tegemeo

5. Local variety (unspecified)

6. Sila
7. Serena

8. Udo

9. KARI Mtama1

10. Modern variety (unspecified)

11. Other sorghum variety...

\section{Maize}

21. America (Local) 29. Staha

22. Kiseku (local) 30. Kilima,

23. Kitumbiri (local) 31. SeedCo

24. Hybrid

25. Pannar

26. Pioneer

27. DK

28. Ilonga
32. Situka

33. Cargil,

34. Katumani

35. Modern variety (unspecified)

36. Local variety (unspecified)

37. Other maize variety

5.4.2 If farmer did not use manure/fertiliser/pesticides, what are the main reasons (If more than 1 reasons, rank them)

\begin{tabular}{|c|c|c|c|c|}
\hline Input & Reason1 & Reason2 & Reason3 & Codes \\
\hline Manure/compost & & & & \multirow{3}{*}{ 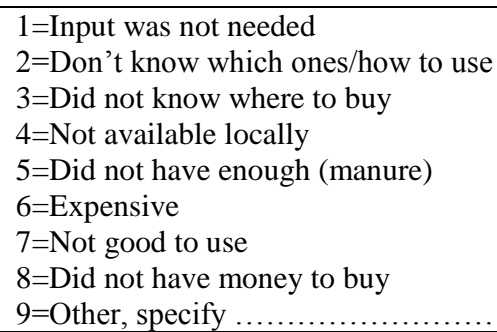 } \\
\hline Fertilizers & & & & \\
\hline Pesticides & & & & \\
\hline
\end{tabular}




\subsection{What were your main sources of seeds for sorghum, finger millet and maize in the 2011/2012 planting season?}

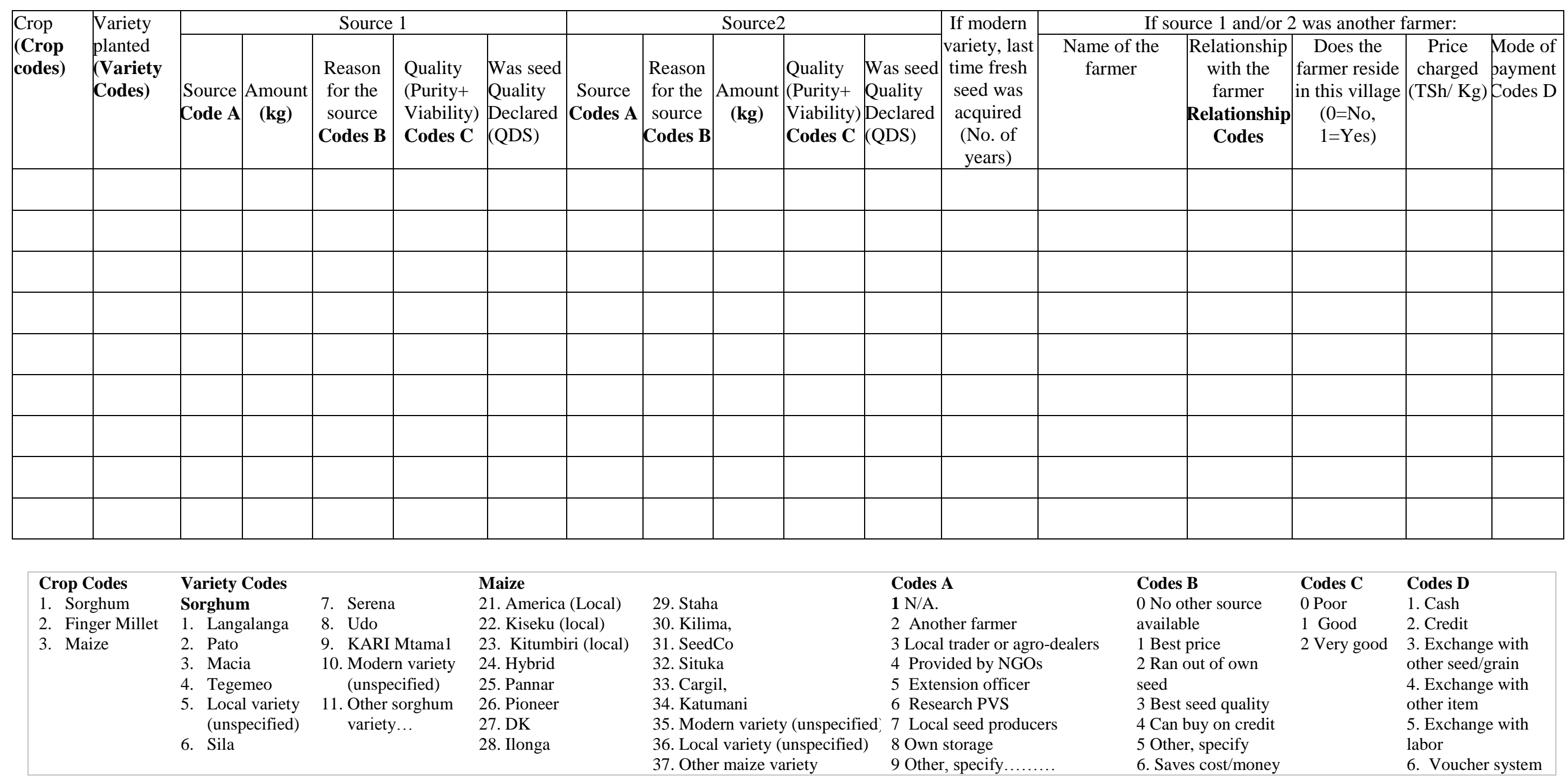


5.6 Labor and machinery costs for crop production

5.6.1 Please let the farmer choose one of the plots on which s/he grew sorghum/finger millet/maize in the 2011/2012 planting season and fill the following table for labour inputs for this plot.

\begin{tabular}{|c|c|c|c|c|c|c|c|}
\hline \multirow[b]{2}{*}{ Operations } & & \multicolumn{2}{|c|}{$\begin{array}{c}\text { Sorghum } \\
\text { Plot................. } \\
\text { Variety.............. }\end{array}$} & \multicolumn{2}{|c|}{$\begin{array}{c}\text { Finger millet } \\
\text { Plot................... } \\
\text { Variety............. }\end{array}$} & \multicolumn{2}{|c|}{$\begin{array}{c}\text { Maize } \\
\text { Plot } \ldots \ldots \ldots \ldots \ldots \ldots \\
\text { Variety............... }\end{array}$} \\
\hline & & $\begin{array}{c}\text { Family } \\
\text { Labour } \\
\text { Days }\end{array}$ & $\begin{array}{c}\text { Total } \\
\text { mandays } \\
\text { for hired } \\
\text { labour }\end{array}$ & $\begin{array}{r}\text { Family } \\
\text { Labour } \\
\text { Days }\end{array}$ & $\begin{array}{c}\text { Total } \\
\text { mandays } \\
\text { for hired } \\
\text { labour }\end{array}$ & $\begin{array}{c}\text { Family } \\
\text { Labour } \\
\text { Days }\end{array}$ & $\begin{array}{c}\text { Total } \\
\text { mandays } \\
\text { for hired } \\
\text { labour }\end{array}$ \\
\hline \multirow{3}{*}{$\begin{array}{l}1 \text { Land preparation (Ploughing } \\
\text { primary and secondary tillage) }\end{array}$} & Total & & & & & & \\
\hline & Adult & & & & & & \\
\hline & Child & & & & & & \\
\hline \multirow{3}{*}{$\begin{array}{l}\text { 2. FYM/C } \\
\text { Compost/Manure application }\end{array}$} & Total & & & & & & \\
\hline & Adult & & & & & & \\
\hline & Child & & & & & & \\
\hline \multirow[t]{3}{*}{ 3. Seed treatment } & Total & & & & & & \\
\hline & Adult & & & & & & \\
\hline & Child & & & & & & \\
\hline \multirow{3}{*}{$\begin{array}{l}\text { 4. Planting/Sowing and } \\
\text { fertilizer application }\end{array}$} & Total & & & & & & \\
\hline & Adult & & & & & & \\
\hline & Child & & & & & & \\
\hline \multirow{3}{*}{$\begin{array}{l}\text { 5.Weeding/Herbicide } \\
\text { application }\end{array}$} & Total & & & & & & \\
\hline & Adult & & & & & & \\
\hline & Child & & & & & & \\
\hline \multirow{3}{*}{$\begin{array}{l}\text { 6. Plant protection (Spraying/ } \\
\text { Dusting/Shaking) }\end{array}$} & Total & & & & & & \\
\hline & Adult & & & & & & \\
\hline & Child & & & & & & \\
\hline \multirow[t]{3}{*}{ 7. Irrigation } & Total & & & & & & \\
\hline & Adult & & & & & & \\
\hline & Child & & & & & & \\
\hline \multirow[t]{3}{*}{ 8.. Watching (Birds, Pigs etc.,) } & Total & & & & & & \\
\hline & Adult & & & & & & \\
\hline & Child & & & & & & \\
\hline \multirow[t]{3}{*}{ 10.. Harvesting } & Total & & & & & & \\
\hline & Adult & & & & & & \\
\hline & Child & & & & & & \\
\hline \multirow[t]{3}{*}{ 11. Threshing } & Total & & & & & & \\
\hline & Adult & & & & & & \\
\hline & Child & & & & & & \\
\hline \multirow[t]{3}{*}{ 12. Seed cleaning, purification } & Total & & & & & & \\
\hline & Adult & & & & & & \\
\hline & Child & & & & & & \\
\hline \multirow{3}{*}{$\begin{array}{l}\text { 13. Storage (including } \\
\text { transport) }\end{array}$} & Total & & & & & & \\
\hline & Adult & & & & & & \\
\hline & Child & & & & & & \\
\hline \multicolumn{8}{|l|}{ Total paid to hired labour (TSh) } \\
\hline \multicolumn{2}{|l|}{ Total paid to hired oxen (TSh) } & & & & & & \\
\hline \multicolumn{2}{|c|}{ Total paid to hired equipment (TSh) } & & & & & & \\
\hline
\end{tabular}


5.6.2. If you have filled in Table 5.6.1, fill in this table for the same plots as Table 5.6.1

Plot name sorghum:

Plot name finger millet:

\begin{tabular}{|c|c|c|c|c|}
\hline Operations & Practices for sorghum & $\begin{array}{c}\text { Tick if } \\
\text { used }\end{array}$ & Practices for finger millet & $\begin{array}{c}\text { Tick if } \\
\text { used }\end{array}$ \\
\hline \multirow{6}{*}{$\begin{array}{l}\text { 1A. Land preparation } \\
\text { (Ploughing } \\
\text { primary and secondary } \\
\text { tillage) }\end{array}$} & Animal traction & & Animal traction & \\
\hline & Tractor plough & & Tractor plough & \\
\hline & Power Tiller & & Power Tiller & \\
\hline & Hand hoe & & Hand hoe & \\
\hline & Zero Tillage & & Zero Tillage & \\
\hline & Other, specify ........... & & Other, specify............ & \\
\hline \multirow{3}{*}{$\begin{array}{l}\text { 2. Compost/Manure } \\
\text { application }\end{array}$} & Farmyard manure & & Farmyard manure & \\
\hline & Compost & & Compost & \\
\hline & Other, specify ........... & & Other, specify........... & \\
\hline \multirow[t]{4}{*}{ 3. Seed treatment } & Fungicide & & Fungicide & \\
\hline & Ash & & & \\
\hline & Neem products & & & \\
\hline & Other, specify ........... & & Other, specify........... & \\
\hline \multirow[t]{4}{*}{ 4. Planting/Sowing } & Row planting $60 \times 20 \mathrm{~cm}$ & & Row planting $40 \mathrm{~cm} \times 10 \mathrm{~cm}$ & \\
\hline & $90 \mathrm{~cm} \mathrm{X} 30 \mathrm{cms}$ (local) & & $30 \mathrm{~cm} \times 15 \mathrm{cms}$ & \\
\hline & $80 \mathrm{~cm} \mathrm{X} 30 \mathrm{cms}$ (improved) & & Other, specify........... & \\
\hline & Other, specify ........... & & & \\
\hline \multirow[t]{3}{*}{ 5. Fertilizer application } & Microdosing & & Microdosing & \\
\hline & Split application & & Split application & \\
\hline & Other, specify ............ & & Other, specify ............ & \\
\hline \multirow{5}{*}{$\begin{array}{l}\text { 6. Weeding/Herbicide } \\
\text { application }\end{array}$} & Hand weeding 1 times & & Hand weeding 1 times & \\
\hline & Hand weeding 2 times & & Hand weeding 2 times & \\
\hline & Herbicide - pre emergence & & Herbicide -pre emergence & \\
\hline & Herbicide post emergence & & Herbicide post emergence & \\
\hline & Other, specify ........... & & Other, specify ........... & \\
\hline \multirow[t]{3}{*}{ 7. Striga control } & $\begin{array}{l}\text { Mechanical (weeding/hand } \\
\text { pulling) }\end{array}$ & & $\begin{array}{l}\text { Mechanical (weeding/hand } \\
\text { pulling) }\end{array}$ & \\
\hline & $\begin{array}{l}\text { Integrated striga management } \\
\text { (ISM) }\end{array}$ & & $\begin{array}{l}\text { Integrated striga management } \\
\text { (ISM) }\end{array}$ & \\
\hline & Other, specify ........... & & Other, specify........... & \\
\hline
\end{tabular}




\begin{tabular}{|c|c|c|c|c|}
\hline Operations & Practices for sorghum & $\begin{array}{c}\text { Tick if } \\
\text { used }\end{array}$ & Practices for finger millet & $\begin{array}{c}\text { Tick if } \\
\text { used }\end{array}$ \\
\hline \multirow{2}{*}{$\begin{array}{l}\text { 8.Plant protection - } \\
\text { Spraying/Dusting/ } \\
\text { Shaking /Hand picking) }\end{array}$} & Insecticide for stalk borer & & Insecticide for stalk borer & \\
\hline & Other, specify........... & & Other, specify........... & \\
\hline \multirow[t]{2}{*}{ 9. Irrigation } & Water harvesting & & In situ water harvesting & \\
\hline & Other, specify ........... & & Other, specify........... & \\
\hline \multirow[t]{2}{*}{$\begin{array}{l}\text { 10. Watching (Birds, } \\
\text { Pigs etc.,) }\end{array}$} & $\begin{array}{l}\text { Bird scaring, specify how } \\
\ldots \ldots \ldots \ldots . . .\end{array}$ & & $\begin{array}{l}\text { Bird scaring, specify how } \\
\ldots \ldots \ldots \ldots . . .\end{array}$ & \\
\hline & Other, specify ........... & & Other, specify........... & \\
\hline \multirow[t]{2}{*}{ 11. Harvesting } & $\begin{array}{l}\text { Manual harvesting (Cutting the } \\
\text { heads) }\end{array}$ & & $\begin{array}{l}\text { Manual harvesting (Cutting the } \\
\text { heads) }\end{array}$ & \\
\hline & Other, specify ............ & & Other, specify........... & \\
\hline \multirow[t]{4}{*}{ 12. Threshing } & Threshers & & Threshers & \\
\hline & Animal tramping & & Animal tramping & \\
\hline & Manual (beating) & & Manual (beating) & \\
\hline & Other, specify ............ & & Other, specify ............ & \\
\hline \multirow{2}{*}{$\begin{array}{l}13 \text { Post-harvest activities: } \\
\text { Dressing }\end{array}$} & Insecticide & & Insecticide & \\
\hline & Other, specify........... & & Other, specify........... & \\
\hline \multirow{5}{*}{$\begin{array}{l}13 \text { Post-harvest activities: } \\
\text { Milling }\end{array}$} & Dehulling & & Dehulling & \\
\hline & Milling without dehulling & & Milling without dehulling & \\
\hline & Hand milling & & Hand milling & \\
\hline & Hammer mill & & Hammer mill & \\
\hline & Other, specify & & Other, specify & \\
\hline
\end{tabular}


6.0 Livestock, farm and non-farm assets

6.1 Livestock production activities.

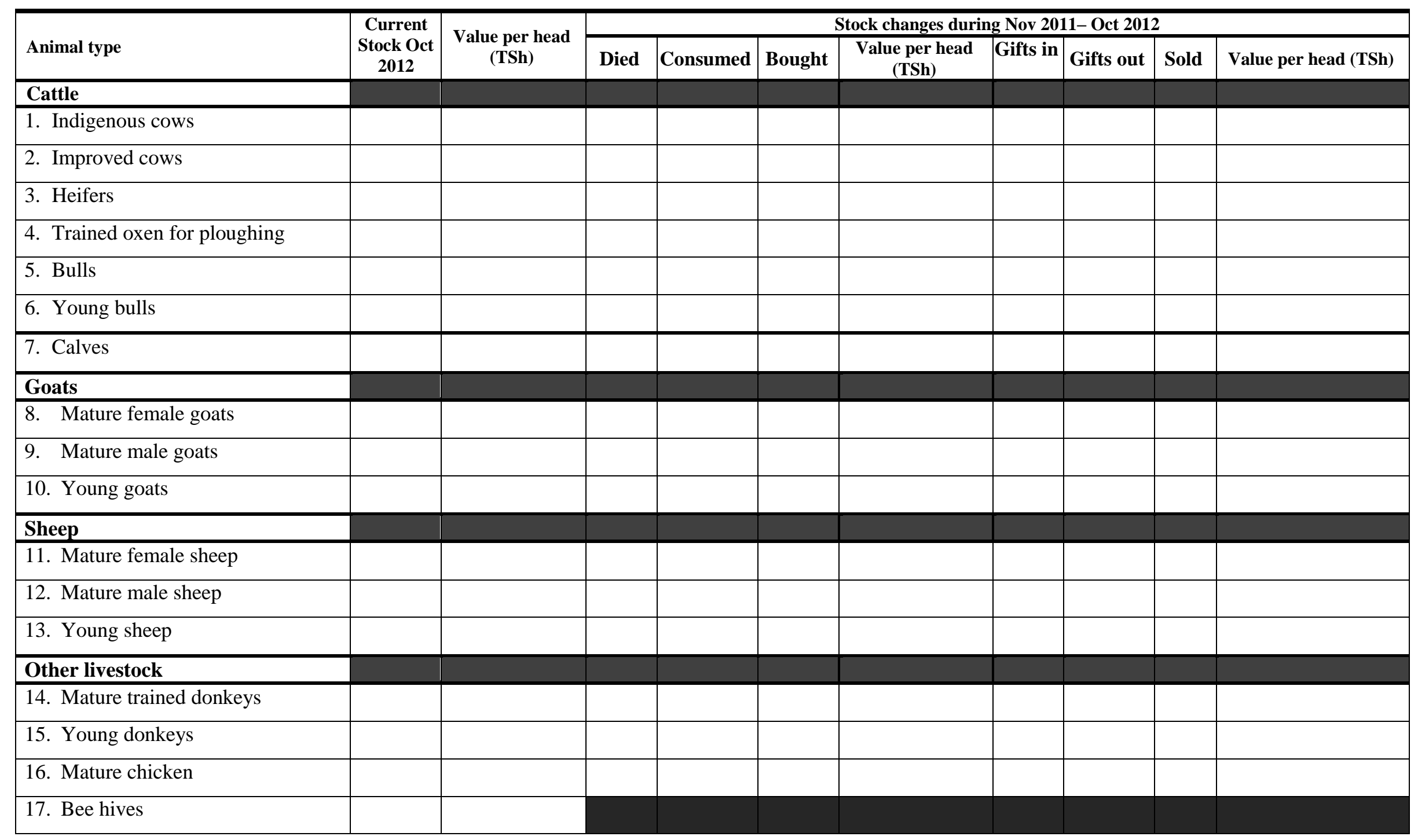


6.2 Livestock input costs (Please record for the last 12 months).

\begin{tabular}{|l|c|}
\hline Description & $\begin{array}{c}\text { Total cost } \\
\text { (TSh) }\end{array}$ \\
\hline 1.Crop residue & \\
\hline 2. Green fodder & \\
\hline 3.Dry fodder (hay) & \\
\hline 4.Concentrates & \\
\hline 5.Veterinary/AI services & \\
\hline 6.Herds boy (animal tending) & \\
\hline Other costs, specify & \\
\hline
\end{tabular}

6.3 Production and utilization of livestock products (Nov 2011 - OCT 2012)

\begin{tabular}{|c|c|c|c|c|c|c|c|}
\hline $\begin{array}{c}\text { Livestock } \\
\text { products }\end{array}$ & $\begin{array}{l}\text { Quantity } \\
\text { produced }\end{array}$ & $\begin{array}{c}\text { Units of } \\
\text { production } \\
(\text { Codes A) } \\
\end{array}$ & $\begin{array}{c}\text { Frequency of } \\
\text { production } \\
(\text { Codes B) }\end{array}$ & $\begin{array}{c}\text { Number of } \\
\text { productive } \\
\text { months } \\
\end{array}$ & $\begin{array}{l}\text { Quantity } \\
\text { consumed }\end{array}$ & $\begin{array}{c}\text { Quantity } \\
\text { sold }\end{array}$ & $\begin{array}{l}\text { price } \\
\text { (TSh) }\end{array}$ \\
\hline \multicolumn{8}{|l|}{ Milk } \\
\hline \multicolumn{8}{|l|}{ Eggs } \\
\hline \multicolumn{8}{|l|}{ Animal skin } \\
\hline Honey & & & & & & & \\
\hline
\end{tabular}

Codes A: 1=Litres; $\mathbf{2}=\mathrm{Kg} ; \mathbf{3}=$ Pieces; $\mathbf{4}=$ Trays; $\mathbf{5}=$ Other, specify.

Codes B: 1=Daily; 2=Weekly; $\mathbf{3}=$ Monthly; $\mathbf{4 = E v e r y ~} 3$ months; $\mathbf{5}=$ =Every 4 months; $\mathbf{6}=$ Every 6 months; $7=$ Annually; $8=$ Other, specify.......

6.4 Please fill the following Table for household farm assets which you currently own

\begin{tabular}{|l|l|l|l|}
\hline Asset name & Number & $\begin{array}{l}\text { Current } \\
\text { value per } \\
\text { piece (TSH) }\end{array}$ & $\begin{array}{l}\text { Total } \\
\text { Current } \\
\text { value (TSH) }\end{array}$ \\
\hline 1. Ox-ploughing set & & & \\
\hline 2. Ox-cart & & & \\
\hline 3. Sickle & & & \\
\hline 4. Panga knife & & & \\
\hline 5. Axe & & & \\
\hline 6. Spade/Shovel & & & \\
\hline 7. Hoes & & & \\
\hline
\end{tabular}

\begin{tabular}{|l|l|l|l|}
\hline Asset name & Number & $\begin{array}{l}\text { Current } \\
\text { value per } \\
\text { piece (TSH) }\end{array}$ & $\begin{array}{l}\text { Total } \\
\text { Current } \\
\text { value (TSH) }\end{array}$ \\
\hline 8. Sprayer & & & \\
\hline 9. Wheel barrow & & & \\
\hline 10. Bicycle & & & \\
\hline 11. Motorized vehicles & & & \\
\hline 12. Radio/radio cassette & & & \\
\hline 13. Mobile phone & & & \\
\hline 14. Television (TV) & & & \\
\hline
\end{tabular}


7.0 Membership to farmer organizations/clubs

\begin{tabular}{|c|c|c|c|c|c|c|c|c|c|c|c|c|c|}
\hline $\begin{array}{l}\text { Is any of your } \\
\text { household } \\
\text { members a } \\
\text { member of an } \\
\text { association, } \\
\text { Group, or club } \\
(\mathbf{0 = N o} \text { 1=Yes) }\end{array}$ & $\begin{array}{l}\text { If no, give } \\
\text { reasons } \\
\text { Codes A, } \\
\text { rank 3) }\end{array}$ & $\begin{array}{l}\text { If Yes, what's the } \\
\text { name of } \\
\text { Association, } \\
\text { Coop, Group, or } \\
\text { club (List all) }\end{array}$ & $\begin{array}{l}\text { Who is a } \\
\text { member } \\
\text { Code B }\end{array}$ & $\begin{array}{l}\text { Type of } \\
\text { membership } \\
(\text { Codes } \mathbf{C})\end{array}$ & $\begin{array}{l}\text { Association } \\
\text { or club } \\
\text { functions } \\
\text { Codes D, } \\
\text { rank 2 }\end{array}$ & $\begin{array}{l}\text { Year } \\
\text { joined }\end{array}$ & $\begin{array}{l}\text { Current } \\
\text { entry fee } \\
\text { (TSH) }\end{array}$ & $\begin{array}{l}\text { Subscription } \\
\text { fee (TSH) }\end{array}$ & $\begin{array}{l}\text { Frequency of } \\
\text { subscriptions } \\
(\text { Codes E) }\end{array}$ & $\begin{array}{l}\text { Frequency of } \\
\text { meetings } \\
(\text { Codes E) }\end{array}$ & $\begin{array}{l}\text { Number of } \\
\text { meetings } \\
\text { member } \\
\text { attended in } \\
2012\end{array}$ & $\begin{array}{l}\text { Total } \\
\text { number of } \\
\text { members }\end{array}$ & $\begin{array}{l}\text { Has your } \\
\text { group been } \\
\text { visited by } \\
\text { extension } \\
\text { officer in the } \\
\text { last } 2 \text { years? } \\
(0=\text { No; } \\
1=\text { Yes })\end{array}$ \\
\hline & & & & & & & & & & & & & \\
\hline & & & & & & & & & & & & & \\
\hline & & & & & & & & & & & & & \\
\hline & & & & & & & & & & & & & \\
\hline & & & & & & & & & & & & & \\
\hline & & & & & & & & & & & & & \\
\hline & & & & & & & & & & & & & \\
\hline
\end{tabular}

\section{Code A}

1. No need to join one

2. No such groups exist in the area

3. Cannot afford subscription fee

4. Does not have time for group meetings

5. No faith in leadership of existing group

6. Other, specify .....
Codes B

1 Household head

2 Spouse

3 Son/daughter

4 Parent

5 Son/daughter in-law

6 Grand child

Other relative

9 Other, specify.....

\section{Codes C}

1 Ordinary member

2 Executive committee member

3 Other committee member

4 Patron

5 Other, specify

\section{Code D}

1 Crop/livestock marketing

2 Input access/marketing

3 Seed production

4 Farmer research group

5 Savings and credit

6 Welfare/funeral club

7 Tree planting and nurseries

8 Soil \& water conservation

9 Input credit

10 Local administration

11 Other, specify
Code E

1. Weekly

2. Bi-weekly

3 . Monthly

4. Every 3 Months

5. Every 4 Months

6. Every 6 months

7. Yearly

8. Not regular

9. Other,

specify.............. 


\subsection{Participation in HOPE activities in the last 2 years}

8.1 Did you participate in any HOPE activity during the last 2 years? $0=$ no; $1=$ yes

8.2 If yes, in which activities did you participate? (Fill in the table below)

\begin{tabular}{|c|c|c|c|c|c|c|}
\hline \multirow{2}{*}{ Activity } & \multirow[b]{2}{*}{$\begin{array}{l}\text { How many } \\
\text { times did } \\
\text { you } \\
\text { participate } \\
\text { in this } \\
\text { activity in } \\
2011\end{array}$} & \multirow[b]{2}{*}{$\begin{array}{l}\text { How many } \\
\text { times did } \\
\text { you } \\
\text { participate } \\
\text { in this } \\
\text { activity in } \\
2012\end{array}$} & \multicolumn{3}{|c|}{ If farmer participated, } & \multirow[b]{2}{*}{$\begin{array}{l}\text { If farmer } \\
\text { did not } \\
\text { participate } \\
\text { what are } \\
\text { the reasons } \\
\text { (Codes B, } \\
\text { rank if } \\
\text { more than1) }\end{array}$} \\
\hline & & & $\begin{array}{l}\text { how did s/he get } \\
\text { information about } \\
\text { the activity } \\
\text { (Codes } \mathbf{A} \text { ) }\end{array}$ & $\begin{array}{l}\text { Which crops } \\
\text { were } \\
\text { covered? } \\
\text { (Crop codes) }\end{array}$ & $\begin{array}{l}\text { Did you } \\
\text { also get } \\
\text { some seeds } \\
(0=\text { No, } \\
1=\text { Yes })\end{array}$ & \\
\hline \multicolumn{7}{|l|}{ Attended/hosted a HOPE field day } \\
\hline \multicolumn{7}{|l|}{ Visited/attended a HOPE trials/demo farm } \\
\hline $\begin{array}{l}\text { Participated in a HOPE' Participatory } \\
\text { Variety Selection (PVS) }\end{array}$ & & & & & & \\
\hline
\end{tabular}

\section{Codes A}

1. Extension officer

2. Village Chairman

3. Village Executive

4. Cell Leader

5. Ward Executive Officer

6. Councillor

\section{Codes B}

1. Did not require extension services

2. Did not know where to get the extension officer

3. Long distance to extension office

4. Cannot afford the cost of bringing extension officer to the farm

5. Was not aware of such an event

6. Was aware but was not invited

7. Invitation came late

8. Was not aware of the agenda
9. Long distance to event venue

10. Other commitments

11. Was sick/attending to a sick person

12. Farmer had travelled out of the village

13. Activity would not have been beneficial

14. Other, specify......

8.3 If the household participated in any HOPE activities please fill the following table

\begin{tabular}{|l|l|l|l|l|}
\hline $\begin{array}{l}\text { Please describe in your own } \\
\text { words the topics covered/ } \\
\text { what you learnt }\end{array}$ & $\begin{array}{l}\text { Had you } \\
\text { learnt about } \\
\text { this before? } \\
\left(\begin{array}{l}0=\text { No, } \\
1=\text { Yes) }\end{array}\right.\end{array}$ & $\begin{array}{l}\text { Do you apply } \\
\text { them on your } \\
\text { farm? (0=No, } \\
1=\text { Yes })\end{array}$ & $\begin{array}{l}\text { If NO, will } \\
\text { you apply } \\
\text { them on your } \\
\text { farm? (0=No, } \\
1=\text { Yes })\end{array}$ & If no: why not? \\
\hline & & & & \\
\hline & & & & \\
\hline & & & & \\
\hline & & & & \\
\hline & & & & \\
\hline
\end{tabular}


8.4 Participation in other activities concerning technology transfer in the last 2 years

\begin{tabular}{|l|l|l|l|l|l|l|}
\hline Activity & $\begin{array}{l}\text { How many } \\
\text { times did } \\
\text { you } \\
\text { participate } \\
\text { in this } \\
\text { activity in } \\
2011\end{array}$ & $\begin{array}{l}\text { How many } \\
\text { times did } \\
\text { you } \\
\text { participate } \\
\text { in this } \\
\text { activity in } \\
2012\end{array}$ & $\begin{array}{l}\text { If farmer participated, } \\
\text { how did s/he } \\
\text { get } \\
\text { information } \\
\text { about the } \\
\text { activity } \\
\text { (Codes A) }\end{array}$ & $\begin{array}{l}\text { Which } \\
\text { crops } \\
\text { were } \\
\text { covered? } \\
\text { (Crop } \\
\text { codes) }\end{array}$ & $\begin{array}{l}\text { Which } \\
\text { topics did } \\
\text { you learn? } \\
\text { (Codes B) }\end{array}$ & $\begin{array}{l}\text { Did } \\
\text { you } \\
\text { also get } \\
\text { some } \\
\text { seeds } \\
\text { participate } \\
\text { what are the } \\
\text { reasons } \\
\text { (Codes C, } \\
\text { rank if more } \\
\text { than1) }\end{array}$ \\
\hline Consulted Village/Ward Extension Officer
\end{tabular}

\section{Codes A}

7. Extension officer

8. Village Chairman

9. Village Executive

10. Cell Leader

11. Ward Executive Officer

12. Councillor

\section{Codes B}

13. Another farmer

14. Radio/TV

15. Newspaper

16. Posters

17. Other, specify

.........

\section{Codes C}

1. Different modern varieties

2. Land preparation

3. Planting methods

4. Striga management

5. Pest \& disease mana

6. Post- harvest handling

7. Soil \& water management

8. Fertilizer use

9. Manure/compost use

10. Produce marketing
15. Did not require extension services

16. Did not know where to get the extension officer

17. Long distance to extension office

8. Cannot afford the cost of bringing extension officer to the farm

19. Was not aware of such an event

20. Was aware but was not invited

21. Invitation came late

22. Was not aware of the agenda
23. Long distance to event venue

24. Other commitments

25. Was sick/attending to a sick person

26. Farmer had travelled out of the village

27. Activity would not have been beneficial

28. Other, specify.....

\subsection{Access to Credit}

9.1 If you needed money, could you borrow it at present?

$\mathbf{0}=$ No; $\quad \mathbf{1}=$ Yes

9.2 If Yes, could you borrow from the following sources? (Read to the respondent)

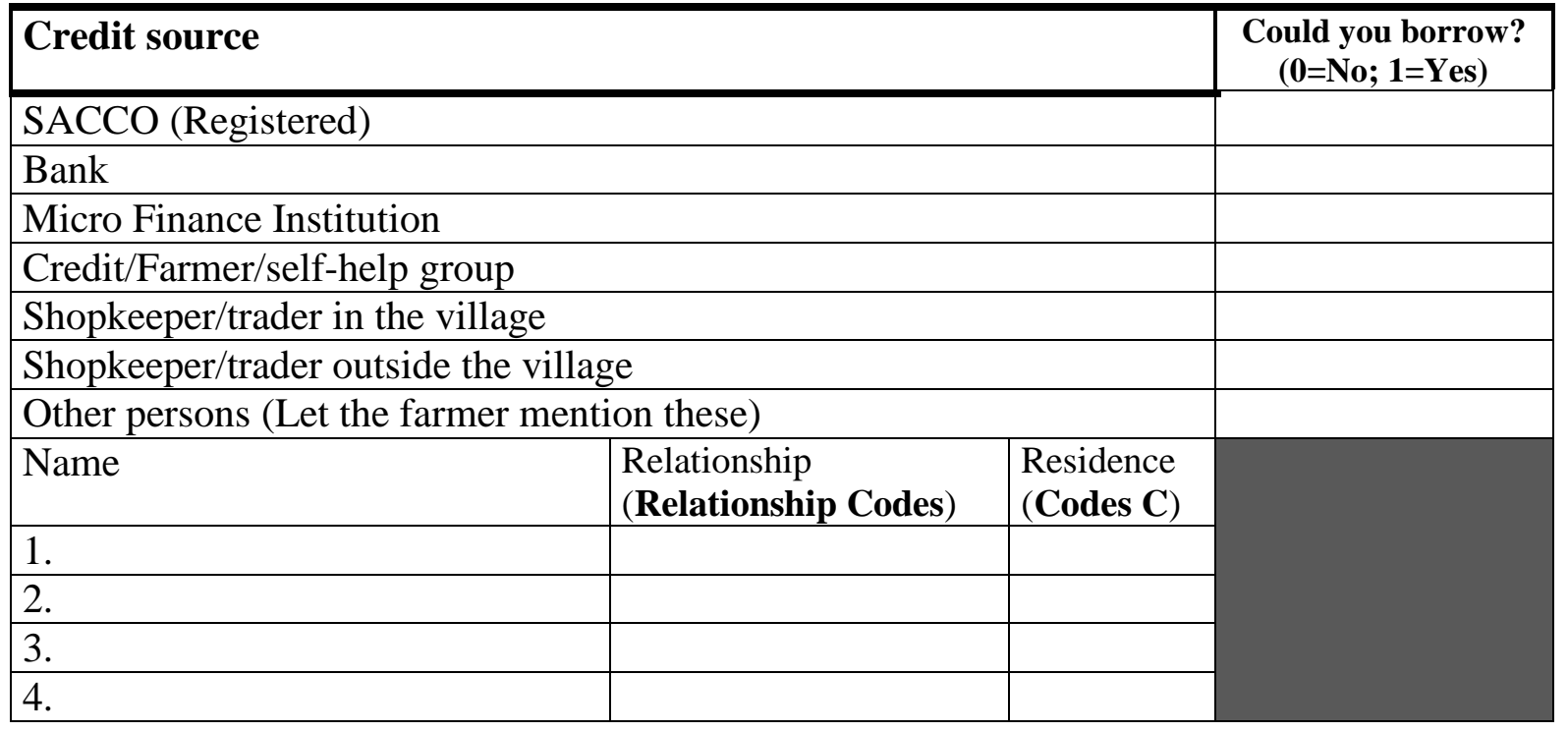

Codes C $\quad \mathbf{1}=$ In this village $\quad \mathbf{2}=$ Outside this village 